\title{
Perceptions of a Chilly Climate: Differences in Traditional and Non-traditional Majors for Women
}

\author{
LaDonna K. Morris \\ University of North Florida
}

Follow this and additional works at: https://digitalcommons.unf.edu/etd

Part of the Educational Administration and Supervision Commons, and the Higher Education and Teaching Commons

\section{Suggested Citation}

Morris, LaDonna K., "Perceptions of a Chilly Climate: Differences in Traditional and Non-traditional Majors for Women" (2004). UNF Graduate Theses and Dissertations. 282.

https://digitalcommons.unf.edu/etd/282

This Doctoral Dissertation is brought to you for free and open access by the Student Scholarship at UNF Digital Commons. It has been accepted for inclusion in UNF Graduate Theses and Dissertations by an authorized administrator of UNF Digital Commons. For more information, please contact Digital Projects.

(c) 2004 All Rights Reserved

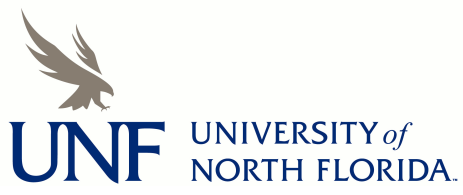




\title{
Perceptions of a Chilly Climate:
}

Differences in Traditional and Non-traditional Majors for Women

\author{
LaDonna K. Morris
}

August, 2004

A dissertation submitted to the Doctoral Faculty of the College of Education and Human Services in partial fulfillment of the requirements for the degree of

\author{
Doctor of Education
}

University of North Florida

College of Education and Human Services 
The dissertation of LaDonna Morris is approved:

Signature Deleted

Signature Deleted

Signature Deleted

Signature Deleted

Committee Chairpotison

Accepting for the Department:

Signature Deleted

Chair

Accepting for the College:

Signature Deleted

Dean, College of Education \& Human Services

Accepting for the University:

Signature Deleted

Dean of Graduate Studies (date)

$7-01-04$

$02-01-04$

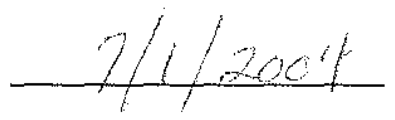

July 1,2004
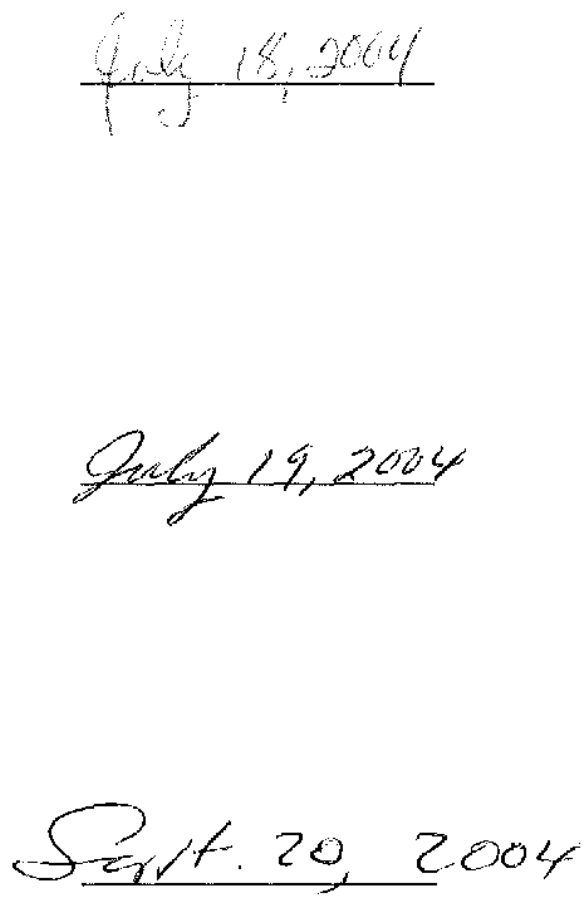


\section{Acknowledgements}

Thanks first and foremost to Dr. Larry Daniel for serving as my committee chair, for mentoring me, and for making quantitative research interesting and fun. Thanks to Dr. Ellie Scheirer for giving me an appreciation for the craft of qualitative research, slowing me down, and challenging me to think my research through. I look forward to learning more and continuing this work.

I would like to thank my committee members, Dr. Sandra Gupton, Dr. Marianne Barnes, and Dr. Susan Wallace, for their support, direction, and enthusiasm for my work. Their commitment to educational equity for women is evident in everything they do. Thanks to Dr. Kathe Kasten for her direction and for the innumerable hours she has spent ensuring that doctoral students get on the right path for their dissertation research.

A heartfelt thanks to Dr. Joyce Jones for her longtime support of the FCCJ Women's Center, for her advice on how to ensure that our programs continue, and sometimes just for listening. Thanks to Dr. Pritchy Smith for helping me to see the world in a different way and making me realize things that should have occurred to me a long time ago. I will not forget you.

I must thank the members of Cohort 10 for their support and friendship over the past four years, especially Camilla Sims-Stambaugh, Cara Christensen, and Sylvia Johnson. May the support continue as we complete our degrees and throughout our careers.

A very special thanks to my partner of twenty years, Dr. Robert Gold, for his love, encouragement, and tolerance of my work habits. I promise to take more time to play from now on. Lastly, thanks to my parents for being my parents, to my father for an inquisitive mind, and to my mother for her work ethic. I couldn't have done it without you. 
Table of Contents

Acknowledgements $\quad$ i

Table of Contents ii

List of Tables vii

$\begin{array}{ll}\text { Abstract } & \text { ix }\end{array}$

Chapter 1: Introduction $\quad 1$

Significance of the Research $\quad 2$

Statement of Purpose 3

Statement of Research Question and Hypotheses 3

Definition of Terms 4

Delimitations 5

Limitations 6

$\begin{array}{ll}\text { Organization of the Study } & 7\end{array}$

Chapter 2: Review of the Literature $\quad 9$

Theoretical Framework 9

Nursing: A Prototype of a Traditional Major for Women 13

$\begin{array}{ll}\text { Choosing a Nursing Major } & 13\end{array}$

$\begin{array}{ll}\text { Caring Values } & 13\end{array}$

$\begin{array}{ll}\text { Perceptions and Role Models } & 16\end{array}$

$\begin{array}{ll}\text { Persisting in a Nursing Major } & 17\end{array}$

$\begin{array}{ll}\text { Self-Efficacy } & 18\end{array}$

$\begin{array}{ll}\text { A Supportive Environment } & 19\end{array}$

IT: A Prototype of a Non-lraditional Major for Women 20 
Choosing an IT Major

Gender-Role Concept

Career Commitment

Self-Efficacy

Pre-College Achievement

Persisting in an IT Major

Pre-College Achievement as a Predictor of Success

A Supportive Environment

Single-Sex Classes

Chilly Climate for Women

Research in Support of the Chilly Climate 38

Evidence Against the Chilly Climate

Summary

Chapter 3: Methodology

Site

Research Design

Research Instrument

Data Collection

Data Entry 59

Study Sample

Informed Consent and Institutional Review Board Approval

60

Data Analysis

60

Summary

62 
$\begin{array}{ll}\text { Demographic Data } & 64\end{array}$

Descriptive Statistics for the Perceived Chilly Climate Scale 68

Descriptive Statistics for the Perceived Chilly Climate Subscales 68

$\begin{array}{ll}\text { Bivariate Correlations } & 70\end{array}$

$\begin{array}{ll}\text { Reliability Analysis } & 71\end{array}$

28-Item Perceived Chilly Climate Scale $\quad 71$

Subscale 1: Climate Students Hear About $\quad 74$

Subscale 2: Sexist Attitudes and Treatment 74

Subscale 3: Climate Students Experience Personally 75

Subscale 4: Classroom Climate/Course Material 75

Subscale 5: Safety 76

$\begin{array}{ll}\text { Canonical Correlation Analysis } & 77\end{array}$

Interpretation of Root $1 \quad 82$

Interpretation of Root 2

Canonical Invariance Analysis $\quad 84$

Analysis of Responses to Open-Ended Question 85

Consideration of the Primary Research Question 89

Research Hypothesis 1: Correlation Between Dependent and $\quad 89$ Independent Variable Sets

Research Hypothesis 2: Gender $\quad 89$

Research Hypothesis 3: Ethnicity 90

Research Hypothesis 4: Age 90

Research Hypothesis 5: College Major $\quad 91$ 
$\begin{array}{ll}\text { Summary } & 92\end{array}$

Chapter 5: Summary, Conclusions, and Recommendations 96

Review of the Methodology 96

Summary of the Results 97

Discussion of the Results $\quad 100$

Relationship of the Present Study to Previous Research $\quad 100$

Interpretation of Results within the Theoretical Framework 103

Limitations of the Research Instrument 106

$\begin{array}{ll}\text { Conclusions and Recommendations } & 109\end{array}$

$\begin{array}{lr}\text { Conclusions } & 109\end{array}$

Recommendations for Educators $\quad 110$

Recommendations for Further Research 111

$\begin{array}{ll}\text { Contributions of the Study } & 112\end{array}$

$\begin{array}{ll}\text { Appendices } & 114\end{array}$

$\begin{array}{ll}\text { Appendix A: Climate Survey } & 114\end{array}$

Appendix B: Perceived Chilly Climate Scale 118

Appendix C: Request for Permission to Use Instrument 121

Appendix D: Request for Access 124

Appendix E: Informed Consent 126

Appendix F: Institutional Review Board Approval 128

Appendix G: Descriptive Statistics for the PCCS Subscales and Total $\quad 130$

Appendix H: Canonical Invariance Analysis 137 
References

Vita 
List of Tables

Number Title

Page

Table $1 \quad$ Sample Demographic Data $\quad 65$

Table $2 \quad$ Major Count by Gender and Ethnicity 66

Table 3 Students' Intentions to Stay or Leave the Field by Major 67 and Gender

Table 4 Descriptive Statistics for the PCCS 28-Item Scale 69

Table 5 Bivariate Correlations for Independent and Dependent Variables $\quad 72$

Table $6 \quad$ Reliability Analysis of 28-Item Scale 73

$\begin{array}{lll}\text { Table } 7 & \text { Reliability Analysis of Subscale 1 } & 74\end{array}$

Table $8 \quad$ Reliability Analysis of Subscale 2

Table $9 \quad$ Reliability Analysis of Subscale $3 \quad 76$

Table $10 \quad$ Reliability Analysis of Subscale 4 76

$\begin{array}{lll}\text { Table } 11 & \text { Reliability Analysis of Subscale 5 } & 77\end{array}$

Table 12 Conversion of Predictor Variables for Canonical Analysis $\quad 79$

Table 13 Frcquencies of Recoded Major, Ethnicity, and Intent to Leave $\quad 80$ the Field

Table 14 Eigenvalues and Canonical Correlations 80

Table $15 \quad$ Funetion and Structure Coefficients for Independent/Predictor $\quad 81$ Variables

Table $16 \quad$ Function and Structure Coefficients for Dependent/Criterion 82 Variables

Table 17 Differences in Treatment by Major and Gender 87

Table $18 \quad$ Descriptive Statistics for PCCS Subscale 1: Climate Students 131 Hear About

Table 19 Descriptive Statistics for PCCS Subscale 2: Sexist Attitudes 
and Treatment

Table 20 Descriptive Statistics for PCCS Subscale 3: Climate Students

133

Experience Personally

Table 21 Descriptive Statistics for PCCS Subscale 4: Classroom

134

Climate/Course Material

Table 22 Descriptive Statistics for PCCS Subscale 5: Safety 135

Table 23 Descriptive Statistics for PCCS Total Scores 136

Table $24 \quad$ Sample 1 Eigenvalues and Canonical Correlations 138

Table $25 \quad$ Sample 1 Function and Structure Coefficients for Independent/ 138 Predictor Variables

Table 26 Sample 1 Function and Structure Coefficients for Dependent/ Criterion Variables

Table 27 Sample 2 Eigenvalues and Canonical Correlations 139

Table 28 Sample 2 Function and Structure Coefficients for Independent/ 140 Predictor Variables

Table 29 Sample 2 Function and Structure Coefficients for Dependent/ 140 Criterion Variables 


\begin{abstract}
The purpose of the present study was to examine how perceptions of a chilly climate differ between students in traditionally female-dominated majors versus traditionally male-dominated majors, and how these perceptions relate to students ' intentions to persist or pursue higher education in their chosen ficld. Participants were 403 students attending a community college in the southern United States, including students majoring in information technology (IT), engineering, education, and nursing. Participants completed the 28-item Perceived Chilly Climate Scale (PCCS) and other informational items.
\end{abstract}

The primary research question asked: To what extent can scores on the five subscales of the PCCS be explained by the predictor variable set of gender, ethnicity, age, college major, and intent to leave the field? Canonical correlation analysis yielded an initial canonical root of $.40\left(\mathrm{R}_{\mathrm{c}}{ }^{2}=.16, p<.001\right)$, indicating that the predictor variables accounted for a moderate portion of the variance in PCCS subscale scores. Gender $\left(r_{s}=.89\right)$ accounted for the highest proportion of explained variance, followed by major $\left(r_{\mathrm{s}}=.75\right)$.

Findings indicated that women found the climate chillier than men, non-white students found the climate chillier than white students, younger students perceived the climate chillier than older students, and students in traditionally female-dominated majors perceived the clinate chillier than students in traditionally male-dominated majors. Intent to leave the ficld was not a significant predictor of perceptions of chilly climate. 
Chapter 1

Introduction

A large gender gap exists in the choice of college majors by males and females (Turner \& Bowen, 1999). Women continue to pursue careers that have been traditionally associated with women, particularly within the health professions, education, and the social and behavioral sciences (Larsen, 2001), despite the availability of much higher salaries in traditionally male-dominated fields such as information technology (IT) and engineering. Over half of all women who do major in science, math, or engineering switch to other majors before completing an undcrgraduate degrec, a much higher drop rate than for men (Scymour \& Hewitt, 1997).

One of the suggested reasons for this continued trend is that women do not feel welcome in traditionally male-dominated career fields and college majors. The perception of being unwelcome can result from women being ignored, treated differently, or sexually harassed. This phenomenon was labeled the "chilly climate" by Hall and Sandler (1982), who contended that differential treatment puts women at a significant educational disadvantage in college classrooms and negatively impacts their performance. The concept of the chilly climate was later expanded to include aspects of the campus environment beyond the classroom (Hall \& Sandler, 1984).

As a result of the chilly climatc, women may choose not to enter traditionally male-dominated college majors or may not persist in these majors. In a two-year 
observational study of college classrooms, Sadker and Sadker (1994) found that, "At the highest educational level, where the instructors are the most credentialed and the students the most capable, teaching is the most biased" (p. 168). A supportive campus climate has been found to be a significant factor in the successful recruitment and retention of women in science majors (Astin \& Sax, 1996).

\section{Significance of the Research}

The significance of this study is that it compares perceptions of chilly climate between women in traditionally lemale-dominated majors and women in traditionally male-dominated majors at a community college. If wonen perceive that they are being treated differently in some departments, it is within the power of the college administration to change this phenomenon. Training can be offered to faculty to make them aware of the importance of classroom climate for women and how they can improve it. Changing the perception of a chilly climate could be a significant factor in retaining women in traditionally male-dominated majors. Further, women who enter nontraditional career fields have the potential to increase their lifetime earnings exponentially. While the focus of the present study is on women's perceptions of the chilly climate, men's perceptions of chilly climate for both women and men will be examined as well.

Identifying whether a chilly climate exists for women in traditionally maledominated majors is the first step in changing it. Improving the campus climate for women in such majors could result in greater retention in their college inajors and greater lifetime earnings for women who enter traditionally male-dominated careers. 


\section{Statement of Purpose}

The purpose of the present study was to examine how perceptions of a chilly climate differ between students in traditionally female-dominated majors versus traditionally male-dominated majors at a community college, and how these perceptions relate to students' intentions to persist or pursue higher education in their chosen career field or leave the field. Perceptions of students in the traditionally female-dominated fields of nursing and education were compared to perceptions of students in the traditionally male-dominated fields of IT and engineering. As data were collected from intact classrooms rather than from a random sample, the generalizability of the results of this study is limited to a degree; however, care was taken to build a broadly representative sample of male and female students from the selected institution.

\section{Statement of Research Question and Hypotheses}

The primary research question was: To what extent can scores on the five subscales of the Perceived Chilly Climate Scale (PCCS) be explained by the predictor variable set of gender, ethnicity, age, college major, and intent to leave the field? The corresponding research hypotheses were:

$\mathrm{H}_{1}$ : There will be a statistically significant $(p=.05)$ correlation $\left(\mathrm{R}_{\mathrm{c}}\right)$ between the dependent variable set of subscale scores on the Perceived Chilly Climate Scale and the predictor variable set of gender, ethnicity, age, college major, and intent to leave the field.

$\mathrm{H}_{2}$ : Gender will be a primary contributing variable to at least one predictor canonical variate which correlates to a statistically significant $(p=.05)$ degree with its corresponding dependent canonical variate.

$\mathrm{H}_{3}$ : Ethnicity will be a primary contributing variable to at least one predictor canonical variate which correlates to a statistically significant $(p=.05)$ degree 
with its corresponding dependent canonical variate.

$\mathrm{H}_{4}$ : Age will be a primary contributing variable to at least one predictor canonical variate which correlates to a statistically significant $(p=.05)$ degree with its corresponding dependent canonical variate.

$\mathrm{H}_{5}$ : College major will be a primary contributing variable to at least one predictor canonical variate which correlates to a statistically significant $(p=.05)$ degree with its corresponding dependent canonical variate.

$\mathrm{H}_{6}$ : Intent to leave the field will be a primary contributing variable to at least one predictor canonical variate which correlates to a statistically significant $(p=.05)$ degree with its corresponding dependent canonical variate.

\section{Definition of Terms}

For the purpose of the present study, the following operational definitions were employed:

Information technology (IT) - career fields and college majors related to computer science.

Information technology (IT) major - Enrollment in either an Associate in Arts (A.A.) degree program with a declared major in Computer Science and Information Systems or enrollment in an Associate in Science (A.S.) or Associate in Applied Science (A.A.S.) degree program in Computer Engineering, Electronics and Telecommunications; Database Development and Administration; Networking and Systems Administration, Programming and Applications Development; Web Development and Administration; or Computer Programming and Analysis.

Engineering major - Enrollment in either an A.A. degree program with a declared major in Engineering or enrollment in an A.S. or A.A.S. degree program in Engineering Technology including Architectural Design and Construction Technology; Civil 
Engineering Technology; Drafting and Design Technology; Building Construction Technology; Computer Integrated Manufacturing; or Industrial Management Technology. Nursing major - Enrollment in an A.S. degree program in Registered Nursing (R.N.).

Education major - Enrollment in an A.A. degree program with a declared major in Education.

Traditionally male-dominated major - A major in which males comprise $67 \%$ or more of enrolled students and femalcs comprise $33 \%$ or less of enrolled students (e.g., IT and engineering).

Traditionally female-dominated major - A major in which females comprise $67 \%$ or more of enrolled students and males comprise 33\% or less of cnrolled students (e.g., nursing and education).

Freshman - a student who has completed from 0 to 29 college credits, including college credit and vocational/technical credits.

Sophomore - a student who has completed 30 or more college credits, including college credit and vocational/technical credits.

\section{Delimitations}

The delimitations of this study were: (a) participants were nlales and females who were at least 18 years of age; (b) participants were enrolled in one of four community college majors including IT, enginecring, nursing, or education during Spring semester 2004; (c) participants completed the survey in a traditional classroom setting as opposed to an online course. 


\section{Limitations}

Investigating perceptions of the chilly campus climate is a sensitive matter. Given the nature of the study, the researcher ran the risk of reduced participation of instructors or students, the risk of students not being honest to protect themselves and their instructors, and even the risk of the college administration prohibiting such a study for fear of the results. Further, students may not have been aware of gender bias enough to be able to identify it. Conversely, while the students in this sample were freshmen and sophomores, the only class rank designations within community colleges, many were beyond the age of the traditional college student. Consequently, they may have had different perceptions of (been more or less aware of) gender bias. Further, students who experienced a chilly campus climate very early in their program of study or during Fall semester 2003 may have dropped out or changed majors and would not have been included in this study.

As the sample was not randomly seleeted, results from the study have limited generalizability. However, results may be generalized to a limited degree to students enrolled in similar majors in community colleges with similar demographics including institution size, gender composition, race, and ethnic composition. The results of the study may not be generalized to students in other majors because of their absence from the study. 


\section{Organization of the Study}

The study is organized into five chapters. Chapter 1 introduces the study and includes the significance of the research, statement of purpose, statement of the research question and hypotheses, definition of terms, and delimitations and limitations.

Chapter 2 provides a review of related literature. The literature review begins with the theoretical framework upon which the study is based. Nursing is used as a prototype for a traditionally female-dominated major and IT is used as a prototype for a traditionally male-dominated major. The literature review concludes with research on the concept of chilly climate, including the evidence for and against it.

Chapter 3 describes the methodology used to conduct the study, including a description of the site, research design, research instruments, data collection procedures, and how informed consent was obtained from study participants. A discussion of the data analysis procedures employed concludes the chapter.

Chapter 4 presents the study findings, including demographic data, a detailed analysis of data, and an explanation of how the analysis can be employed to answer the research question and corresponding hypotheses. Responses to the open-ended question are categorized and bivariate correlations for the independent and dependent variables are presented. Results of the reliability analysis of the 28-item PCCS and its five subscales and the canonical correlation analysis are presented. The chapter concludes with an analysis of the primary research question that guided the study and the six related research hypotheses. 
Chapter 5 provides an overview of the study, a summary of the findings, and a detailed discussion. Findings of the present study are related to previous research and results are interpreted within the theoretical framework upon which the study is based. Conclusions are drawn, recommendations are made for educators, and recommendations for further research on the chilly climate are presented. The chapter concludes with the contributions of the study to the field of education. 


\section{Chapter 2}

Review of the Literature

This review of literature provides the theoretical framework upon which the study was based with a focus on reasons why women choose and persist in traditionally femaledominated versus traditionally male-dominated majors. Nursing was used as a prototypc for a traditionally female-dominated major, and information technology (IT) was used as a prototype for a traditionally male-dominated major. The literature review concludes with research on the concept of chilly climate as an explanation for the underrepresentation of women in traditionally male-dominated majors, including empirical evidence that supports the existence of chilly climates within academic institutions, as well as the evidence against it.

\section{Theoretical Framework}

Fralf of college students are women, but they earn less than $20 \%$ of bachelor's degrees in computer science and computer engineering (Olsen, 2000). In fact, participation has actually been dropping since 1984 when $37 \%$ of such degrees were awarded to women (Olsen, 2000). Two models have bcen suggested to explain why women are less likely than men to complete degrees in science and be successful in science careers, namely, the defïcit model and the difference model (Barbercheck, 2001). According to the deficit model, there are fewer women in science because they are treated differently from men due to formal and informal structural barriers. The 
difference model, on the other hand, suggests that the obstacles to a successful career lie within women themselves and are innate or result from gender-role socialization and cultural values.

Social learning theory may also help explain why women are less successful in science majors and careers. According to social learning theory, an individual's perceptions of self and of society are interconnected (Bandura, 1997). Three sets of factors interact with each other in a dynamic model: personal factors including cognitive, affective, and biological events; behavior; and environmental events. Because environments influence people's cognitions and behavior, understanding how college students perceive the environment is important. Further, according to self-efficacy theory (Bandura, 1997), people's beliefs in their ability to succeed in certain areas influence what they choose to pursue and how much effort they are willing to put forth to be successful. Individuals with high self-efficacy in a given area are more likely to persist and succeed. Perceptions of college environment can influence students' self-efficacy and, consequently, their success.

In order for institutions of higher education to help women be successful, it is essential to consider how women learn best. However, despite the increasing number of women in higher education, college faculties, which are predominantly male ("Characteristics of faculty members," 2001), often resist the idea that women's educational needs are different from men's (Belenky, Clinchy, Goldberger, \& Tarulc, 1986). Research has, in fact, demonstrated that women and men learn differently (Belenky et al., 1986; Chapman, 1993; Gilligan, 1993). Belenky et al. found that women 
are more socialized to be "connected" learners whereas males tend to be "separate" learners. Separate learning, which is more rational, analytical, impersonal, and competitive, is the approach found more commonly in college classrooms where students attend lectures, listen, and do homework. In connected learning, knowledge comes from experience rather than listening to an authority figure. Hence, traditional course delivery and instruction methods may favol men over women.

Similarly, Chapman (1993) noted that women are more oriented toward interpersonal relationships and prefer connected knowing, as opposed to separate knowing, as their primary mode of functioning. Considering that cooperative, smallgroup learning is most relevant to conneeted knowing, Chapman recommended that classroom practices be revised to incorporate the concept of the classroom as a community rather than a collection of individuals. In a case study of three first-year community college females ages 18 and 19 , Chapman concluded that the manner in which math is traditionally taught does not serve students whose way of knowing is more connected than separate. She suggested three ways to faeilitate the learning of connected knowers in mathematics classrooms, including relevant problem text, allowing time to construct both social and mathematical connections, and being sensitive to appropriate times to intervene in discussions so as not to silence the group.

In addition to concluding that women learn differently from men, Gilligan (1993) found that women's cognitive development is different from men 's, and challenged development theories which emphasize separation from others as applying only to men. Gilligan 's research indicated that interdependence remains important as women develop 
because relationships are embedded in women's lives. Consequently, women tend to subordinate achievement to care, and may feel conflicted over competitive success. According to Gilligan, "The failure to see the different reality of women's lives and to hear the differences in their voices stems in part from the assumption that there is a single mode of social experience and interpretation" (p. 173).

Incorporating "feminist pedagogies" (i.e., instructional methods that appeal to the needs and preferred learning styles of women) may be one way to increase the success of women, especially those in non-traditional majors. In contrast to traditional teaching methods, feminist pedagogies may help create a classroom climate that is more conducive to learning for women (Rosser, 1990). Feminist pedagogies encourage women to create their own meanings and find their own "voices" in relation to the material (Maher \& Tetreault, 2001). Examples of feminist pedagogies include incorporating constructivist methods into the classroom, replacing competition with collaboration, and replacing didactic teaching methods with morc inclusive strategies (Roger, Cronin, \& Duffield, 1999). An example of incorporating feminist pedagogy into a technology classroom would be for the instructor to divide the students into groups of five, assign a computer repair problem, have cach of the groups brainstorm a solution to the problem and share their solutions with the collective group, then facilitate a discussion to help the groups come to a consensus ahout the best solution.

It should be noted that practices that improve the learning experiences of women have not been shown to be harmful to men. In fact, according to Crawford and McLeod 
(1990), creating a better classroom climate for female students creates a better learning environment for all students.

\section{Nursing: A Prototype of a Traditional Major for Women}

Nursing has long been considered a women's career, yet each year fewer women major in nursing. In fact, the number of freshmen choosing nursing as a major has decreased by $40 \%$ since 1973 (Staiger, Auerbach, \& Buerhaus, 2000). As more women move into the traditionally male-dominated careers, the shortage of nurses is becoming problematic (Staiger et al., 2000). According to Jeffreys (1998), nursing students today tend to be "non-traditional" students who are older, work while attending college, and have greater family responsibilities. Many complete associate degrees in nursing at community colleges.

Choosing a Nursing Major

Women choose nursing majors based on their personal values and attributes (Boughn, 1992; Boughn, 2001; Boughn \& Lentini, 1999; Kersten, Bakewell, \& Meyer, 1991; Lackland \& DeLisi, 2001; Thorpe \& Loo, 2003), as well as their perceptions of the nursing profession and role models (Mendez \& Louis, 1991; Pillitteri, 1994).

Caring values. The overarching reason students give for choosing nursing as a major is the desire to care for others (Boughn \& Lintini, 1999). In a sample of 498 associatc degree students and 254 baccalaureate students (92\% women), Kersten et al. (1991) found that the most frequently cited reasons for choosing nursing were nurturance $(62.6 \%)$, emotional needs $(52.4 \%)$, employment opportunities (51.2\%), financial benefits $(32.9 \%)$, and interest in science $(19.4 \%)$. When asked what nursing meant to them, 
$78.2 \%$ of respondents indicated "caring," A total of $37.5 \%$ indicated that the person most influential in their choice of nursing as a major was a nurse.

In comparing men's and women's reasons for choosing nursing as a career in a qualitative study, Boughn (2001) found that while both male and female students demonstrated a commitment to caring for their patients, there were marked differences between the genders in practical reasons for choosing nursing. While men cited salary and working conditions as factors in their choice of major, women did not. Both men and women were interested in power and empowerment for themselves, but differed in their desire to use power. Women wanted to empower patients, whereas men were more interested in empowering themselves as professionals and the nursing profession as a whole.

In addition to the value of caring, other values students hold figure prominently into their choice of college major and differ between students in different majors. Using the Life Roles Inventory-Values Scale, Thorpe and Loo (2003) compared the values of nursing undergraduate students to the values of undergraduates majoring in management. Results indicated that personal development and altruism werc most important to the nursing students. The nursing sample ( $n=152$ ) had a significantly higher mean than the management sample $(n=111)$ on the "altruism" value and significantly lower means on the "life style," "advancement," "autonomy," "authority," "creativity," "economic," and "risk" values, as measured by this scalc.

Beyond personal values, differences in other attributes have been found between students in traditionally male-dominated majors and traditionally female-dominated 
majors. In studying choices of traditional and non-traditional majors by male and female college students, Lackland and De Lisi (2001) found that students who majored in nursing, education, and English had greater confidence, satisfaction, and expectations for future success than students who majored in engineering, mathematics, and physics. A traditional college major was one that had a recent and continuing history of gender enrollment differentials of $80 \%$ or greater for the majority gender. The sample consisted of 242 university students (143 female, 99 malc) in six majors. Physics and engineering were selected as representative of male-dominated majors and were grouped together as "scicnce" majors. Nursing, special education, and elementary education were selected as the female-dominated majors and were grouped together as the "helping professions" category. Mathematics and English were selected as majors in the "neutral" majors grouping. Students completed several instruments including the Bem Sex Role Inventory (BSRI), Rokeach Value Survey, student academic questionnaire, Academic Self-Concept Scale, task values questionnaire, Internal Control Index, Personal Attributes Questionnaire, and the Internal-External Locus of Control Scale.

Lackland and De Lisi (2001) found that significant predictors of college major were humanitarian concerns, femininity scores, masculinity scores, and utility values of the major: Students who had higher femininity scores and endorsed humanitarian concerns were more likely to be in the helping professions. Conversely, students who had low femininity scores and did not endorsc humanitarian concerns were more likely to be in the sciences. For both women and men, endorsing humanitarian concerns was associated with majoring in the helping professions and not endorsing humanitarian 
concerns was associated with majoring in science. Students who had higher masculinity scores, endorsed utility values, and had higher male-female sex role scores were more likely to be in the seiences. Students who had lower masculinity scores, did not endorse utility values, and had lower malc-female sex role scores were more likely to be in the helping professions.

Boughn (1992) also employed the BSRI to compare nursing students to women students in the traditionally female-dominated field of education and to women students in the traditionally male-dominated fields of business, technology, arts and scicnces. Findings indicated that scores of nursing students did not differ significantly from scores of women students in the schools of education and business. However, students in nursing and education scored significantly higher on femininity than women students in the schools of technology and arts and sciences $(p<.001)$. There was no significant difference in scores on masculinity between nursing students and women in any of the other schools.

Perceptions and role models. How students perceive nurses has been found to differ between majors and non-majors, which may contribute to their choice of major. Pillitteri (1994) compared how 99 undergraduate students (75\% female) in different majors viewed nursing. Findings indicated that perceptions differed according to college major, gender, and cxposure to a relative who was a nurse. Women indicated that nursing was more difficult, more challenging, and more responsible than did the men in the sample. Nursing majors found nursing significantly more challenging, more difficult, more responsible, and more dangerous than non-majors, but also more fun, more 
enjoyable, more Iucrative, and more satisfying as a lifetime career. Engineering majors in Pillitteri 's study viewed nursing as more of a women's profession, not a lifetime career, and lower paying than did nursing majors. Students with a nurse in the family found nursing to be more challenging, a source of higher pay, and of greater benefit to society than students who did not.

Mendez and Louis (1991) also found that exposure to a nursing role model positively affected students' perceptions of nursing and the choice of nursing as a career. The researchers studicd the image college students had of nursing, comparing perceptions of 93 nursing students enrolled in a baccalaureate program in nursing to 161 non-1nursing students (29 community college students, 132 university students). Among the nursing majors, $70 \%$ reported having had a nursing rolc model, compared to $43.5 \%$ of the nonmajors, and $60 \%$ of the majors reported that a nursing role model made a difference in their choice of a career. Interestingly, Mendez and Louis also found that the overall image of nursing as a career was not highly positive. Although nursing majors' perceptions of a nursing career correlated more positively with their perceptions of an ideal career than did non-nursing students' pcrceptions, neither group's perceptions correlated the nursing profession highly with an ideal career.

\section{Persisting in a Nursing Major}

Women persist in nursing majors for a variety of reasons, from perceptions of ability to succeed in the major (Aber \& Arathuzik, 1996; Harvey \& McMurray, 1997; Jeffreys, 1998) to perceptions of a supportive environment (Shelton, 2003). 
Self-efficacy. Research on the persistence of nursing students has provided support for the self-efficacy theory. Aber and Arathuzik (1996) studied the relationship between self-efficacy and student success in 123 senior nursing students (109 females, 14 males) in a baccalaureate nursing program. Students completed the Clinical Self-Efficacy Scale (CLINSE), which is a measure of nursing students' confidence in their ability to perform clinical nursing skills, and the Study Skills Self-Efficacy (SSSE) Instrument, a measure of students' efficacy beliefs about study skills. Statistically significant correlations were found between student success, as measured by GPA, and competency in clinical skills, as measured by scores on the CLINSE, as well as competency in study skills, as measured by scores on the SSSE.

Jeffreys (1998) also examined the influence of self-efficacy, as well as the influence of selected academic and environmental variables, on retention among nontraditional nursing students. In Jeffreys' study, non-traditional students were defined as those who were age 25 or older, male, spoke English as a second language, wcrc of an ethnic or racial minority, had dependent children, or had a GED. A total of 97 firstsemester non-traditional nursing students participated in the study. Participants completed two instruments designed by the researchers: a self-efficacy instrument, which the author designed for students in their first-semester research course, and a student perception appraisal, which focused on how much restrictive or supportive academic and external environmental variables were perceived to influence a student's retention and academic achievement. There was a $91 \%$ retention rate in the first nursing course. Results indicated that only a student's perception of self-efficacy was a statistically significant predictor of 
achievement. Students rated faculty advisement and helpfulness second in influencing their retention in a nursing major.

How accurately students perceive what a nursing program will entail has also been found to be related to persistence in nursing majors. In Harvey and McMurray's (1997) study of nursing students at a college in Australia, pre-course expectations of what nursing education would involve were compared to perceptions held by students who persisted $(n=57)$ and those who did not $(n=16)$. Participants completed a questionnaire that included items concerning problems encountered in clinical placement, perceived difficulty of academic topics, expectations about what a nurse would learn, living arrangements, financial pressures, social interaction, and time management. Six possible factors were identified which may contribute to a student's decision to leave: difficulty in passing, dislike of clinical experiences, dislike of academic experiences, financial pressure, unsatisfactory accommodations, and inability to adapt to student life. However, persisters and non-persisters did not weight these iteins as significantly different in importance. A greater percentage of students who did not persist reported that the content of the nursing program differed from their expectations, especially with regard to scientific knowledge. The authors posited that students' expectations of success in nursing programs may be based on preconceptions of nursing which minimize the importance of scientific knowledge and suggested that combating such perceptions before students enter nursing majors could help reduce attrition.

A supportive environment. In studying the effect of faculty support on student retention, Shelion (2003) sampled 458 nursing students ( $89 \%$ women) who were 
categorized into threc groups: those who had persisted throughout a nursing program without withdrawing $(n=300)$; students who had withdrawn voluntarily during the past 9 months $(n=83)$; or students who had been required to withdraw because of academic failure $(n=75$ ). Participants completed the Perceived Faculty Support Scale, which was developed by the researchers for the study. Findings indicated that there were statistically significant differences between the three groups in perceived faculty support. Students who had persisted to the final semester perceived greater faculty support than students who withdrew voluntarily or because of academic failure. The authors suggested that the feeling that faculty cared and wanted students to succeed may have created an atmosphere more conducive to academic success and encouraged students to persist.

\section{IT: A Prototype of a Non-traditional Major for Women}

As fewer women select traditionally female-dominated majors such as nursing today than in the past, some are breaking the gender barrier and entering traditionally male-dominated majors such as IT. Much less is known about why women select and persist in non-traditional majors than is known about their reasons for remaining in traditional majors.

Few empirical studies have been conducted on either which factors influence or which factors deter women from pursuing IT careers, and much of the research that is available is ancedotal. Several studies have focused on the broader area of women in science and/or technology; however, IT is rarely separated out as a specific ficld of study, possibly because it is a relatively new field. Much more is known about why women do not major in IT than why they do choose such majors. 
Although some progress has been made in recruiting women into carcers in technology, only $30 \%$ of those employed as mathematical and computer scientists are women, and only 10\% of engineers are women (Commission on Professionals in Scicnce and Technology, 2002). Majors leading to careers in technology continue to be dominated by men and young men are five times more likely than young women to choose computer science or computer engineering majors (Cohen, 2001). Of great concern is that the participation of women in IT has actually been dropping, with $37 \%$ of computer science degrees awarded to women in 1984 , but only $26 \%$ going to women in 1998 (Camp, 2001).

Of those who do complete IT training, many do not persist in the career field and studies have shown a high degree of career dissatisfaction among women in TT careers. According to Deloitte and Touche (2001), $60 \%$ of women currently working in the high technology field would choose a different profession if starting out in a career today. Further, while $69 \%$ of the men surveyed indicated that they werc very interested in continuing on an IT carccr path, only $56 \%$ of women indicated that they were. Choosing an IT Major

A wide range of factors may influence a woman's decision whether or not to pursue a carcer in technology, from gender-role concept (Baker, 1987; Bem, 1974; Rea \& Strange, 1983), to career commitment (Cooper \& Robinson, 1985; Eisenhart \& Holland, 2001; Turner \& Bowen, 1999), to pereeptions of ability to succeed in an IT major (Camp, 2001; Ethington, 1988; Neuman, 1991; Weinman \& Pamela, 1999), to pre-college achievement (Ethington, 1988; Grandy, 1990; Turner \& Bowen, 1999). The low 
participation of women in science, engineering, and technology majors does not begin when students enter college, but is related to historical and cultural factors that predate the decision to enter college (Roger et al., 1999). According to Weinman and Pamcla (1999), gender gaps in experience with and attitudes toward computer technology in K12 classrooms reverberate into postsecondary education and the job market.

In cxamining how to recruit more women into technology careers, Flowers (1998) surveyed women who had made a professional commitment to technology education regarding their attitudes toward their career choice. Suggested areas for improving recruitment were to change the attitudes of male teachers in technology progranıs, make the climate more female-friendly, and encourage technology teachers to help improve self-concept and build self-confidence in their students.

Gender-role concept. Gender-role self-concept has been posited as an explanation for women's continued preferences for traditionally female-dominated careers (Baker, 1987). While individuals who are androgynous have a flexible sex-role concept and are able to engage in both masculine and feminine behaviors depending on situational appropriateness, individuals who are strongly sex-typed may be very limited in their range of behaviors, engaging only in behaviors considered appropriate for their gender (Bem, 1974).

The BSRI (Bem, 1974), measures masculinity, femininity, and androgyny. The androgyny scorc on the BSRI reflects the relative anounts of self-described masculinity and femininity and characterizes an iudividual 's total sex role. In studying cross-gender majors among male $(n=85)$ and female undergraduates $(n=101)$ using the BSRI, Rea 
and Strange $(1983)$ found a statistically significant $(p<.001)$ difference in the distribution of sex role self-concept by type of major for females only. A total of $51 \%$ of respondents were enrolled in "same-gender majors," with $49 \%$ in "cross-gender majors." Among women in cross-gender majors, 34\% reported a masculine sex-role concept, $25.6 \%$ were feminine, $14.9 \%$ were androgynous, and $25.6 \%$ were undifferentiated. Among women in same-gender majors, $3.7 \%$ were masculine, $48.1 \%$ feminine, $27.8 \%$ androgynous and $20.4 \%$ undifferentiated. It is noteworthy that almost twice the proportion of androgynous females was found in traditional same-gender majors as in non-traditional cross-gender majors in this study.

Baker (1987) also used the BSRI to study the influence of role-specific selfconcept and sex-role identity on career choices in science. Findings indicated that females preferring science careers such as engineering and computer science as well as females preferring allied health careers such as nursing perceived themselves as more masculine than did females in traditional careers such as teaching.

Career commitment. Because women in traditionally male-dominated majors tend to be less certain of their career choices than men, career counseling may be needed to help solidify those choices. Cooper and Robinson (1985) studied gender differences in interpersonal characteristics and vocational identity of students in highly technical careers. The Leary Intcrpersonal Checklist was administered, along with a questionnaire, to 268 male and 57 female freshmen in college. The researchers conducted a $2 \times 2$ chisquare test of vocational certainty by gender to examine the relationship of gender to 
certainty about vocational choice. Female students' scores indicated that they were, to a statistically significant degree, less certain of their career choices than the male students.

Peer influence has been shown to have a detrimental effect on career commitment. In a longitudinal study of university women from 1979 to 1987 , Eisenhart and Holland (2001) found career commitment to mathematics and science remained low or diminished during college and that peer groups and cultures play an important role in keeping women in traditional occupations. According to these authors, peers actively encourage women to see themselves as romantic partners of men, but say virtually nothing about academics or future careers. Consequently, academic work and careers are devalued, and the peer culture essentially pulls women away from their career commitment.

Women may prefer fields in which their skills are unlikely to become obsolete, as many women take several years off work to raise their children (Turner \& Bowen, 1999). Extended maternity leaves may also be interpreted by employers as a lack of career commitment. Staying current in the ficld during a leave of absence from work is a concern for many career women, but is of special concern in the IT field where changes occur rapidly. If a woman in the computer science field takes a 5-year leave of absence, her computer science skills will be outdated when she returns to the workforce, which may be why women who pursue careers in science gravitate toward the life sciences. Self-efficacy. Another factor affecting the choice of IT as a college major is the perception that only the best students should pursue such majors, a perception which 
begins in high schools. In 1999 , only $17 \%$ of high school students taking the advanced placement exam in computer science were female (Weinman \& Pamela, 1999).

While men with average grades cnroll in college computer science programs, women with average grades are much less likely to pursue such a major (Camp, 2001). Self-selection plays an important role in determining which women major in traditionally male-dominated fields. Vetter (1996) suggested that despite having consistently higher grades than males in whatever they studied, females lacked confidence in their abilities and tended to drop out to avoid disgracing themselves. Students might also be put off by the prerequisites for taking computing courses, with unnecessarily high prerequisites for computer courses depriving average students of computer opportunities (Neuman, 1991).

Even women who are proficient in mathematics are less likely than males to attribute their success in mathematics to their ability. Ethington (1988) studied differences among women planning to major in quantitative fields of study. Data were taken from the College Board Admissions Testing Program's samplc of 10,000 collegebound high school seniors in 1982-83, including SAT scores and information from the Student Descriptive Qucstionnaire. The Student Descriptive Questionnaire was completed by students when they registered for the SAT and included information on personal characteristics, family background, high school experience, and educational aspirations. Findings indicated that choice of major was affected by race, years of mathematics and science studicd in high school, pcrceptions of mathematics and science ability, high school rank, and parental income. In particular, women who had higher sclfratings of their mathematics and science abilities, completed morc high school science 
courses, and had higher indices of family background (e.g., income and education), wcre more likely to select a quantitative field of study.

Pre-college achievement. While pre-college achievement is often cited as a reason for women not choosing majors in IT, several studies have shown that even highly capable and well prepared women shy away from technical majors (Ethington, 1988; Grandy, 1990; Turner \& Bowen, 1999). Turner and Bowen (1999) studied the extent to which pre-college achievement in mathematics, as measured by SAT scores, accounted for the differences in choice of major at the college level. Data were taken from the College and Beyond database which was assembled by the Andrew W. Mellon Foundation in cooperation with 34 colleges and universities. Analysis was completed on cohorts of students who started college in 1976 and 1989 at selective schools, including three universities (Princeton, Stanford, and Yale), six coeducational institutions (Hamilton, Kenyon, Oberlin, Wesleyan, Williams, and Swarthmore), and three women 's colleges (Bryn Mawr, Smith, and Wellesley).

Findings indicated that the higher the student's mathematics SAT, the higher the probability that he or she would major in a field other than humanities. Although the authors noted that differences in academic preparation of women and men help explain observed differences in choice of major, they also found that differences in $\mathrm{SA}^{\mathrm{T}} \mathrm{T}$ scores accounted for less than half of the total gender gap. While men generally scored higher on the mathematics SAT than women, even women with high mathematics SAT scores were more likely to major in life sciences and the humanities rather than engineering, mathematics, or the physical sciences. The higher the mathematics SAT score, the more 
likely a woman would major in economics or life sciences rather than the humanities, but higher mathematics SAT scores did not have as large an effect on the probability of choosing engineering or physical sciences as a major. In short, few women who had strong mathematics ability were inclined to pursue a technical science major.

Like Turner and Bowen (1999), Grandy (1990) found that judging from SAT scores, many highly capable students were not interested in majoring in the sciences. In looking at the SAT scores of high school seniors between 1977 and 1988, Grandy noted that even though male students continued to express more interest in mathematics, science, engineering, and computer science than female students, the interest of males seemed to be declining in these areas while the interest of females was increasing slightly. Still, considering that fewer than $15 \%$ of females scoring at the $90^{\text {th }}$ percentilc or above on the SAT sclected a major in a highly quantitative science, many of the students who had the greatest quantitative skills chose not to use them.

Persisting in an IT Major

Even when women are successfully recruited into technology majors, it is difficult to retain them to complction of a degree, and persistence rates of women in sciencerelated fields are significantly lower than those of men. According to Seymour (1995), the persistence rate of men in mathematics, engineering, and science majors was as high as $61 \%$ at highly selective institutions, with an average of $39 \%$ for national samples, whereas the persistence rate of women was only $46 \%$ at highly selective institutions and $30 \%$ nationally. Factors affecting persistence of women in IT include pre-college achievement (Campbell \& McCabe, 1984; Farmer, Wardrop, Anderson, \& Risinger, 
1995; Murray, 1998; Odell \& Schumacher, 1998; Wright, Pamler, \& Miller, 1996), perception of a supportive environment (Astin \& Sax, 1996; Bauer, 2000; Brown, 2001; Camp, 2001; Chapman, 1993; Etzkowitz, Kemelgor, \& Uzzi, 2000; Flowers, 1998; Jackson, 1993; Kruschwitz \& Peter, 1995; National Research Council, 1991; Neuman, 1991; Olsen, 2000; Smith, 2000; Thom, 2001), and single-sex versus coeducational college environments (Solnick, 1995).

Pre-college achievement as a predictor of success. Studies have shown conflicting evidence regarding the importance of pre-college achievement in predicting student success. While some researchers (Farmer et al,, 1995; Murray, 1998) found prccollege achievement to be a good predictor of success, others (Campbell \& McCabe, 1984; Odell \& Schumacher, 1998; Wright et al., 1996) did not.

Farmer et al. (1995) found that career persistence among women in science, mathematics, and technology was most related to the number of high school science courses taken and that mathematics self-efficacy had an indirect effect on persistence, which was mediated by math-science utility. The rescarchers studied 173 participants (97 women, 76 men), who had aspired to a science, mathematics, or technology career when they were in high school in 1980. Findings indicated (a) that by 1990, only $36 \%$ of women and $46 \%$ of men had persisted in a science-related career and (b) wonen who had high career commitment were even more likely to switch away from careers in science, mathematics, and technology than women with less career commitment. One suggested explanation was that women's career devclopment is more complex, with career intcrests crystallizing later in women. 
In particular, the value of SAT scores as a predictor of student success has been disputed. Although women score lower on mathematics SAT scores at a variety of colleges and universities and across levels of mathematics courses, they earn higher grades in mathematics than males and complete their course of study with higher GPAs, discounting the usefulness of the SAT in predicting actual mathematics performance (Wright et al., 1996). According to Odell and Schumacher (1998), despite the fact that females score lower than nales in mathematics on standardized tests such as the SAT, they do as well as males on college mathematics placement tests, and females' grades are as good as or better than those of males in college. Males, however, have more confidence in their mathematics ability and are generally more positive about mathematics. While Murray (1998) did find the SAT to be the best predictor of coursc grades, the .58 correlation between SAT scores and first-year college grades is moderate at best.

Campbell and McCabe (1984) examined the statistical relationship between a student's SAT scores, high-school rank, and high-school science and mathematics background upon entrance to college and his or her success in the first year of a computer science major. The sample consisted of 256 first-semester freshman computer science majors. Of the 98 women in the sample, only 38 (39\%) persisted in science and engincering majors, whereas 96 of the 158 men $(61 \%)$ persisted. The researchers found that the observed differences were not indicative of differences in academic achicvement or potential and suggested that differences might be due to the demands of the major, as girls are socialized to avoid demanding situations whereas boys are socialized to deal 
with them. In order to counteract this effect, Campbell and McCabe suggested that "overt evidence of support for women majors is probably necessary to modify social forces. With such support, sex may cease to be a significant variable in future classification models" (p. 113).

A supportive environment. In order to foster the retention of females in IT majors, many authors have cited the importance of an environment that supports the learning of women such as incorporating female-friendly instructional methodologies (Bauer, 2000; Camp, 2001; Chapman, 1993; Jackson, 1993; Kuuschwitz \& Peter, 1995; Olsen, 2000; Thom, 2001), positive associations with professors (Camp, 2001; Etzkowitz et al., 2000; Flowers, 1998; National Research Council, 1991), the absence of "weed out" classes (Astin \& Sax, 1996; Etzkowitz et al., 2000; Neuman, 1991), and presence of mentors and role models (Astin \& Sax, 1996; Brown, 2001; Camp, 2001; Etzkowitz et al., 2000; Smith, 2000). While these assertions have strong face validity, there is a paucity of empirical evidence to support them.

In a study of female attrition in computer science majors, Bunderson and Christensen (1995) found that factors contributing to attrition included gender bias, interactions with other students in the major, the nature of computer science as a discipline, and lack of previous experience with computers. The sample consisted of 275 students enrolled in beginning, intermediate, and advanced computer science courses. Although the sample included only 28 fcmales, these women constituted the entire population of women computer science students in these classes. All students completcd a questionnaire about their experiences in the computer science department, and all 
students were interviewed. Additionally, 46 former computer science students (26 females, 20 males) were interviewed by phone. The survey instrument for current computer science students included students' attitudes toward computer science professors and teaching assistants in the department, students' attitudes toward women in the department, and students' interactions with teachers and other students, along with two open-ended questions. The survey instrument for former computer science students included questions about reasons for leaving the program, opinions about the helpfulness of professors and teaching assistants, including encouraging students to remain in the major, and students' attitudes about gender discrimination.

Bunderson and Christensen's (1995) results indicated that females expressed dissatisfaction with the major more often than males. The reason most frequently cited by women for leaving the major was that it wasn't enjoyable or interesting (35\% of women, $25 \%$ of men). Nineteen percent of women indicated they changed majors because they wanted a more peoplc-oriented major, a reason that was not listed by any of the former male students. Men were more likely to switch majors because they liked another major better ( $51 \%$ of men, $31 \%$ of women).

In all classes, women were more reluctant to ask questions than men (41\% of women, $31 \%$ of men), which the authors suggested may have contributed to the high level of attrition among women. Students found professors to be more helpful as class standing increased, with $34 \%$ agreeing that they received help when they needed it in the beginning class, compared to $66 \%$ in the advanced class. Interestingly, females perceived the facuity to care more about their success than did males. Among the former eomputer 
science students, $42 \%$ of females, but only $35 \%$ of males indicated that faculty encouraged them to continue in computer science.

One in 5 women indicated that they had been treated differently because of their gender compared to fewer than 1 in 20 males. The researchers noted that the discrimination reported might only be a fraction of the discrimination actually occurring in classrooms, as discrimination is often accepted as unremarkable. While $89 \%$ of females thought women had as much innate computer ability as males, only $78 \%$ of males thought females had equal ability. Comments from female students indieated they had experienced gender bias, reporting that (a) professors and teaching assistants had talked down to them and/or implied that women were incapable of understanding computer science, and (b) teaching assistants had flirted with them. The authors suggested that the dissatisfaction with the computer science program reported by half of the female students might be due to a sense of underlying gender discrimination, which students did not openly recognize, and this discrimination may further contribute to the attrition of women.

Bunderson and Christensen (1995) noted that both males and females agreed that the computer science department was oriented toward students with previous computer programming experience and that experience beyond the required prerequisites was presumed. Consequently, women were at a greater disadvantage, as they had less experience with computers than men. In fact, the authors suggested that the unrealistic expectations by the faculty that students had computer expertise before entcring the program was the most striking finding of the study. Of note was the authors' report that 
the computer science professors interviewed for the study, all of whom were male as there were no female professors in the department, were not aware of the high level of female attrition. These authors further suggested that lack of female role models may also contribute to attrition.

In searching for reasons why high-ability women drop out of undergraduate majors in science, mathematics, and engineering, Seymour (1995) conducted a 3-year ethnographic study of 460 students on seven college campuses and also found a misfit between the expectations of female students in these majors and those of faculty and malc peers. Whereas males are socialized to develop an intrinsic sense of self-worth, females are socialized to attach feelings of self-worth and confidence to signs, such as praise, that others are pleased. According to this researcher:

What young women bring to their experience of science, mathematics, and engineering (SME) disciplines is a pattern of socialization which is entirely different from that of young men. Many aspects of SME majors, which have evolved largely to meet the needs of young men, force women into conflict with their own socialization experiences. The resolution of these conflicts is sometimes accomplished by leaving the major; sometimes by making personal adjustments to the dominant male social system. These adjustments tend to be psychologically uncomfortable, and some coping strategies provoke disapproval from other women, male peers, or both. (p. 463)

In a similar vein, Etzkowitz et al. (2000) suggested that faculty who teach "weed out" courses discourage the type of personal contact that young women came to rely 
upon in high school, and loss of such contact is damaging to their self-confidence. Etzkowitz et al. further noted that:

The system for intellectual and moral education of young men in the sciences and engineering contradicts female expectations. Young women, who worked hard in high school and used their teacher's praise and encouragement as the basis for their self-esteem become disoriented in college. Lacking experience with the "male" culture of science and engineering majors, most women do not know how to respond appropriately. Women quite realistically sense that its standards differ from their previous experience and that many men resent their presence. (p. 53) Single-sex classes. While graduates of women's colleges are more likely than female graduates of coeducational colleges to be found in traditionally male career fields, Solnick (1995) found that approximately $22 \%$ of women at both single-sex and coeducational schools left male-dominated majors. Because comparing the distribution of majors only at graduation could be misleading, the researcher compared changes in women's majors from entrance to graduation at women's colleges versus coeducational colleges. The sample consisted of 1,700 students at eight women's colleges and 828 female students at seven coeducational colleges. Data on students' anticipated major during the freshman year and their actual major upon graduation were provided by the colleges. Results indicated that women at single-sex colleges were more likely to leave female-dominated majors than women at coeducational institutions. At women's colleges, $36 \%$ of women who intended to major in a traditionally female-dominated field as a freshman graduated in such a field, compared to $75 \%$ at cocducational colleges. 
Solnick (1995) noted that this overall pattern of movement does not support the "tokenism" theory that women are less likely to persist in a department in which they are a minority.

Research has clearly demonstrated that highly capable women continue to be reluctant to major in the traditionally male-dominated field of IT. When women do select such majors, persistence rates are lower for women than for men. Given women 's lack of confidence in these majors despite their abilities, the perception of a supportive environment is crucial to increasing the recruitment and persistence of women in IT. One aspect of the college environment in particular that warrants further research is the chilly climate for women.

\section{Chilly Climate for Women}

The original report on the chilly climate, entitled The Classroom Climate: A Chilly One for Women?, was written by Hall and Sandler in 1982 and published by the Project on the Status and Education of Women of the Association of American Colleges. According to Hall and Sandler's report, some faculty treat women differently from men in the classroom, often inadvertently. Women may either be singled out or ignored because of their gender, which leads to a loss of confidence in their abilities and puts them at an educational disadvantage.

As noted by Hall and Sandler (1982), overt examples of the chilly climate include discouraging women's participation in class; preventing women from seeking help outside of class; causing women to drop classes or switch majors; making disparaging comments about women; disparaging women 's intellectual abilitics; implying that 
women lack commitment; making comments about women's physical attributes or appearance; disparaging women's professional accomplishments; referring to males as "men" and females as "girls"; making sexist jokes; ridiculing scholarship that deals with women's perceptions and feelings; and making direct sexual overtures to women.

Less obvious expressions of the chilly climate include making eye contact with men more often than with women; nodding and gesturing more often in response to men's comments; using a patronizing or impaticnt tone with women; appearing more attentive, such as by leaning forward when male students speak, but not when female students speak; habitually standing closer to males when lecturing; giving men detailed instructions on an assignment, but doing the assignment for women, which implies they are incapable; calling on men more than women; calling male students by name more often than female students; waiting longer for men than for women to answer a question; interrupting women students or allowing them to be interrupted by peers more often than men; asking women lower order factual questions and men higher order questions that require critical thinking; using classroom examples that reflect stereotyped roles such as referring to a doctor as "he" and a secretary as "she"; using the generic "he" to represent both men and women (Hall \& Sandler, 1982).

After the release of the Hall and Sandler report, which was essentially a review of the literature, there was much controversy about the existence of the chilly climate. Critics of Hall and Sandler's original work (e.g., Heller, Puff, \& Mills, 1985) accurately pointed out that no data were collected and much of the information presented was anecdotal in nature. 
In 1984, Hall and Sandler expanded the concept of the chilly climate to include the campus in their report, Out of the Classroom: A Chilly Campus Climate for Women? According to this report, the campus environment was defined as including interactions with other students and staff, and students " experiences with support services such as admissions, financial aid, academic advising and career counseling, lab and field work, campus employment, internships, health care, campus safety, dormitory life, athletics, and student government and leadership, all of which may potentially contribute to a less than accepting campus climate. The authors also suggested that certain groups of women (c.g., minorities, older women, and disabled women) may especially be affected by a chilly campus climate.

Since the initial reports, empirical research on the chilly climate for women has yielded conflicting results over the past 20 years. Some researchers have found evidence of a chilly campus climate for women (Janz \&. Pyke, 2000; Pascarella et al., 1997; Whitt, Nora, Edison, Tcrenzini, \& Pascarella, 1999), but others have not (Constantinople, Cornclius, \& Gray, 1988; Crawford \& MacLeod, 1990; Drew \& Work, 1998; Heller et al., 1985). While some rescarchers focused exclusively on the classroom environment (Constantinople et al., 1988; Crawford \& MacLeod, 1990; Heller et al., 1985), others have included the campus environment as well (Drew \& Work, 1998; Janz \& Pyke, 2000; Pascarella et al,, 1997; Whitt et al,, 1999). All research cited in this section of the literature review specifically stated the focus of the study was the chilly climate for women. 


\section{Research in Support of the Chilly Climate}

There is empirical evidence that the chilly climate persists in postsecondary institutions. Pascarella et al. (1997) investigated how perceptions of a chilly campus climate affected the cognitive outcomes of women during their first year of college. A total of 23 institutions in 16 different states participated, including 18 four-year colleges and universities and 5 two-year institutions. Out of a target sample of 5,000 students, 3,840 participated. During the initial data collection in Fall 1992, students completed a pre-college survey and the Collegiate Assessment of Academic Proficiency (CAAP). The survey included items related to demographic characteristics and background, aspirations and college expectations, and orientation toward learning. The CAAP included three modules on reading comprehension, mathematics, and critical thinking. Follow-up data were collected during Spring 1993. The CAAP was re-administered, along with the College Student Experiences Questionnaire (CSEQ) and a follow-up instrument which had been developed by the National Study of Student Learning (NSSL) to measure a wide range of both in-class and out-of-class experiences in the first year of college. Included in the NSSL instrument were eight Likert-scale items which together constituted the Perceived Chilly Climate for Women Scale (PCCWS). The PCCWS yielded scores with a mean of 26.98 , a standard deviation of 5.48 , and an internal consistency reliability

of .81. Analysis of data was limited to the 1,636 women in the sample, which represented a population of the 18,129 female freshınen in the participating institutions.

Results at the two-year colleges $(n=176)$ indicated that students' perceptions of a chilly climate had statistically significant negative associations with end-of-first-year 
cognitive development and self-reported gains in academic preparation for a career. At four-year colleges $(n=1,460)$, the perception of a chilly climate had a statistically significant negative association only with sclf-reported gains in academic preparation for a career.

To determine the impact of a perceived chilly climate on women's cognitive growth during the second and third years of college, Whitt et al. (1999) did a follow-up to Pascarella et al. 's (1997) study with the same women. The sample consisted of 1,078 sophomore women attending the 23 two-year and four-year institutions participating in the NSSL and 651 junior women attending the 18 four-year institutions. The sample represented populations of 13,017 second-year women and 12,557 third-year women at those instilutions. The first follow-up data were collected in Spring 1993, including Form 88B CAAP reading comprehension, mathematics, and critical thinking modules; the CSEQ; and a follow-up instrument developed for the NSSL to measure students' in-class and out-of-class experiences, including the 8-item PCCWS. The second follow-up data collected in Spring 1994, including the CSEQ, the NSSL follow-up survey, and Form 88A CAAP writing and reading skills module.

In the second-year sample, two-year college women's $(n=85)$ perceptions of a chilly climate had statistically significant negative associations with three cognitive outcomes: self-reported gains in writing and thinking skills, understanding science, and understanding the arts and humanitics. Two-year collcge women who perceived chilly campus climates reportcd significantly lower gains in thesc areas than peers who perceived a less chilly or not chilly climate for women. For four-year college women 
( $n=993$ ), perceptions of a chilly climate had statistically significant negative associations with four cognitive outcomes: self-reported gains in writing and thinking skills, understanding science, academic preparation for a career, and understanding arts and humanities. While self-reported gains in understanding self and others were also negatively correlated with perceptions of a chilly climate, the relationship was not statistically significant.

In the third-year sample $(n=651)$, the perception of a chilly climate had a statistically significant negative effect on four self-reported cognitive outcomes including gains in writing and thinking skills, understanding science, academic preparation for a career, and understanding the arts and humanities. Surprisingly, there was a statistically significant positive effect of chilly climate on CAAP reading comprehension scores. While the perception of a chilly climate had a negative association with the CAAP eritical thinking score, the correlation was not statistically significant. There were no statistically significant differences between two-year and four-year colleges in averagc scores on the PCCWS, after background characteristics were controlled for.

The relationship between perception of a chilly campus climate and various cognitive outcomes was clearly demonstrated in Whitt et al.'s study. The authors pointed out that the nature of the scale used to estimate perceptions of the chilly climate might explain the difference in two-year and four-year students' experiences, as the PCCWS emphasizes gender discrimination in classroom settings more than non-classroom settings. As two-year college women tend to live off campus, they may view campus climate primarily as what occurs in class, so the scale described a comparatively large 
part of their college experience. Hence, choice of a scale to measure chilly climate is a consideration for future studies.

In order to study the existence of the chilly climate with a Canadian sample, Janz and Pyke (2000) developed the most comprehensive scale available to date to measure it. Initial items were generated based on Hall and Sandler's (1982) original definition of a chilly climate, which ensured face validity, and included aspects of classroom experiences, mentoring, curriculum, informal activities, peer interactions, safety, sexist behaviors, and sexual harassment. Additional items were derived from research in progress and from other scales designed to measure chilly climate. The result was a 123item Preliminary Perceived Chilly Climate Scale (PPCCS). Responses werc on a 7-point Likert scale, with additional options of "do not know" and "does not apply." The PPCCS was distributed to 416 graduate and 281 undergraduate students at a large Canadian university, and 202 were returned. Statistically significant differences were found between males and females, with females perceiving the academic climate to be chillier than males. Reliability as measured by Cronbach's alpha was .92 .

In order to further assess the validity and reliability of scores on the instrument, the researchers then went through an extensive process to construct the final scale. Frequency distributions were run on each item, and items were deleted if less than $10 \%$ of the sample did not respond, or answered "do not know" or "does not apply." The variance of each item was examined, and preference was given to items with bimodal distributions. Items were retained if $15 \%$ responded at low and high ends. Internal consistency was measured by three procedures, including inter-item correlation, factor 
analysis, and calculation of Cronbach 's alpha. Items with a minimum correlation of $r=$ .3 with the total score werc retained.

Factor analysis yielded five factors: climate students hear about, sexist treatment, climate students experience personally, classroom climate, and safety. Factor saliency was determined using a criterion of $|.40|$. Using Cronbach's alpha, internal consistency was measured for scores on the 55 items remaining. If deleting an item increased Cronbach's alpha, it was removed. The final version of the Perceived Chilly Climate Scale (PCCS) consisted of 28 items. The possible range of scores is 28 to 196 , with a midpoint of 112 . The higher the score, the chillier the student perceives the climate to be. A second study was then conducted (Janz \& Pyke, 2000). Questionnaire packets, including the PCCS, Alienation Scale, and the short form of the Marlow-Crowne Social Desirability Scale, were distributed to a sample of 488 undergraduate and graduatc students. A total of 327 completed responses were returned (269 females, 57 males, 9 unspecified). Reliability of the PCCS scores as measured by Cronbach's alpha was .90 . To further assess construct validity, scores on the PCCS were correlated with scores on Dean's Alienation Scale, a psychometrically sound scale that measures alienation, a theoretically related construct. A statistically signifieant positive relationship was found. As valid scores should not reflect socially desirable responding, scores on the PCCS were correlated with scores on the Marlow-Crowne Social Desirability Scale. No statistically significant relationship was found.

Janz and Pyke found significant gender differences in scores on the PCCS, with females $(M=101, S D=27)$ perceiving the climate to be chillier than males $(M=84$, 
$S D=21), t(324)=4.4, p<.0003$ (one-tailed). Students who described themselves as feminists $(M=105, S D=35)$ perceived the climate to be chillier than those who did not $(M=83, S D=20), t(152)=4.28, p<.0003$ (one-tailed) and those who had taken a course in women's studies $(M=106, S D=34)$ reported a chillier climate than students who had never enrolled in a women's studies course $(M=95, S D=32), t(187)=2.3$, $p<.01$ (one-tailed). Minority students $(M=102, S D=27)$ perceived the climate to be significantly chillier than non-minority students $(M=95, S D=26), t(316)=2.0, p<.02$ (one-tailed). Students who had been in school longer perceived the climate to be chillicr, as graduate students $(M=122, S D=34)$ scored significantly higher on the PCCS than undergraduate students $(M=96, S D=25), t(325)=4.32, p<.003$ (one-tailed).

Although the sample was not random and the results of the study are not necessarily generalizable to students at other collcges, the value of this study is in the development of the instrument. The process used to create the PCCS and demonstrate the validity and reliability of its scores was systematic and thorough. Consequently, the scale will be of great value in future research, and is the instrument that will be used to collect data on the dependent variables in the present study.

\section{Evidence Against the Chilly Climate}

Although several authors investigating the chilly climate found no evidence of its existence (Constantinoplc ct al., 1988; Crawford \& MacLeod, 1990; Drew \& Work, 1998; Heller et al., 1985), these studies focused on specific aspects of the classroom environment. In an observational study of college classroorns, Constantinople et al. examined differences between male and female student participation and the effect of 
instructor gender on differences. The researchers hypothesized that gender of the instructor and gender of the student would influence patterns of intcraction in the college classroom. A total of 168 students from 29 different departments at one college participated in the study. Courses observed were at the introductory (100) or intermediate (200) level from arts, social sciences, or natural sciences. Instructors had agreed to participate, but did not know if their courses were being observed. A total of 58 undergraduate students (47 females, 11 males) werc trained as observers for courses in which they werc enrolled. Observers completed a classroom map and a coding sheet of classroom interactions.

The researchers concluded that although their data did lend some support to the assertion that males are more active in the classroom than females, the effects of student gender on classroom participation are limited. There wcre stronger effects related to gender of the instructor, with females inviting more participation than males. Class sizc did have an effect, as male instructors tended to teach larger classes in which there was less discussion. When class size was held constant, gender of the instructor was less important, and gender of the student was more a determinant of classroom behavior. When the number of males in a class was held constant, the effect of instructor gender on student behaviors was very limited. The most consistent factor in influencing both student and instructor behaviors was the type of curriculum, as natural science classes had more lecture, arts classes had more discussion, and social sciences were a combination of lecture and discussion. 
Crawford and MacLeod (1990) sought to assess students' perceptions of classroom climate via a survey and to empirically test two of Hall and Sandler's (1982) hypotheses: that women and men behave differently in the classroom, with women participating less frequently and less assertively; and that gender differences in classroom interaction can be at least partly attributed to teacher behaviors that discriminate against women. The first hypothesis was supported, but the second was not. Two separate studies were conducted, one with 627 undergraduates (347 females, 280 males) in 31 classes at a state university. A total of 15 classes were sampled at the 100 level; seven at the 200 level; seven at the 300 level; and two at the 400 level. The other study was at a small liberal arts college where 761 students (52\% female) in 37 classes were surveyed. The instrument employed was an adaptation of the Student Perception Questionnaire, a selfreport measure of classroom interaction which assesses perceptions of both instructor and student behaviors. Validity or reliability information for scores on the Student Perception Questionnaire was not provided.

Three aspects of classroom climate were studied: overall climate (what class is like for everybody), individual climate (what class is like for me), and teacher behaviors (what the teacher does in the class). Students were instructed to answer all questions about only this class and not classes in general. Data were collected between the $10^{\text {th }}$ and $13^{\text {th }}$ weeks of a 15 -week semester at the university and sometime during the last month of the semester at the small college.

Results at both sites indicated that class size was the variable most related to classroom participation. Findings indicated that all three aspects of climate studied were 
highly related to class size, overall climate was unrelated to teacher or student gender, and teacher behaviors were related to teacher gender, but not student gender. Overall, climate was significantly better in small classes. Women instructors were somewhat more likely to engage students in active participation, and men instructors were somewhat more likely to engage in negative behaviors such as offensive humor, but it was reportedly not directed more at women than men and had similar effects on both genders. Students did not believe that teachers of either gender discriminated against female students. Student participation was significantly affected by gender, with women less verbally engaged in class than men, which the authors interpreted as women being less assertive. Men perceived that they volunteered more often and were called on more often even when their hand was not raised. Men also reported that tcachers responded more positively to their questions. Women were less confident in their intellectual abilities even though they had higher GPAs than men.

Drew and Work (1998) also found no evidence that women suffer from a chilly classroom climate in higher education. The researchers examined 15,960 student records (9,882 females, 6,078 males) from the College Student Experience Questionnaire (CSEQ, $3^{\text {rd }}$ cdition) database. The class breakdown was $32 \%$ freshman, $24 \%$ sophomore, $14 \%$ junior, $28 \%$ senior, and $2 \%$ graduate. The CSEQ was selected as it had been used by over 300 colleges and universities to provide an index of student satisfaction with college and ratings of key characteristics of the college environment. This instrument has 8 college environment scales, 14 college activity scales to measure student effort, and 23 estimate 
of gains scales. While the researchers reported that the CSEQ yielded reliable scores, validity and reliability information was not provided.

Results indicated that females reported interacting more in class with faculty and participating more frequently in class than males, and they also assessed their relationships with faculty and other students more positively than men. On the other hand, female students did not interact with faculty as frequently as males did after class, and interacted less frequently with faculty than males on research projects. Ovcrall, the authors concluded that there was no evidence in their study that women are suffering from a chilly classroom climate. However, it was noted that male students reported higher gains than female students in science, technology, and quantitative skills areas; differences which were small, but meaningful. As these differences could be due to differences in programs of study, further research in this area was recommended.

The stated purpose of the chilly climate study by Heller et al. (1985) was to give women an opportunity to anonymously indicate the extent to which they perceived that faculty engaged in any of the behaviors described in Hall and Sandler's (1982) original report. The sample consisted of 429 undergraduate students (216 females, 213 males) who volunteered to participate, including 127 freshmen, 152 sophomores, 85 juniors, and 65 seniors. Students in introductory and advanced courses in psychology, economics, and classics were asked to complete a survey. The authors used Hall and Sandler's report to design a survey, which included questions about faculty behaviors, students' confidence, the type of questions faculty asked students, and student's perceptions of themselves and 
their education. No data on validity or reliability for scores on the instrument were provided.

Results indicated no differences between men and women in any of the faculty behaviors identified by Hall and Sandler (1982) as contributing to the chilly academic climate. The only statistically significant difference was found in the opposite direction, that women perceived less faculty use of sexual humor than men did. While there were no statistically significant differences in students' confidence overall, when results were broken out by class, freshman males were significantly more confident in their academic ability than females. Confidence did increase significantly for women between the freshman and senior years. At the freshman level there was a statistically significant difference in women 's and men's confidence in mathematics, with women (48.9\%) indicating they lacked mathematics skills with much greater frequency than men $(22.0 \%)$.

There was a statistically significant difference between the extent to which men and women agreed with the statement, "I lack skills in argumentation." Overall, $27.2 \%$ of women agreed, while only $14.7 \%$ of men agreed. Males indicated that they were asked more lower-level factual questions than females, who were asked more higher-level analytical questions.

Several shortcomings of these studies are noteworthy (Constantinople et al., 1988; Crawford \& McLeod, 1990; Drew \& Work, 1998; Heller et al., 1995). First, all four of the studies which reportedly provided evidence against the chilly climate werc, in fact, studies of classroom interactions, and classroom climate is not equivalent to campus climate. Questions about sexual harassment are essential to the assessment of a chilly 
climate, but were deliberately excluded from the studies by Crawford and MacLeod and Drew and Work, and were not an issue in the observational study by Constantinople et al. A variety of instruments were used to assess classroom climate, about which no validity or reliability data were provided. In the study by Crawford and McLeod, data were collected late in the semester, presumably past the deadline to drop classes. Consequently, students who had perceived classroom gender bias may have dropped classes and would not have been included in the sample. Further, the samples consisted of more freshman and sophomore students than juniors, seniors, or graduate students, and research has demonstrated that students who have been in school longer are more aware of gender bias (Janz \& Pyke, 2000).

While these studies did find that women participated less than men, the question of why women participated less remains to be answered. Perhaps more subtle expressions of gender bias had an effect, for example, lack of instructor eye contact or responding with more interest to the comments of males than females. Such subtle discrimination may not be openly recognized by students, but may, as Bunderson and Christensen (1995) suggested, be sensed by female students and thereforc contribute to their attrition.

\section{Summary}

Research has shown that women are more oriented to interpersonal relationships than men and prefer to lcarn through collaboration rather than competition (Belenky et al., 1986; Chapman, 1993; Gilligan, 1993). Hence, the perception of a supportive college environment is especially important to wornen. It can affect women's self-efficacy (Bandura, 1997), which in turn affects their success in college. 
Women choose traditionally female-dominated majors in nursing primarily because of caring values (Boughn \& Lintini, 1999; Kersten et al., 1991). They are often influenced by nurses with whom they have had personal contact and who served as role models (Mendez \& Louis, 1991; Pillitteri, 1994). Factors found to be influential in the persistence of nursing majors include a student's self-efficacy (Aber \& Arathuzik, 1996; Jeffreys, 1998), accurate perceptions of what a nursing major will entail (Harvey \& McMurray, 1997), and the perception of a supportive environment (Shelton, 2003).

More is known about why women do not choose and persist in traditionally maledominated majors in IT than why they do. A woman's gender-role concept can have an effect on her carcer choice, as women who choose traditionally male-dominated careers rate themselves as higher in masculinity than women in traditionally female-dominated careers (Baker, 1987; Rea \& Strange, 1983). Studies have shown that even women with high quantitative abilities and good pre-college preparation are disinclined to major in traditionally male-dominated technical fields (Ethington, 1988; Grandy, 1990; Turner \& Bowen, 1999). Some suggested deterrents are that women may prefer fields in which their skills will not become obsolete (Turner \& Bowen, 1999), negative peer influence (Eisenhart \& Holland, 2001) and lack of role models (Astin \& Sax, 1996). As women often lack confidence despite their abilities (Ethington, 1988; Odell \& Schumacher, 1998; Vetter, 1996), the perception of a supportive campus environment is important to persistcnce of women in these majors. Gender bias, in particular, has been cited as a reason for the attrition of women in computer science majors, as has lack of pre-collegc experience with computers (Bunderson \& Christensen, 1995). 
Empirical rescarch has documented the existence of the chilly climate for women pursuing higher education. The perception of a chilly climate has been found to negatively affect cognitive gains of women attending both 2-year and 4-year colleges (Pascarella et al., 1997). Further, women have been found to perceive the climate to be chillier than men, minorities perceived the climate to be chillier than non-minorities, and students who had been in school longer perceived the climate to be chillier than other students (Janz \& Pyke, 2000). Studies claiming to refute the existence of the chilly climate have focused only on the classroom climate rather than the campus climate as a whole (Constantinople et al., 1988; Crawford \& MacLeod, 1990; Drew \& Work, 1998; Heller et al., 1985). While these studies did document that women participated in class less than men, they did not explain this phenomenon.

This literature review revealed some changes in trends over the past 20 years. The awareness that women develop and learn differently from men came about in the $1980 \mathrm{~s}$ (Belenky et al., 1986) and was further developed in the 1990s (Chapman, 1993; Gilligan, 1993). In response to this awareness, the concept of "feminist pedagogies" to enhance the learning of women emerged (Maher \& Tetreault, 2001). As women began to move into the traditionally male-dominated fields, enrollment in nursing programs declined to the point that a shortage of nurses exists today (Staiger et al., 2000). Paradoxically, the enrollment of women in computer science and computer engineering programs peaked in 1984 and has actually dropped over the past two decades (Olsen, 2000). This trend may be due, in part, to the perception of a chilly climate. When the initial chilly climate report was published (Hall \& Sandler, 1982), attention was drawn to the phenomenon and 
empirical research was conducted (Constantinople et al., 1988; Crawford \& MacLeod, 1990; Drew \& Work, 1998; Heller et al., 1985). However, there was a gap of 8 years between 1990 and 1998 when no research was published on this topic. Since the publication of Drew and Work's (1998) study, there has been renewed interest in the study of the chilly climate and further studies have been published (Janz \& Pyke, 2000; Pascarella et al., 1997; Whitt et al., 1999). 


\section{Chapter 3}

\section{Methodology}

The purpose of this research was to examine how perceptions of a chilly climate differed between students in traditionally female-dominated majors versus traditionally male-dominated majors at a community college, and how the perceptions related to students' intentions to persist or pursue higher education in their chosen career field or leave the field. There was one major research question in the study: To what extent can scores on the five subseales of the Perceived Chilly Climate Scale (PCCS) be explained by the predictor variable set of gender, ethnicity, age, college major, and intent to leave the field? This chapter includes how the site was selected, the research design, information about the research instrument and study sample, and how data were collected, entered, and analyzed. The chapter concludes with how informed consent was obtained from study participants and how Institutional Review Board approval was obtained prior to data collection.

\section{Site}

A two-year community college in the southern United States was selected as the site for the present study because it offers academic programs in information technology and nursing. This institution ranks in the top 10 nationwide in the number of associate's degrees awarded in nursing, and in the total number of associate in science and associate in arts degrees awarded. A multi-campus institution located in an urban environment, the 
college has a student body of approximately 60,000 . The median student age is $27 ; 59 \%$ of students are women; and $38 \%$ are minorities (28\% African American, $5 \%$ Hispanic, 4\% Asian, and $1 \%$ Native American). The college has received several public recognitions for its commitment to technology.

\section{Research Design}

The present study investigated the differences in perceptions of a chilly climate between females and males in traditionally female-dominated and traditionally maledominated majors and explored the relationship of these perceptions to students intentions to remain in their chosen field or leave the field. This design was correlational and multivariate in that there was no manipulation of data and there were at least two variables in each set. The dependent or criterion variables wcre perception of chilly climate as measured by scores on the five subscales of the PCCS. The independent or predictor variables were gender, age, ethnicity, major, and intent to leave the field. All data were gathered via self-report surveys (See Appendix A).

The variables of gender and ethnicity were selected as they were found to be corrclated with perceptions of a chilly climatc (Janz \& Pyke, 2000). While students who had been in school longer were found to perceive the climate to be chillier in Janz and Pyke's (2000) research, it is not clear if this difference was a function of age or the actual number of years the student had attended college. As class rank designations in community colleges are limited to either freshman or sophomore, the variable of age was selected because it offered a greater variation of responses. The variable of major was selected in order to test differences in perceptions of chilly climate in traditionally male- 
dominated and traditionally female-dominated majors. The variable of intent to leave the field was selected as a measure of satisfaction with the chosen major and to study the relationship between the perception of a chilly climate and satisfaction with the major.

\section{Research Instrument}

The instrument for collecting data on perceptions of the chilly climate was the PCCS, which was supplemented by a questionnaire with demographic data and questions about students' intentions to persist or pursue higher education in their chosen career field or leave the field (see Appendix A). For the purposes of the present study, the combined PCCS and questionnaire were entitled the "Climate Survey," as any reference to a chilly climate could have biased the responses of study participants and skewed the results.

The PCCS (see Appendix B), which was developed by Janz and Pyke (2000), consists of 28 items which are rated on a 7-point Likert scale. The possible range of scores is 28 to 196 , with a mid-point of 112 . For both the subscale and total scores, the higher the score, the chillier the student perceives the climate to be. Subscale score ranges vary due to differing lengths of the subscales:

- Subscale 1: Climate Students Hear About (range of scores is 8-56),

- Subscale 2: Sexist Attitudes and Treatment (range of seores is 6-42),

- Subscale 3: Climate Students Experience Personally (range of scores is 6-42),

- Subscale 4: Classroom Climate/Course Material (range of scores is 5-35), and

- Subscale 5: Safety (rangc of scores is 3-21). 
Using Cronbach's alpha, internal consistency reliability for scores on the PCCS was calculated to be .90 and .92 in the two studies conducted by Janz and Pyke (2000). Validity and reliability of scores on the instrument was established through an extensive process, which is described in the Review of Literature (Chapter 2). As the PCCS was pilot tested by its developers, pilot testing was not necessary in the present study. Permission to use the PCCS was obtained from Dr. Sandra Pyke (see Appendix C).

The first part of the survey, items 1 though 8 , consisted of questions to collect demographic data including the student's major, estimated grade point average (GPA), class standing, estimated number of credits completed, estimated date of graduation, gender, age, and ethnicity. Item 9 addressed the student's intent to stay in or leave the field. Students were instructed to check one of the following: pursue further education in my major, get a job related to my major, pursue further education in a different major, or get a job in a field NOT related to my major.

The next 28 items consisted of the PCCS items, which are rated on a 7-point Likert scale. Students were asked to rate each statement on a continuum, from 1-strongly agree to 7-strongly disagree. The final itcm on the Climate Survey was a two-part question that read, "Do you think that women are treated differently from men in classes in your major? If so, how?"

\section{Data Collection}

Data were collected during the first 5 weeks of Spring semester 2004. The survey was administered in class to ensure a high response rate. Instructors were asked to grant access to their classrooms, a request which was made by e-mail from the rescarcher to the 
instructors via their supervising deans. The communication from the deans included a letter from the researcher outlining the purpose of the study and assuring their confidentiality (see Appendix D), a copy of the Climate Survey (see Appendix A), and a copy of the Informed Consent for Research Project Participation (see Appendix E). Instructors responded directly to the researcher to indicate their interest in participating in the study. The researcher sent a follow-up e-mail to instructors who did not respond within 1 week.

A total of 13 instructors ( 7 men, 6 women) granted classroom access to conduct the survey and seven instructors agreed to have multiple sections of their classes surveyed. Classes of all instructors who granted access were surveyed. A total of 30 classes in the areas of IT ( 9 classes), engineering ( 8 classes), nursing ( 5 classes), and education ( 8 classes) were visited and students completed the Climate Survey in class. As students who perceived a chilly climate may have been more likely to drop out or change majors prior to graduation than students who did not, the sample included both freshman and sophomore students.

Classes sampled represented a cross-section of freshman-level (16 classes) and sophomore-level (14 classes) classes that students in the major typically take during Spring semester. IT classes surveyed included: Operating Systems I, Introduction to Network Configuration, Computer Peripherals and Interfacing, Introduction to Programming and Algorithm Design, Network Installation, and Introduction to Windows Programming Using Visual Basic. Engineering (technology) classes surveyed included: Engineering Materials and Processes, Occupational Safety, Architectural Drafting, 
Introduction to Building Construction, Structural Drafting, Surveying, and Concrete. Nursing classes surveyed included: Nursing Leadership, Nursing Care of Children, Nursing Care of the Childbearing Family. Education classes surveyed included: Introduction to Education, Teaching Diverse Populations, and Introduction to Educational Technology.

The researcher personally visited each classroom to collect the data. After a brief introduction by the instructor, in most cases, the instructor left the room until surveys were completed. Each student received a consent form and a Climate Survey, Although the consent form included written instructions, students were given verbal instructions as well. Students were instructed that their participation in the study was voluntary, the purpose of the study was to examine differences in perceptions of campus climate between women and men in traditional majors versus non-traditional majors, they should respond to the items based on their experience as a whole at the community college and not limited to the class in which they were completing the survey, that their confidentiality would be maintained, and that they must be 18 years of age or older to participate. Three students were excluded from participation, as they were under 18 years of age. As students turned the completed surveys in, to the extent possible, the rescarcher reviewed their responses and prompted them to fill in missing data.

Of the 470 surveys collected, 67 were excluded due to either incomplete data or students bcing enrolled in a major outside of the four areas of consideration in the present study. The final research sample consisted of 403 students. If 4 or fewer responses (15\%) on the PCCS were left blank, the average score for the sample was filled in. Surveys with 
more than 4 incomplete items were eliminated from the sample. If a student omitted an item that pertained to any of the predictor variables (gender, ethnicity, age, major, intent to leave), the survey was excluded from the sample.

\section{Data Entry}

The completed surveys were scored manually. Reverse scoring of 14 items on the PCCS (items 1, 4, 8, 10, 16, 20, 21, 22, 23, 24, 25, 26, 27, 28) was completed prior to manually entering the data into Excel spreadsheets. Responses to the final item on the Climate Survey, which included an open-ended question, were data processed verbatim as written by students.

\section{Study Sample}

The population of interest consisted of students majoring in IT, engineering, nursing or education at a multi-campus conmunity college in Florida. The sample was a convenience sample of students in intact classes in IT, engineering, nursing, and education. The target sample was to consist of at least 300 students, with approximately equal numbers of students in each of the majors under consideration. The final sample was comprised of 403 students, including 91 IT majors (74 males, 17 females), 82 engineering majors (65 males, 17 females), 118 education majors (34 males, 84 females), and 112 nursing majors (13 males, 99 females). According to data provided by the participating institution, the distribution of students enrolled in the four majors of interest during the 2002-2003 academic year was as follows: 2,210 IT majors (1,520 men, 690 women), 818 engineering majors ( 642 men, 176 women), 302 nursing majors (43 men, 
259 women), and 1,509 education majors ( 301 men, 1,208 women). Data from the 20032004 academic year were not yet available.

\section{Informed Consent and Institutional Review Board Approval}

All participants were asked to sign an informed consent form (see Appendix E) and their participation in the study was strictly voluntary. Students' responses were held confidential, as indicating that they perceived the climate to be chilly could have resulted in disapproval from instructors. Further, instructors were assured that the responses of their classes would be held confidential to ensure that no negative perceptions or punitive action by the administration would result from their participation in the study. Only aggregated data were presented. Approval for the study was obtained from the Institutional Review Board at the University of North Florida (see Appendix F) prior to the collection of any data. The participating community college did not have an Institutional Review Board.

\section{Data Analysis}

The data analysis included examining demographic data, categorizing the data collected from the open-ended question, running bivariate correlations for independent and dependent variables, and conducting a reliability analysis and a canonical correlation analysis. All statistical analyses were performed using the Statistical Package for the Social Sciences (SPSS) version 11.5 (SPSS, Inc, 2002). Canonical correlation analysis (Thompson, 1984) was utilized to determine if the dependent or criterion variable set of subscale scores on the PCCS could bc collectively predicted by the independent variables grouped together. The five independent variables included: gender (male, female), major 
(IT, engineering, nursing, education), age (numeric), ethnicity (white, African American, Hispanic, Native American, Asian, other) and intent to leave (pursue further education in major; get a job related to major; pursue further education in a different major; get a job in a field not related to major). The five dependent variables, which were subscales of the PCCS, included: Climate Students Hear About, Sexist Attitudes and Treatment, Climate Students Experience Personally, Classroom Climate/Course Material, and Safety.

For purposes of the canonical correlation analysis, three variable categories were collapsed into dichotomous categories. Violations of multivariate normality assumption becomes problematic if there are too few responses in a given category for one or more variables, which was the case with the variables ethnicity and intent to leave the field. The variable ethnicity was collapsed from the original six categories of white, African American, Hispanic, Native American, and other into white and non-white. The variable intent to leave the field was collapsed from the original four categories into intent to stay (pursue further education in major; get a job related to major) and intent to leave (pursue further education in a different major; get a job in a field not related to major). Further, the variable major was collapsed from the four original categories of IT, engineering, nursing, and education into the categories of traditional male (TT and engineering), and traditional female (nursing and education).

These dichotomous transformations helped assure that the data were multivariate normal and therefore appropriate for use in canonical correlation analysis. The data analysis resulted in five canonical solutions or roots, which were useful in addressing the study's six research hypotheses as posited in Chapter 1. 


\section{Summary}

The site selected for the present study was a two-year community college in the southern United States. The design employed was correlational and multivariate. The independent variables were gender, age, ethnicity, major, and intent to leave the field. The dependent variables were scores on the five subscales of the PCCS. This scale, together with demographic and other informational items, constituted the Climate Survey, which was the research instrument used for data collection.

Data were collected during Spring semester 2004 from intact classrooms in IT, enginecring, nursing, and education. The final sample consisted of 403 students in the four majors of interest including 101 IT majors, 72 engineering majors, 119 education majors, and 111 nursing majors. Approval for the study was obtained from the Institutional Review Board at the University of North Florida, prior to the collection of data. Informed consent was obtained from students prior to their participation in the study. The data analysis consisted of examining demographic data, categorizing the data collected from the open-ended question, running bivariate correlations for independent and dependent variables, and conducting a reliability analysis and a canonical correlation analysis.

In Chapter 4 , the results of the data analyses are presented. The findings are then applied to test the six research hypotheses and answer the primary research.

In Chapter 5, the findings of the study are summarized and discussed. Conclusions are drawn based on the findings, recommendations are made, and contributions of the study to the field of education are presented. 


\section{Chapter 4}

\section{Findings}

As stated in Chapter 1, the present study examined how perceptions of a chilly climate differed between students in traditionally female-dominated majors versus traditionally male-dominated majors at a community college, and how these perceptions related to students' intentions to persist or pursue higher education in their chosen career field or leave the field. There was one major research question in the study: To what extent can scores on the five subscales of the Perceived Chilly Climate Scale (PCCS) be explained by the predictor variable set of gender, ethnicity, age, college major, and intent to lcave the field?

In order to answer the primary research question and test the corresponding hypotheses, a data analysis was conducted. The analysis included examining demographic data and descriptive statistics, categorizing the data collected from the open-ended survey question, running bivariate correlations for independent and dependent variables, conducting a reliability analysis, and performing a canonical correlation analysis to test the study's research question. All statistical analyses were performed using SPSS version 11.5 (SPSS, Inc., 2002). After the data analyses are presented, each research hypothesis is addressed separately. 


\section{Demographic Data}

Demographic data were collected from study participants in order to better understand students' perceptions of chilly climate. Among the 403 students in the sample, $46 \%$ were male $(n=186)$ and $54 \%(n=217)$ were female. White students constituted the largest ethnicity represented in the sample, with $68.5 \%(n=276)$ being white, $16.6 \%$ African American $(n=67), 5.7 \%$ Hispanic $(n=23), 4 \%$ Asian $(n=17)$, and $1 \%(n=4)$ Native American. A total of $4 \%(n=16)$ of students categorized their ethnicity as "other." Education majors comprised 29.3\% (34 males, 84 females) of the sample, with $27.8 \%$ majoring in nursing ( 13 males, 99 females), $22.6 \%$ in IT (74 males, 17 females), and $20.3 \%$ in enginecring ( 65 males, 17 females). A total of $50 \%$ of the sample planned to get a job related to their major, $45 \%$ planned to further their education in their current major, $4 \%$ intended to pursue further education in a different major, and only $1 \%$ planned to get a job in a field not related to their major. Ages of students in the sample ranged from 18 to 60 , with a mean age of $29.6(S D=9.5)$, which was approximately equal for both genders ( $M=30.2, S D=9.8$ for males; $M=29.1, S D=9.3$ for females). Descriptive statistics for independent variables are presented in Table 1. The specific count of students in each major by gender and ethnicity is provided in Table 2. Information about students' intentions to stay in or leave the field is provided by major and gender in Table 3.

Data were also collected that were not among the dependent or independent variable sets in the present study, but pertained to perceptions of chilly climate. 
Information was collected on students' estimated GPA, class standing, estimated number of credits completed, and estimated date of graduation. Self-reported estimates of GPA of students in the sample ranged from 1.50 to 4.00 , with a mean of $3.19(M=3.18$, $S D=.53$ for men; $M=3.20, S D=.43$ for women). Estimated date of graduation for students in the sample was $46.9 \%(n=189)$ in $2004,26.1 \%(n=105)$ in $2005,14.6 \%(n$ $=59)$ in $2006,3.7 \%(n=15)$ in $2007,2 \%(n=8)$ in 2008 , and $6.7 \%(n=27)$ unspecified. Table 1

Sample Demographic Data

\begin{tabular}{|c|c|c|c|}
\hline $\begin{array}{c}\text { Demographic } \\
\text { Variable } \\
\end{array}$ & Category & $n$ & $\%$ \\
\hline \multirow[t]{2}{*}{ Gender } & Male & 186 & 46.0 \\
\hline & Female & 217 & 54.0 \\
\hline \multirow[t]{6}{*}{ Ethnicity } & Whitc & 276 & 68.5 \\
\hline & African American & 67 & 16.6 \\
\hline & Hispanic & 23 & 5.7 \\
\hline & Native American & 4 & 1.0 \\
\hline & Asian & 17 & 4.2 \\
\hline & Other & 16 & 4.0 \\
\hline \multirow[t]{4}{*}{ Major } & IT (74 males, 17 females) & 91 & 22.6 \\
\hline & Engineering ( 65 males, 17 females) & 82 & 20.3 \\
\hline & Education (34 males, 84 females) & 118 & 29.3 \\
\hline & Nursing (13 males, 99 females) & 112 & 27.8 \\
\hline \multirow[t]{4}{*}{ Intent to Leave } & Further education in my major & 181 & 45.0 \\
\hline & Job related to my major & 203 & 50.0 \\
\hline & Further education in DIFFERENT major & 16 & 4.0 \\
\hline & Job in field NOT related to major & 3 & 1.0 \\
\hline Age & \multicolumn{3}{|c|}{$\begin{array}{l}\text { Range }=42(\mathrm{~min}, \text { of } 18 \text { to max. of } 60) \\
\text { Mean }=29.6, \text { Standard Deviation }=9.5 \\
(M=30.2 \text { for males, } S D=9.8 ; M=29.1, S D=9.3 \text { for females })\end{array}$} \\
\hline
\end{tabular}


There was appreciable variance across the class standing variable, which could possibly warrant further study as a factor in perceptions of chilly climate. When students were asked to indicate their class standing and were given the option of either freshman or sophomore, $23 \%$ responded that they were freshmen and $77 \%$ responded that they were sophomores.

Table 2

Major Count by Gender and Ethnicity

\begin{tabular}{|c|c|c|c|c|c|c|c|}
\hline \multirow{2}{*}{\multicolumn{2}{|c|}{ Ethnicity }} & & \multicolumn{4}{|c|}{ Major } & \multirow[b]{2}{*}{ Total } \\
\hline & & & IT & Engineering & Education & Nursing & \\
\hline \multirow[t]{3}{*}{ White } & Gender & Male & 46 & 45 & 23 & 11 & 125 \\
\hline & & Female & 6 & 11 & 54 & 80 & 151 \\
\hline & & Total & 52 & 56 & 77 & 91 & 276 \\
\hline \multirow{4}{*}{$\begin{array}{c}\text { African } \\
\text { American }\end{array}$} & & & & & & & \\
\hline & Gender & Male & 16 & 6 & 10 & 0 & 32 \\
\hline & & Female & 7 & 4 & 14 & 10 & 35 \\
\hline & & Total & 23 & 10 & 24 & 10 & 67 \\
\hline \multirow[t]{3}{*}{ Hispanic } & Gender & Male & 3 & 6 & 1 & 0 & 10 \\
\hline & & Female & 1 & 0 & 9 & 3 & 13 \\
\hline & & Total & 4 & 6 & 10 & 3 & 23 \\
\hline Native & & & & & & & \\
\hline \multirow{3}{*}{ American } & Gender & Male & & 1 & 0 & & 1 \\
\hline & & Female & & 2 & 1 & & 3 \\
\hline & & Total & & 3 & 1 & & 4 \\
\hline \multirow[t]{3}{*}{ Asian } & Gender & Male & 5 & 1 & 0 & 1 & 7 \\
\hline & & Female & 1 & 0 & 4 & 5 & 10 \\
\hline & & Total & 6 & 1 & 4 & 6 & 17 \\
\hline \multirow[t]{3}{*}{ Other } & Gender & Male & 4 & 6 & 0 & 1 & 11 \\
\hline & & Female & 2 & 0 & 2 & 1 & 5 \\
\hline & & Total & 6 & 6 & 2 & 2 & 16 \\
\hline
\end{tabular}


Students were then asked to estimate the total number of college credits they had completed at all institutions of higher education. Responses ranged from 0 to 200 credits, with a mean of 57.7 . When class standings of students were categorized based on the total number of credits completed, with freshmen having 0-29 credits and sophomores having 30 credits or more, the sample was $22.5 \%$ freshmen and $77.5 \%$ sophomores, which is comparable to students' self-reported class standing as either freshmen or sophomores.

Table 3

Students' Intentions to Stay or Leave the Field by Major and Gender

\begin{tabular}{|c|c|c|c|c|c|c|c|}
\hline \multirow{2}{*}{\multicolumn{2}{|c|}{ Intent }} & \multicolumn{6}{|c|}{ Major } \\
\hline & & & IT & Engineering & Education & Nursing & Total \\
\hline \multirow[t]{3}{*}{$\begin{array}{l}\text { Further ed in } \\
\text { my major }\end{array}$} & Gender & Male & 25 & 32 & 19 & 7 & 83 \\
\hline & & Female & 5 & 10 & 45 & 38 & 98 \\
\hline & & Total & 30 & 42 & 64 & 45 & 181 \\
\hline \multirow{4}{*}{$\begin{array}{l}\text { Job related to } \\
\text { my major }\end{array}$} & & & & & & & \\
\hline & Gender & Male & 42 & 32 & 13 & 6 & 93 \\
\hline & & Female & 12 & 5 & 32 & 61 & 110 \\
\hline & & Total & 54 & 37 & 45 & 67 & 203 \\
\hline \multicolumn{8}{|l|}{$\begin{array}{l}\text { Further ed in } \\
\text { DIFFERENT }\end{array}$} \\
\hline \multirow[t]{3}{*}{ major } & Gender & Male & 6 & 1 & 1 & & 8 \\
\hline & & Female & 0 & 2 & 6 & & 8 \\
\hline & & Total & 6 & 3 & 7 & & 16 \\
\hline \multirow{4}{*}{$\begin{array}{l}\text { Job in field } \\
\text { NOT related } \\
\text { to inajor }\end{array}$} & & & & & & & \\
\hline & Gender & Male & 1 & & 1 & & 2 \\
\hline & & Female & 0 & & 1 & & 1 \\
\hline & & Total & 1 & & 2 & & 3 \\
\hline
\end{tabular}


Information about class standing is important to the discussion of perceptions of chilly climate. Janz and Pyke (2000) compared the scores of undergraduate students and graduate students and found that students who had been in school were more likely to have higher scores on the PCCS. Because class standing designations in community colleges are cither freshman or sophomore, the variable age was used instead of the variable class size for the purpose of the present study.

\section{Descriptive Statistics for the Perceived Chilly Climate Scale}

Each of the 28 items of the PCCS has a theoretical minimum of 1 and a maximum of 7. The theoretical range of scores on the PCCS total scale is from a minimum of 28 to a maximum of 196. As a comparison, the scores for the present sample ranged from 28 to 155 , with a mean of 74.7 and a standard deviation of 25.9. Descriptive statistics for each of the items on the scale, the total score, and the five criterion variable subscales (PCCS 1, PCCS 2, PCCS 3, PCCS 4, PCCS 5) are presented in Table 4.

\section{Descriptive Statistics for the Perceived Chilly Climate Subscales}

PCCS total scores for students in all of the four majors combined were higher for women $(M=78.9, S D=26.1, n=217)$ than for men $(M=69.7, S D=24.8, n=186)$. Further, scores were higher for women than for men on four of the five PCCS subscales. Only on Subscale 4, Classroom Climate/Course Material, did men $(M=16.7, S D=5.6)$ score slightly higher than women $(M=16.5, S D=5.6)$, a negligible difference.

Examination of scores of women in traditionally male-dominated majors and traditionally female-dominated majors indicated that PCCS total scores of women in the traditionally-male dominated majors of IT and engineering were lower $(M=72.9$, 
Table 4

Descriptive Statistics for the PCCS 28-Item Scale*

\begin{tabular}{|c|c|c|c|c|}
\hline & Minimum & Maximum & Mean & Std. Deviation \\
\hline 1 & 1.00 & 7.00 & 2.6 & 2.2 \\
\hline 2 & 1.00 & 7.00 & 2.6 & 2.2 \\
\hline 3 & 1.00 & 7.00 & 3.3 & 2.3 \\
\hline 4 & 1.00 & 7.00 & 2.6 & 2.3 \\
\hline 5 & 1.00 & 7.00 & 2.3 & 2.0 \\
\hline 6 & 1.00 & 7.00 & 2.4 & 2.0 \\
\hline 7 & 1.00 & 7.00 & 2.7 & 2.1 \\
\hline 8 & 1.00 & 7.00 & 2.7 & 2.3 \\
\hline 9 & 1.00 & 7.00 & 3.1 & 1.8 \\
\hline 10 & 1.00 & 7.00 & 2.0 & 1.4 \\
\hline 11 & 1.00 & 7.00 & 2.2 & 1.6 \\
\hline 12 & 1.00 & 7.00 & 2.2 & 1.7 \\
\hline 13 & 1.00 & 7.00 & 3.3 & 2.0 \\
\hline 14 & 1.00 & 7.00 & 2.1 & 1.7 \\
\hline 15 & 1.00 & 7.00 & 2.1 & 1.8 \\
\hline 16 & 1.00 & 7.00 & 2.2 & 1.6 \\
\hline 17 & 1.00 & 7.00 & 2.1 & 1.8 \\
\hline 18 & 1.00 & 7.00 & 2.1 & 1.8 \\
\hline 19 & 1.00 & 7.00 & 2.2 & 1.8 \\
\hline 20 & 1.00 & 7.00 & 2.4 & 1.5 \\
\hline 21 & 1.00 & 7.00 & 3.5 & 1.8 \\
\hline 22 & 1.00 & 7.00 & 4.1 & 1.7 \\
\hline 23 & 1.00 & 7.00 & 3.1 & 1.7 \\
\hline 24 & 1.00 & 7.00 & 4.0 & 1.8 \\
\hline 25 & 1.00 & 7.00 & 1.9 & 1.3 \\
\hline 26 & 1.00 & 7.00 & 3.8 & 1.9 \\
\hline 27 & 1.00 & 7.00 & 2.8 & 2.3 \\
\hline 28 & 1.00 & 7.00 & 2.6 & 1.6 \\
\hline PCCS 1 & 8.00 & 56.00 & 21.0 & 12.3 \\
\hline PCCS 2 & 6.00 & 38.00 & 14.8 & 6.8 \\
\hline PCCS 3 & 6.00 & 40.00 & 13.1 & 6.6 \\
\hline PCCS 4 & 5.00 & 35.00 & 16.6 & 5.6 \\
\hline PCCS 5 & 3.00 & 21.00 & 9.1 & 4.7 \\
\hline PCCS Total & 28.00 & 155.00 & 74.7 & 25.9 \\
\hline
\end{tabular}

*Note: Text of the PCCS items is presented in Appendix A, $n=403$. Subscales are: PCCS 1 (Climates Students Hear About); PCCS 2 (Sexist Attitudes and Treatment); PCCS 3 (Climate Students Experience Personally); PCCS 4 (Classroom Climate/Course Material); PCCS 5 (Safety). 
$S D=20.0, n=34$ ) than scores of women in the traditionally femalc-dominated majors of nursing and education $(M=80.0, S D=27.0, n=183)$. This trend was consistent across four of the five PCCS subscales. Only on Subscale 4, Classroom Climate/Course Material, did women in traditionally male-dominated majors ( $M=19.4, S D=5.4$ ) score higher than women in traditionally female-dominated majors $(M=16.0, S D=5.5)$. In comparing scores of women in the two traditionally male-dominated majors of IT and engineering, women majoring in IT scored lower $(M=68.9, S D=20.7, n=17)$ than women majoring in engineering $(M=77.0, S D=19.0, n=17)$ on the PCCS total, as well as across all of the PCCS subscales.

Descriptive statistics for scores of males and females for each of the PCCS subscales and the PCCS total are presented in Appendix G.

\section{Bivariate Correlations}

Intercorrelations among all of the dependent and independent variables are presented in Table 5. Because the categorical variables were recoded into bivariate variables, the Pearson correlations arc appropriate. Major was recoded into traditional male (IT and engineering) and traditional female (nursing and education); ethnicity was recoded into white and non-white (African American, Hispanic, Native American, Asian, and other); intent to leave the field was recoded into stay (pursue further education in my major, or get a job related to my major) and leave (pursue further education in a different major, or get a job in a field NOT related to my major). Examination of the bivariate correlations indicates that the dependent variables of the five PCCS subscales are moderately to highly correlated. Four of the ten unique values had Pearson correlations 
above $.3(.32, .47, .56, .63)$, with three of the remaining six with values just under $.3(.20$, $.22, .22, .26, .26, .29)$. Other than the high correlation of .60 between gender and major, interrecorrelations of the independent variables of gender, age, recoded major (traditional male/traditional female), recoded ethnicity (white/non-white), and recoded intent to leave the field (stay/leave) are not noteworthy.

Examination of the correlations between the PCCS total scores and each of the independent variables, which are also presented in Table 5, indicates small correlations with gender (.18), ethnicity (.14), age (-.17), and major (.16). There was a very low correlation (.08) between the PCCS total scores and the intent to leave the field variable.

\section{Reliability Analysis}

Internal consistency reliability analyses were conducted on scores from the 28 item PCCS scale and each of the five PCCS subscales (Subscale 1: Climate Students Hear About; Subscale 2: Sexist Attitudes and Treatment; Subscale 3: Climate Students Experience Personally; Subscale 4: Classroom Climate/Course Material, and Subscale 5: Safety.) A minimum coefficient alpha of .70, as recommended by Nunnally (1978), was used to indicate an adequate level of internal consistency for the subscale scores.

\section{8-Item Perceived Chilly Climate Scale}

Table 6 presents results of the internal consistency analysis of the PCCS data. Each of the 28 itcms on the PCCS was correlated with the total score for the scale, and alpha values were computed with each item removed. Coefficient aipha for scores on the 28-item scale was .89 . Deleting any of the individual items on the scale would not have 
Table 5

Bivariate Correlations for Independent and Dependent Variables*

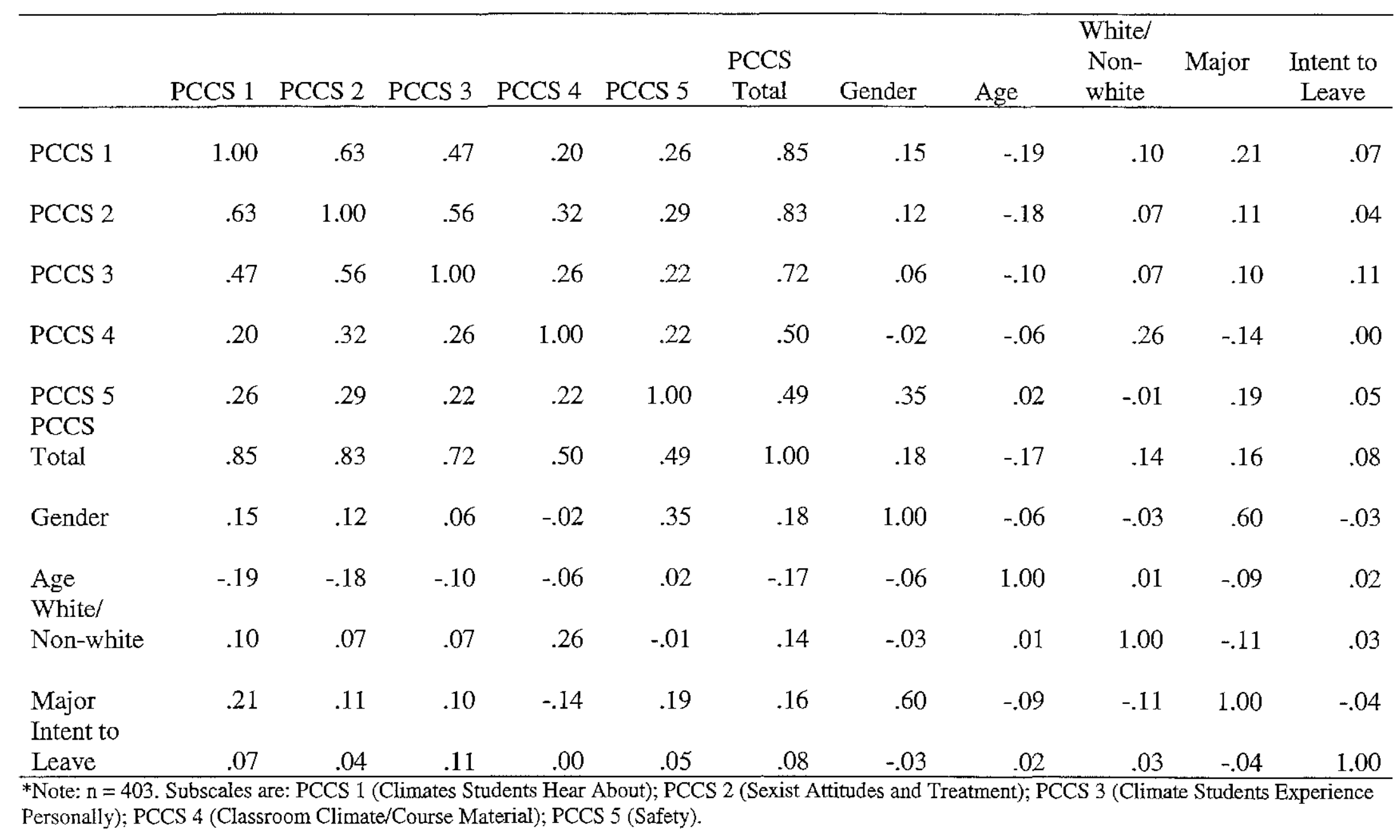


resulted in a higher alpha. Hence, the reliability analysis indicated that scores on the PCCS scale were adequately reliable measures of perceptions of chilly climate.

Table 6

Reliability Analysis of 28-Item Scale

\begin{tabular}{lcccc}
\hline & $\begin{array}{c}\text { Scale Mean } \\
\text { if Iten } \\
\text { Deleted }\end{array}$ & $\begin{array}{c}\text { Scale } \\
\text { Variance if } \\
\text { Item Deleted }\end{array}$ & $\begin{array}{c}\text { Corrected } \\
\text { Item-Total } \\
\text { Correlation }\end{array}$ & $\begin{array}{c}\text { Alpha if } \\
\text { Item } \\
\text { Deleted }\end{array}$ \\
\hline Q1 & 72.10 & 612.87 & .50 & .88 \\
Q2 & 72.03 & 604.70 & .59 & .88 \\
Q3 & 71.37 & 616.86 & .43 & .88 \\
Q4 & 72.11 & 610.75 & .50 & .88 \\
Q5 & 72.39 & 613.36 & .54 & .88 \\
Q6 & 72.29 & 605.58 & .63 & .88 \\
Q7 & 71.99 & 597.96 & .66 & .88 \\
Q8 & 71.99 & 609.57 & .51 & .88 \\
Q9 & 71.56 & 636.04 & .36 & .88 \\
Q10 & 72.70 & 639.82 & .43 & .88 \\
Q11 & 72.47 & 624.13 & .55 & .88 \\
Q12 & 72.42 & 616.13 & .62 & .88 \\
Q13 & 71.39 & 622.59 & .46 & .88 \\
Q14 & 72.58 & 617.19 & .62 & .88 \\
Q15 & 72.55 & 626.56 & .47 & .88 \\
Q16 & 72.42 & 638.95 & .37 & .88 \\
Q17 & 72.55 & 643.45 & .29 & .88 \\
Q18 & 72.58 & 625.65 & .49 & .88 \\
Q19 & 72.43 & 628.39 & .45 & .88 \\
Q20 & 72.29 & 641.47 & .38 & .88 \\
Q21 & 71.20 & 643.82 & .27 & .88 \\
Q22 & 70.57 & 654.41 & .16 & .89 \\
Q23 & 71.53 & 637.08 & .36 & .88 \\
Q24 & 70.64 & 659.59 & .10 & .89 \\
Q25 & 72.72 & 633.93 & .54 & .88 \\
Q26 & 70.90 & 637.63 & .32 & .88 \\
Q27 & 71.85 & 635.49 & .27 & .89 \\
Q28 & 72.11 & 635.55 & .41 & \\
\hline & & & & .89 \\
\hline
\end{tabular}

Alpha $=.89$ 


\section{Subscale 1: Climate Students Hear About}

Item analyses were conducted on the 8 items of the subscale hypothesized to assess climate students hear about and presented in Table 7. Each of the 8 items was correlated with the total score for the scale with the item removed. Coefficient alpha for scores on the subscale was .86 , and deleting any of the items would not have resulted in a higher alpha. Hence, scores on the 8-item subscale were adequately reliable.

Table 7

Reliability Analysis of Subscale 1

\begin{tabular}{lrrrr}
\hline Item & $\begin{array}{c}\text { Scale Mean } \\
\text { if Item } \\
\text { Deletcd }\end{array}$ & $\begin{array}{c}\text { Scale } \\
\text { Variance if } \\
\text { Item Deleted }\end{array}$ & $\begin{array}{c}\text { Corrected } \\
\text { Item-Total } \\
\text { Correlation }\end{array}$ & $\begin{array}{c}\text { Alpha if } \\
\text { Item } \\
\text { Deleted }\end{array}$ \\
\hline Q1 & 18.43 & 118.64 & .58 & .84 \\
Q2 & 18.36 & 118.33 & .60 & .84 \\
Q3 & 17.69 & 121.04 & .48 & .85 \\
Q4 & 18.43 & 119.72 & .54 & .85 \\
Q5 & 18.72 & 118.28 & .65 & .83 \\
Q6 & 18.62 & 119.28 & .63 & .84 \\
Q7 & 18.32 & 112.43 & .75 & .82 \\
Q8 & 18.32 & 117.83 & .57 & .84 \\
\hline
\end{tabular}

Alpha $=.86$

Subscale 2: Sexist Attitudes and Treatment

Item analyses were conducted on the 6 items of the subscale hypothesized to assess sexist attitudes and treatment and are presented in Table 8. Coefficient alpha for scores on the subscale was .75 , and removing any of the individual items would not have resulted in a higher alpha. Therefore, scores on the 6 -item subscale wcre adequately reliable. 
Table 8

Reliability Analysis of Subscale 2

\begin{tabular}{lrrrr}
\hline Item & $\begin{array}{c}\text { Scale Mean } \\
\text { if Item } \\
\text { Deleted }\end{array}$ & $\begin{array}{c}\text { Scale } \\
\text { Variance if } \\
\text { Item Deleted }\end{array}$ & $\begin{array}{c}\text { Corrected } \\
\text { Item-Total } \\
\text { Correlation }\end{array}$ & $\begin{array}{c}\text { Alpha if } \\
\text { Item } \\
\text { Deleted }\end{array}$ \\
\hline Q9 & 11.72 & 35.61 & .39 & .75 \\
Q10 & 12.86 & 39.26 & .35 & .75 \\
Q11 & 12.63 & 34.07 & .54 & .71 \\
Q12 & 12.58 & 31.93 & .64 & .68 \\
Q13 & 11.55 & 32.82 & .46 & .73 \\
Q14 & 12.74 & 32.69 & .61 & .69 \\
\hline
\end{tabular}

Alpha $=.75$

Subscale 3: Climate Students Experience Personally

Item analyses were conducted on the 6 items of the subscale hypothesized to assess climate students experience personally and are presented in Table 9 . Each of the 6 items was correlated with the total score for the scale with the item removed. Coefficient alpha for scores on the subscale was .72. Deleting any of the any of the 6 items would not have resulted in a greater alpha. Hence, scores on the subscale were adequately reliable.

Subscale 4: Classroom Climate/Course Material

Item analyses were conducted on the 5 items of the subscale hypothesized to assess climate students hear about and presented in Table 10. Coefficient alpha for scores on the subscale was .68, which is just under Nunnally's (1978) recommended minimum alpha of .70. Alpha would have increased negligibly to .69 had item 25 been deleted. Although the reliability of scores on this scale was a bit more marginal, the scale 
had few items, which resulted in less variance and consequently a lower reliability estimate. Future development of this subscale should include addition of items in an attempt to enhance reliability.

Table 9

Reliability Analysis of Subscale 3

\begin{tabular}{|l|r|r|r|r|}
\hline Item & $\begin{array}{c}\text { Scale Mean } \\
\text { if Item } \\
\text { Deleted }\end{array}$ & $\begin{array}{c}\text { Scale } \\
\text { Variance if } \\
\text { Item Deleted }\end{array}$ & $\begin{array}{c}\text { Corrected } \\
\text { Item-Total } \\
\text { Correlation }\end{array}$ & $\begin{array}{c}\text { Alpha if } \\
\text { Item } \\
\text { Deleted }\end{array}$ \\
\hline Q15 & 11.02 & 30.08 & .53 & .66 \\
\hline Q16 & 10.88 & 34.27 & .35 & .71 \\
\hline Q17 & 11.02 & 31.72 & .44 & .69 \\
\hline Q18 & 11.04 & 30.41 & .51 & .66 \\
\hline Q19 & 10.89 & 29.53 & .56 & .65 \\
\hline Q20 & 10.75 & 35.40 & .34 & .71 \\
\hline
\end{tabular}

Alpha $=.72$

Table 10

Reliability Analysis of Subscale 4

\begin{tabular}{lrrrr}
\hline & $\begin{array}{c}\text { Scale Mean } \\
\text { if Item } \\
\text { Deleted }\end{array}$ & $\begin{array}{c}\text { Scale } \\
\text { Variance if } \\
\text { Item Deleted }\end{array}$ & $\begin{array}{c}\text { Corrected } \\
\text { Item-Total } \\
\text { Correlation }\end{array}$ & $\begin{array}{c}\text { Alpha if } \\
\text { Item } \\
\text { Delcted }\end{array}$ \\
\hline Q21 & 13.17 & 19.93 & .51 & .60 \\
Q22 & 12.53 & 21.26 & .44 & .63 \\
Q23 & 13.49 & 21.07 & .45 & .63 \\
Q24 & 12.60 & 20.38 & .49 & .61 \\
Q25 & 14.69 & 25.60 & .29 & .69 \\
\hline
\end{tabular}

Alpha $=.68$

Subscale 5: Safety'

Finally, item analyses were conducted on the 3 items of the subscale hypothesized to assess safety and presented in Table 11. Coefficient alpha for scores on the subscale 
was .74. Coefficient alpha would be reduced if any of the 3 items was deleted. Scores on the subscale were adequately reliable.

Table 11

Reliability Analysis of Subscale 5

\begin{tabular}{lrrrr}
\hline & $\begin{array}{c}\text { Scale Mean } \\
\text { if Item } \\
\text { Deleted }\end{array}$ & $\begin{array}{c}\text { Scale } \\
\text { Variance if } \\
\text { Item Deleted }\end{array}$ & $\begin{array}{c}\text { Corrected } \\
\text { Item-Total } \\
\text { Correlation }\end{array}$ & $\begin{array}{c}\text { Alpha if } \\
\text { Item } \\
\text { Deleted }\end{array}$ \\
\hline Q26 & 5.36 & 12.23 & .51 & .73 \\
Q27 & 6.31 & 9.21 & .59 & .65 \\
Q28 & 6.57 & 12.47 & .65 & .60 \\
\hline
\end{tabular}

Alpha $=.74$

\section{Canonical Correlation Analysis}

To examine to what extent scores on the criterion variable set of the five subscales of the PCCS could be explained by the predictor variable set of gender, ethnicity, age, college major, and intent to leave the field, a canonical correlation analysis was conducted. Descriptive statistics for each of the variables included in the canonical analysis were presented in Tables 1 and 2 . Canonical correlation was selected as the data analysis procedure because it allows for the complex interrelationships within and among two sets of variables to be considered simultaneously. The SPSS (2002) multivariate analysis of variance (MANOVA) procedure was utilized, as it results in a default canonical correlation analysis when variables in the predictor set are specified as covariates instead of as independent variables (Daniel, Adams, \& Simith, 1994).

For the purpose of conducting the canonical analysis, the five independent or predictor variables included gender, major, age, ethnicity, and intent to leave the field. 
The five dependent or criterion variables consisted of scores on the five subscales of the PCCS, including Climate Students Hear About, Sexist Attitudes and Treatment, Climate Students Experience Personally, Classroom Climate/Course Matcrial, and Safety.

Three of the independent variables, including major, ethnicity, and intent to leave the field, were collapsed from multiple categories into dichotomous categories. Collapsing the categories of these variables alleviated problems associated with low cell counts in certain variable categories and allowed for ease of use of these variables in the canonical correlation analysis. The major variable was collapsed from the four original categories of IT, engineering, nursing, and education into the categories of traditional male (IT and engineering), and traditional female (nursing and education) majors. The ethnicity variable was collapsed from the original six categories of white, African American, Hispanic, Native American, and other into white and non-white. The intent to leave the field variable was collapsed from the original four categories into intent to stay (pursue further education in major; get a job related to major) and intent to leave (pursue further education in a different major; get a job in a field not related to major). The converted values are presented in Table 12, and frequencies of the recoded variables are presented in Table 13.

The number of canonical roots or functions for a given analysis is equal to the number of variables in the smaller of the two sets. As both sets of variables in this analysis contained five variables, five canonical roots or functions were yielded by the analysis (see Table 14). Each root explains a smaller amount of variance than the 
previous root. To determine the number of canonical roots to interpret, the combination of the magnitude of each root and its statistical significance are considered.

Table 12

Conversion of Categorical Predictor Variables for Canonical Analysis

\begin{tabular}{lll}
\hline Original Variable & Original Values & Conversion Values \\
\hline Gender & 1-Male & No conversion needed for \\
& 2-Female & dichotomous data \\
Major & 1-IT & 1-Traditional \\
& 2-Engineering & 1-Traditional \\
& 3-Education & 2-Traditional \\
4-Nursing & 2-Traditional \\
Ethnicity & 1-White & 1-White \\
& 2-African American & 2-Non-white \\
& 3-Hispanic & 2-Non-white \\
& 4-Native American & 2-Non-whitc \\
& 5-Asian & 2-Non-white \\
& 6-Other & 2-Non-white \\
1-Pursue further education & 1-Stay \\
Intent to Leave & in my major & \\
& 2-Get a joh related to my & 1-Stay \\
& major & \\
& 3-Pursue further education & 2-Leave \\
& in a different major & \\
& 4-Get a job in a field NOT & 2-Leave \\
& related to my major & \\
\hline
\end{tabular}

Root $1\left(\mathrm{R}_{\mathrm{c}}{ }^{2}=.16\right)$ indicated that using the best set of weights for variables across the two sets, the independent variables share approximately $16 \%$ of their variances with the dependent variables, which is small but well above the 10\% standard suggested by Pedhazur (1982) to be considered noteworthy. Using the second best set of statistical weights, root $2\left(\mathrm{R}_{\mathrm{c}}{ }^{2}=.09\right)$ accounted for about $9 \%$ of the shared variance across the two sets. Similarly, root $3\left(\mathrm{R}_{\mathrm{c}}{ }^{2}=.07\right)$ accounted for $7 \%$ of the variance, root $4\left(\mathrm{R}_{\mathrm{c}}{ }^{2}=.02\right)$ 
accounted for $2 \%$ of the variance, and root $5\left(\mathrm{R}_{\mathrm{c}}{ }^{2}<.01\right)$ accounted for less than $1 \%$ of the variance.

Table 13

Frequencies of Recoded Major, Ethnicity, and Intent to Leave the Field Variables

\begin{tabular}{llrr}
\hline \multicolumn{1}{c}{ Variable } & \multicolumn{1}{c}{ Category } & $n$ & $\%$ \\
\hline Major & Traditional Male & 173 & $42.9 \%$ \\
& Traditional Female & 230 & $57.1 \%$ \\
Ethnicity & White & 276 & $68.5 \%$ \\
& Non-White & 127 & $31.5 \%$ \\
Intent to Leave & Stay & 384 & $95.3 \%$ \\
& Leave & 19 & $4.7 \%$ \\
\hline
\end{tabular}

As root 1 produced a result of greater than $.10\left(\mathrm{R}_{\mathrm{c}}{ }^{2}=.16, p<.001\right)$, and root 2 produced a result of just under $.10\left(\mathrm{R}_{\mathrm{c}}{ }^{2}=.09, p<.001\right)$, these two roots were interpreted. Although root 3 was statistically significant, the result was not of sufficient magnitude to be of practical significance $\left(\mathrm{R}_{\mathrm{c}}{ }^{2}=.07, p<.001\right)$, and roots 4 and 5 were both statistically non-significant and expressed a negligible level of correlation.

Table 14

Eigenvalues and Canonical Correlations

\begin{tabular}{lrrrrr}
\hline $\begin{array}{l}\text { Root } \\
\text { No. }\end{array}$ & Eigenvalue & Percentage & $\begin{array}{c}\text { Cumulative } \\
\text { Percentage }\end{array}$ & $\begin{array}{c}\text { Canonical } \\
\text { Correlation }\end{array}$ & $\begin{array}{c}\text { Squared } \\
\text { Correlation }\end{array}$ \\
\hline 1 & .19 & 48.42 & 48.42 & .40 & .16 \\
2 & .10 & 25.85 & 74.27 & .30 & .09 \\
3 & .08 & 20.85 & 95.11 & .27 & .07 \\
4 & .02 & 4.12 & 99.23 & .13 & .02 \\
5 & $<.01$ & .77 & 100.00 & .05 & $<.01$ \\
\hline
\end{tabular}

The canonical function and structure coefficients for the predictor and criterion variables across the five canonical roots are presented in Tables 15 and 16 . While both sets of coefficients may be useful in determining the contribution of a given variable to 
the variate composite, structure coefficients arc considered more reliable indicators of variable contribution (Daniel, Adams, \& Smith, 1994) and were employed for the interpretation of these results. Gorsuch (1983) suggested |.3| as a minimum level for factor saliency in factor analysis, a standard which can be applied to structure coefficients $\left(\mathrm{r}_{\mathrm{s}}\right)$ in canonical correlation analysis as well. However, this criterion is somewhat arbitrary, and higher criteria may be set in cases in which coefficients are appreciably larger than |.3|. For the purpose of this analysis, structure coefficients with a saliency level of $|.5|$ and greater were examined.

Table 15

Function and Structure Coefficients for Independent/Predictor Variables

\begin{tabular}{lccccc}
\hline \multicolumn{1}{c}{ Variable } & Root 1 & Root 2 & Root 3 & Root 4 & Root 5 \\
\hline \multicolumn{1}{c}{ Independent/Predictor Variable } & Standardized Canonical Function Coefficients \\
Gender & .70 & -.04 & -.95 & -.29 & .26 \\
Age & .07 & -.63 & -.22 & .67 & -.33 \\
Ethnicity & -.31 & .70 & -.40 & .38 & -.36 \\
Intent & .20 & .22 & .16 & .58 & .75 \\
Major & .31 & .33 & .91 & .40 & -.63 \\
\multicolumn{1}{c}{ Gender } & Independent/Predictor Variable Canonical Structure Coefficients & \\
Age & .89 & .17 & -.39 & -.11 & -.11 \\
Ethnicity & $<-.01$ & -.64 & -.25 & .67 & -.28 \\
Intent & -.35 & .67 & -.47 & .36 & -.28 \\
Major & .15 & .21 & .13 & .59 & .75 \\
\hline
\end{tabular}


Table 16

Function and Structure Coefficients for Dependent/Criterion Variables*

\begin{tabular}{cccccc}
\hline Variable & Root 1 & Root 2 & Root 3 & Root 4 & Root 5 \\
\hline \multicolumn{2}{c}{ Dependent/Criterion Variable Standardized Canonical Function Coefficients } \\
PCCS 1 & .22 & .82 & .36 & .21 & -.92 \\
PCCS 2 & .03 & -.01 & -.02 & -1.26 & .70 \\
PCCS 3 & .01 & .11 & .35 & .90 & .76 \\
PCCS 4 & -.59 & .42 & -.76 & .18 & -.09 \\
PCCS 5 & .87 & -.19 & -.55 & .17 & $<.01$ \\
& Dependent/Criterion Variable Canonical Structure Coefficients & \\
PCCS 1 & .35 & .90 & .22 & -.08 & -.14 \\
PCCS 2 & .24 & .65 & $<-.01$ & -.51 & .52 \\
PCCS 3 & .17 & .55 & .19 & .38 & .70 \\
PCCS 4 & -.35 & .59 & -.73 & .09 & .16 \\
PCCS 5 & .81 & .13 & -.55 & .09 & .12
\end{tabular}

* Subscales are: PCCS 1 (Climates Students Hear About); PCCS 2 (Sexist Attitudes and Treatment); PCCS 3 (Climate Students Experience Personally); PCCS 4 (Classroom Climate/Course Material); PCCS 5 (Safety).

\section{Interpretation of Root 1}

The squared canonical correlation coefficient for root $1\left(\mathrm{R}_{\mathrm{c}}{ }^{2}=.16, p<.001\right)$, indicated that, as a set, the predictor variables accounted for approximately $16 \%$ of the variance in subscale scores on the PCCS. Analysis of the structure coefficients $\left(\mathrm{r}_{\mathrm{s}}\right)$ across the predictor variable set for the first canonical function indicated that gender $\left(r_{s}=.89\right)$ accounted for the highest proportion of variance of the function, followed by major $\left(r_{s}=.75\right)$. Among the structure coefficients for the criterion variable set, only PCCS Subscale 5 (Safety) was highly correlated with root $1\left(r_{s}=.81\right)$.

These results indicated that gender and major were positively related to PCCS subscale scores, with women perceiving the climate to be chillier than men and students 
in traditionally female-dominated majors perceiving the climate to be chillier than students in majors that are traditionally male-dominated. The analysis of the structure coefficients indicated that this trend was particularly the case with regard to perceptions of safety, with women and students in traditionally female-dominated majors perceiving the campus as less safe than did men and students in traditionally male-dominated majors.

\section{Interpretation of Root 2}

The squared canonical correlation coefficient for root $2\left(\mathrm{R}_{\mathrm{c}}{ }^{2}=.09, p<.001\right)$ indicated that the predictor variables, as a set, accounted for approximately $9 \%$ of the variance in subscale scores on the PCCS. Analysis of the structure coefficients $\left(\mathbf{r}_{\mathrm{s}}\right)$ across the predictor variable set for the second canonical function indicated that ethnicity $\left(r_{s}=.67\right)$ accounted for the highest percentage of variance of the function, followed by age $\left(r_{s}=-64\right)$. Among the structure coefficients for the criterion variable set, PCCS Subscale 1 (Climate Students Hear About) and Subscale 2 (Sexist Attitudes and Treatment) were most highly associated with their canonical variate for root 2 , with $\mathrm{r}_{\mathrm{s}}$ values of .90 and .65 , respectively. Subscale 3 (Climate Students Experience Personally) and Subscale 4 (Classroom Climate/Course Material) were moderately correlated with root 2, with $\mathrm{r}_{\mathrm{s}}$ values of .55 and .57 , respectively.

These results indicated that ethnicity was positively related to PCCS subscale scores, with non-white students perceiving the climate to be chillier than white students. Age was found to be negatively related to PCCS subscale scores, with younger students perceiving the climate to be chillier than older students. The analysis of the structure 
coefficients indicated that, compared to white students and older students, non-white students and younger students found the climate to be particularly chilly with regard to the climate students hear about and perceptions of sexist attitudes and treatment, and somewhat chilly regarding the climate students experience personally and perceptions of classroom climate and course material.

\section{Canonical Invariance Analysis}

To test for the degree to which the canonical results are not sample dependent, an analysis of canonieal invariance was conducted by splitting the sample in half, based on alternately numbering each case " 1 " or " 2 ," and running the canonical correlation for each of the two new samples. In Sample $\mathrm{I}(n=202)$, roots $1\left(\mathrm{R}_{\mathrm{c}}{ }^{2}=.15, p<.001\right)$ and 2 $\left(\mathrm{R}_{\mathrm{c}}{ }^{2}=.10, p<.00 \mathrm{I}\right)$ were statistically significant. Root 1 had a similar structure as the combined sample, as gender $\left(r_{s}=.70\right)$ and major $\left(r_{s}=.42\right)$ accounted for the highest percentage of variance of the function, and PCCS Subscale $5\left(1_{s}=.80\right)$ was highly correlated with root 1 . In root 2 , ethnicity accounted for the greatest percentage of variance $\left(r_{s}=-.54\right)$, which was also the case in the combined sample, and PCCS Subscale $4\left(r_{s}=-.93\right)$ was highly correlated with root 2 . These results differ somewhat from the combined sample, in which Subscale 3 was most highly correlated with root 2 and Subscale 4 had the next highest correlation.

In Sample $2(n=201)$, roots $1\left(\mathrm{R}_{\mathrm{c}}{ }^{2}=.21 p<.001\right)$ and $2\left(\mathrm{R}_{\mathrm{c}}{ }^{2}=.10, p<.001\right)$ were statistically significant. In root 1 , again gender $\left(r_{s}=-.92\right)$ and major $\left(r_{s}=-.82\right)$ accounted for the highest percentage of variance in the function. As in the combined 
sample, PCCS Subscale $1\left(r_{s}=-.54\right)$ was highly correlated with root 1 . In Sample 2, Subscale $5\left(r_{s}=-.78\right)$ was highly correlated with root 1 as well. For root 2 , ethnicity $\left(r_{s}=.82\right)$ accounted for the greatest percentage of variance, as in the combined sample. As in the combined sample, PCCS Subscale $1\left(r_{s}=.63\right)$ was highly correlated with root 2 . In Sample 2, Subscale $4\left(r_{s}=.69\right)$ had a somewhat higher correlation with root 2 than in the combined sample. Tables showing the results of the analysis of canonical invariance are presented in Appendix $\mathrm{H}$.

Results indicated that the samples were invariant. Roots 1 and 2 were statistically significant in the combined sample, as well as in both sub-samples. In all of the samples, gender and major accounted for the greatest percentage of variance in root 1 , and ethnicity accounted for the greatest percentage of variance in root 2.

Although the two smaller samples had slightly different structures than in the combined sample, this difference may be due to sample fluctuation. Because the dependent variables of the five subscales of the PCCS are tightly corrclated, there may be more shifting in which of the dependent variables define a root based on sample fluctuation. However, the overall consistency of the results across subsamples suggested the invariance of the findings.

\section{Analysis of Responses to Open-Ended Question}

The final item on the climate survey was a two-part question: "Do you think that women are treated differently from men in classes in your major? If so, how?" The overwhelming response, by $95 \%$ of students who answered $(n=316)$ the first part of the question, was "no." Despite only 14 "yes" responses $(5 \%)$, students' responses to the 
next part of the question indicated that differences in treatment of men and women were, in fact, observed.

After examining the 141 responses to this item, the responses were categorized into six areas: differences in treatment for males; differences in treatment for females; differences in treatment for both males and females; no differences in treatment; don 't know; and other. Of the 141 total responses, $75(53.2 \%)$ indicated there were no differences in treatment; $6(4.3 \%)$ indicated they were uncertain; and 5 responses $(3.5 \%)$ were categorized as "other." While the majority of students in the sample indicated no differences, 27 students $(19.1 \%)$ indicated in their narrative comments that males were treated differently, 24 students $(17.0 \%)$ indicated that females were treated differently in classes in their major, and 4 students $(2.8 \%)$ indicated differences in treatment for both men and women.

Females in the sample were more likely than men to indicate that there were differences in treatment of either gender. Of the students who indicated that males were treated differently, 4 were males and 23 were females. Of the students who indicated that females were treated differently, 9 were males and 15 were females.

In looking at differences in treatment of women in nontraditional majors, 11 students ( 5 males, 6 females) indicated that women were treated differently in engineering majors. However, only 4 students ( 2 males, 2 females) indicated that wonen were treated differently in IT majors. In exarnining differences in treatment of men in nontraditional majors, a total of 17 students ( 2 males, 15 females) commented that males were treated differently in nursing majors. A total of 9 students ( 1 male, 8 females) 
indicated that males were treated differently in education majors. Differences in treatment by major and gender are presented in Table 17.

Table 17

Differences in Treatment by Major and Gender

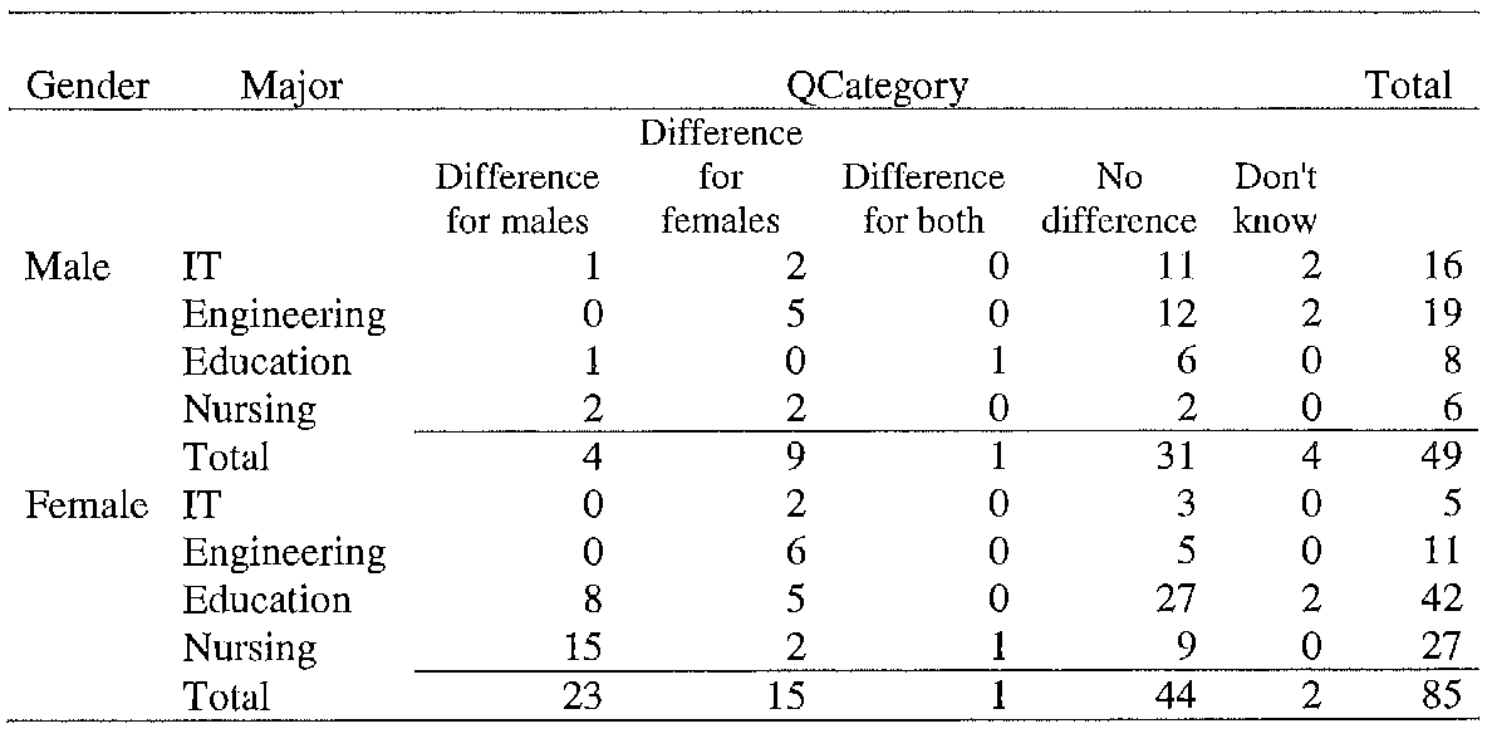

Indications of differences in treatment were further categorized into positive treatment and negative treatment. Of the 4 males who indicated differences in treatment of males, 1 found the treatment to be positive, and 3 found it to be negative. Of the 23 females who indicated differences in treatment of males, 14 indicated the treatment was positive and 9 indicated it was negative. Of the 9 males who indicated differences in treatment of females, 4 found it to be positive and 5 found it to be negative. Of the 15 females who indicated that females were treated differently, 6 found the treatment to be positive and 9 found it to be negative. Examples of student comments regarding the positive and negative treatment of women and men are listed below. 


\section{Negative treatment of women:}

"A lot of men still refuse to accept women as equals intellectually and academically." [A 29 year-old white female, majoring in IT]

"Some male teachers make you [female students] feel stupid when they talk to you. Like you are unable to comprehend what they are saying."

[A 21 year-old white female, majoring in engineering technology]

"I believe male teachers are harder on female students. Not all but a [sic] enough were [sic] I feel that its [sic] unfair at time [sic]. To me it makes me work harder..."

[A 22 year-old African-American female, majoring in engineering technology]

\section{Positive treatment of women:}

"Women get more attention from istructors [sic] and they are helped more (ie. [sic] Answers directly given instead of having to figure it out, and possibly graded easier)." [A 25 year-old white male, majoring in engineering technology]

"Instructors (and male classmates) have treated me respectfully. Instructors have been helpful [sic] and patient, sometimes probably more so, than with the men..."

[A 31 year-old white female, majoring in engincering technology]

"Women have the inside track. Nursing is typically a female role."

[A. 23-year old white male, majoring in nursing]

\section{Negative treatment of men:}

"In a sense, because teaching on the elementary level is particularly dominated by females. So when you do have a male that is interested in tcaching kindergarten for instance, he may be looked at like he may have perverted tendencies or he may be gay. When for most men that is far from the truth, but a woman would not be looked at twice." [A 21-year-old African-American male, majoring in education]

"Our major is mostly women, so many examples seem to highlight women and leave the men out." [A 24 year-old white female, majoring in nursing]

"Some areas of nursing seam [sic] to be off limits to men, i.e., labor and delivery." [A 35 year-old white male, majoring in nursing]

\section{Positive treatment of men:}

“...It seems like the majority of my teachers like to call on men instead of women to 
answer questions..." [A 20 year-old white male, majoring in education]

"There have been a few instructors (female) who have been somewhat more open to the male students more so than the female students initially" [A 29 year-old white female, majoring in nursing]

"If anything in nursing it is reversed. I think they encourage men to get into nursing." [A 33 year-old white male, majoring in nursing]

\section{Consideration of the Primary Research Question}

The primary research question that guided the present study was: To what extent can scores on the five subscales of the PCCS be explained by the predictor variable set of gender, ethnicity, age, college major, and intent to leave the field? In order to answer this question, the six corresponding research hypotheses will now be examined.

Research Hypothesis 1: Correlation Between Dependent and Independent Variable Sets

The first research hypothesis stated: There will be a statistically significant $(p=.05)$ correlation $\left(\mathrm{R}_{\mathrm{c}}\right)$ between the criterion variable set of subscale scores on the PCCS and the predictor variable set of gender, ethnicity, age, college major, and intent to leave the field. This hypothesis was supported.

Three of the five roots yielded by the canonical correlation analysis were statistically significant: $\operatorname{root} 1\left(\mathrm{R}_{\mathrm{c}}{ }^{2}=.16, p<.001\right)$, root $2\left(\mathrm{R}_{\mathrm{c}}{ }^{2}=.09, p<.001\right)$, and root $3\left(\mathrm{R}_{\mathrm{c}}{ }^{2}=.07, p<.001\right)$. Roots 4 and 5 were not statistically significant. Although root 3 was statistically significant, the result was not of sufficient magnitude to be of practical significance. Consequently, only root 1 and root 2 were interpreted.

Research Hypothesis 2: Gender

The second research hypothesis stated: Gender will be a primary contributing 
variable to at least one predictor canonical variate which correlates to a statistically significant $(p=.05)$ degree with its corresponding dependent canonical variate. This hypothesis was supported.

Analysis of the structure coefficients across the predictor variable set for the first canonical root indicated that gender $\left(r_{\mathrm{s}}=89\right)$ accounted for the highest percentage of variance of the function. These results indicate that gender was positively related to PSSC subscale scores, with women perceiving the climate to be chillier than men.

\section{Research Hypothesis 3: Ethnicity}

The third research hypothesis stated: Ethnicity will be a primary contributing variable to at least one predictor canonical variate which correlates to a statistically significant $(p=.05)$ degree with its corresponding dependent canonical variate. This hypothesis was supported.

Analysis of the structure coefficients across the predictor variable set for the second canonical root indicated that ethnicity $\left(r_{s}=67\right)$ accounted for the highest percentage of variance of the function. These results indicate that ethnicity was positively related to PCCS subscale scores, with non-white students perceiving the climate to be chillier than white students.

Research Hypothesis 4: Age

The fourth research hypothesis stated: Age will be a primary contributing variable to at least one predictor canonical variate which correlates to a statistically significant $(p=.05)$ degree with its corresponding dependent canonical variatc. This research hypothesis was supported. 
Analysis of the structure coefficients across the predictor variable set for the second canonical root indicated that age $\left(\mathrm{r}_{\mathrm{s}}=-.64\right)$ accounted for the second highest percentage of variance of the function after ethnicity. These results indicate that age was negatively rclated to PCCS subscale scores, with younger students perceiving the climate to be chillier than older students.

Research Hypothesis 5: College Major

The fifth research hypothesis stated: College major will be a primary contributing variable to at least one predictor canonical variate which correlates to a statistically significant $(p=.05)$ degree with its corresponding dependent canonical variate. This hypothesis was supported.

Analysis of the structure coefficients across the predictor variable set for the first canonical root indicated that major $\left(r_{\mathrm{s}}=.75\right)$ accounted for the second highest percentage of variance of the function after gender. These results indicate that college major was positively related to PCCS subscale scores, with students in traditionally female majors perceiving the climate to be chillier than students in majors that are traditionally male.

\section{Research Hypothesis 6: Intent to Leave the Field}

The sixth research hypothesis stated: Intent to leave the ficld will be a primary contributing variable to at least one predictor canonical variate which correlates to a statistically significant $(p=.05)$ degree with its corresponding dependent canonical variate. This research hypothesis was not supported.

The structure coefficient for the variable intent to leave the field did not meet the 
saliency criterion value of $|.5|$ to be considered noteworthy in this study, or even the lower criterion of |.3| recommended by Gorsuch (1983). However, it should be noted the responses to this item were quite skewed, with only 19 students out of 403 expressing an intention to leave the field. Consequently, this skewness resulted in the inability of this variable to correlate adequately with the canonical variate.

\section{Summary}

In this chapter, data collected via the survey instrument were analyzed and used to examine the rescarch question and test the six research hypotheses. Demographic data were provided about the study sample and descriptive statistics were presented for the PCCS. Results of the data analysis were presented, including bivariate correlations among the variables, a reliability analysis, the canonical correlation analysis, and the categorical analysis of students' responses to the open-ended question. Findings indicated that five of the six research hypotheses were supported.

Among the 403 students in the sample, $46 \%$ were male and $54 \%$ were female. The ethnic breakdown for the sample was $68.5 \%$ white, $16.6 \%$ African American, $5.7 \%$ Hispanic, 4\% Asian, $1 \%$ Native American, and 4\% other. The sample consisted of $29.3 \%$ education majors (34 males, 84 females), $27.8 \%$ nursing majors (13 males, 99 females), $22.6 \%$ IT majors (74 males, 17 females), and 20.3\% engineering majors ( 65 males, 17 females). Half of the students in the sample (50\%) planned to get a job related to their major, $45 \%$ planned to pursue further education in their current major, $4 \%$ intended to pursue further education in a different major, and $1 \%$ planned to get a job in a field 
To examine to what extent scores on the criterion variable set of the five subscales of the PCCS could be explained by the predictor variable set of gender, ethnicity, age, college major, and intent to leave the field, a canonical correlation analysis was conducted. Three of the five resulting canonical roots were statistically significant and two of the roots were of great enough magnitude to be considered noteworthy. For root 1 , results indicated that gender and major were positively related to PCCS subscale scores, with women perceiving the climate to be chillier than men and students in traditionally female majors perceiving the climate to be chillier than students in traditionally male majors. PCCS Subscale 5 (Safety) was highly correlated with root 1. For root 2, ethnicity was positively related to PCCS subscale scores, with non-white students perceiving the climate to be chillier than white students. Age was negatively related to PCCS subscales scores, with younger students perceiving the climate to chillier than older students. PCCS Subscale 1 (Climate Students Hear About) and Subscale 2 (Sexist Attitudes and Treatment) were highly correlated with root 2. Results of the canonical invariance analysis indicated that the samples were invariant.

The analysis of responses to the open-ended question indicated that $95 \%$ of students who responded to the question found no differences in treatment of men and women in their major. However, responses to the second part of the question indicated otherwise. While $53 \%$ of responses were categorized as "no differences in treatment," $19 \%$ indicated that males were treated differently and $17 \%$ indicated that females were treated differently. Women in the sample were more likely than men to indicate that therc were differences in treatment of either gender. Within the two majors which were non- 
traditional for women, there were more comments by both women and men about differences in treatment for women majoring in engineering than for those majoring in IT.

Five of the six research hypothescs were supported. There was, in fact, a statistically significant correlation between the criterion variable set of scores on the five subscales of the PCCS and the predictor variable set of gender ethnicity, age, college major, and intent to leave the field. Each of the variables of gender, ethnicity, age, and college major was a primary contributing variable to at least one predictor canonical variate which correlated to a statistically significant degree with its corresponding dependent canonical variate. Only one of the five predictor variables, intent to leave the ficld, was not a significant contributor.

Chapter 5 presents a summary of the study, a discussion of the results, and conclusions drawn. Recommendations for future studies are made and contributions of the present study are presented. 


\section{Chapter 5}

\section{Summary, Conclusions, and Recommendations}

The purpose of the present study was to examine how perceptions of a chilly climate differ between students in traditionally female-dominated majors versus traditionally male - dominated majors at a community college, and how these perceptions relate to students' intentions to persist or pursue higher education in their chosen career field or lcave the field. Perceptions of students in the traditionally female-dominated fields of nursing and education were compared to perceptions of students in the traditionally male-dominated fields of IT and engineering.

In this final chapter, the methodology employed is reviewed. Next, findings are summarized, discussed and related to past research, as well as to the theoretical framework upon which the present study is based. Conclusions are drawn and recommendations are made for future research. The chapter concludes with the contributions the study has made to the field of education.

\section{Review of the Methodology}

Four hundred and three students attending a community college in the southern United States participated in the study. The participants included 186 males and 217 females majoring in 1T (74 males, 17 females), engineering (65 males, 17 females), education ( 34 males, 84 females), and nursing (13 males, 99 females). The research instrument, which was referred to as the Climate Survey, consisted of the 28 -item 
PCCS and other informational items. Classes sampled represented a cross-section of freshman-level and sophomore-lcvel classes in the four majors of interest. Institutional Review Board approval was obtained prior to data collection, and all participants completed informed consent forms prior to their participation in the study. Students completed the survey in classes in their majors during Spring semester 2004.

The dependent variable set included perception of chilly climate as measured by scores on the fivc subscales of the PCCS. The independent variable set included gender, age, ethnicity, major, and intent to leave the field. Analysis of the data consisted of examining demographic data, categorizing the data collected from the open-ended question, running bivariate correlations for dependent and independent variables, conducting a reliability analysis, and running a canonical correlation analysis to test the present study's research questions.

\section{Summary of the Results}

Overall, the findings indicated that women found the climate to be chillier than men, non-white students found the climate to be chillier than white students, younger students perceived the climate to be chillier than older students, and students in traditionally female-dominated majors perceived the climatc to be chillicr than students in traditionally male-dominated majors. Intent to leave the field was not a significant predictor of perceptions of chilly climate. Findings for the primary research question and each of the corresponding research hypotheses follow.

The primary research question in the present study asked: To what extent can scores on the five subscales of the PCCS be cxplained by the predictor variable set of 
gender, ethnicity, age, college major, and intent to leave the field? The results of this study suggest that scores on three of the five PCCS subscales including Subscale 1 (Climate Students Hear About), Subscale 2 (Sexist Attitudes and Treatment), and Subscale 5 (Safety) can be explained to some degree by the predictor variables of gender, ethnicity, age, and college major.

The first research hypothesis was: Therc will be a statistically significant $(p=.05)$ correlation $\left(R_{c}\right)$ between the dependent variable set of subscale scores on the PCCS and the predictor variable set of gender, ethnicity, age, college major, and intent to leave the field. This hypothesis was supported by the data, as three of the five canonical roots yielded by the analysis were statistically significant. Each of the variables in the predictor variable set will now be examined separately.

The second research hypothesis was: Gender will be a primary contributing variable to at least one predictor canonical variate which correlates to a statistically significant $(p=.05)$ degree with its corresponding dependent canonical variate. This hypothesis was supported by the data. Females were more likely to perceive a chilly climate than males, Gender $\left(\mathrm{r}_{\mathrm{s}}=.89\right)$ was a primary contributing variable to root 1 , with major $\left(r_{\mathrm{s}}=.75\right)$ also making a noteworthy contribution. In the dependent variable set, PCCS Subscale $5\left(r_{s}=\right.$ of 81$)$, Safety, was the most noteworthy contributor to root 1. The third research hypothesis was: Ethnicity will be a primary contributing variable to at least one predictor canonical variate which corrclates to a statistically significant $(p=.05)$ degree with its corresponding dependent canonical variate. This hypothesis was supported by the data. Non-white students were more likely to perceive a 
chilly climate than white students. Ethnicity $\left(r_{\mathrm{s}}=.67\right)$ was a primary contributing variable to root 2 , with age $\left(\mathrm{r}_{\mathrm{s}=-}-64\right)$ making a noteworthy contribution as well. Among the dependent variables, PCCS Subscale $1\left(\mathrm{r}_{s}=.90\right)$, Climate Students Hear About, and PCCS Subscale $2\left(\mathrm{r}_{\mathrm{s}}=.65\right)$, Sexist Attitudes and Treatment, were noteworthy contributors to root 2 .

The fourth research hypothesis was: Age will be a primary contributing variable to at least one predictor canonical variate which correlates to a statistically significant $(p=.05)$ degree with its corresponding dependent canonical variate. This hypothesis was supported by the data. Younger students were more likely to perceive a chilly climate than older students. Age $\left(r_{s}=-.64\right)$, was a primary contributing variable to root 2 , with ethnicity $\left(r_{s}=67\right)$ making a noteworthy contribution as well. In the dependent variable set, PCCS Subscale $1\left(r_{s}=.90\right)$, Climate Students Hear About, and PCCS Subscale 2 $\left(r_{s}=.65\right)$, Sexist Attitudes and Treatment, were noteworthy contributors to root 2 .

The fifth research hypothesis was: College major will be a primary contributing variable to at least one predictor canonical variate which correlates to a statistically significant $(p=.05)$ degree with its corresponding dependent canonical variate. This hypothesis was supported by the data. Students in traditionally female-dominated majors were more likely to perceive a chilly climate than students in traditionally maledominated nuajors, Major $\left(\mathrm{r}_{s}=.75\right)$ was a primary contributing variable to root 1 , with gender $\left(\mathrm{r}_{\mathrm{s}=} .89\right)$ making a noteworthy contribution as well. In the dependent variable set, PCCS Subscale $5\left(\mathrm{r}_{\mathrm{s}}=\right.$ of .81$)$, Safety, was the most noteworthy contributor to root 2 .

The sixth research hypothesis was: Intent to leave the field will be a primary 
contributing variable to at least one predictor canonical variate which correlates to a statistically significant $(p=.05)$ degree with its corresponding dependent canonical variate. This hypothesis was not supported by the data. The intent to leave the field variable was not a primary contributing variable to any of the canonical roots, and, conscquently, not a significant predictor of scores on any of the subscales of the PCCS.

\section{Discussion of the Results}

The findings of the present study will be discussed in relationship to past research studies and to the theoretical framework upon which the study is based. Limitations of the research instrument which was employed in the study will be addressed.

\section{Relationship of the Present Study to Previous Research}

To date, few empirical studies have been eonducted on perceptions of chilly climate, and with conflicting results. While some researchers have found evidence in support of the existence of the chilly climate (Janz \& Pyke, 2000; Pascarella et al., 1997; Whitt et al., 1999), others did not (Constantinople et a1., 1988; Crawford \& MacLeod, 1990; Drew \& Work, 1998; Heller et al., 1985).

Previous research on the chilly climate has focused primarily on students attending 4-year colleges. In fact, only two studies (Pascarella et al., 1997; Whitt et al., 1999) included community college students. Both studies were conducted using the same small sample of community college women. Only 176 community college women were included in the first study (Pascarella et al., 1997), compared to 1,460 women attending 4-year colleges. In the sccond study (Whitt et al., 1999), which was a follow-up to Pascarella et al. 's (1997) study, 85 of the original community college women remained 
compared to 993 4-year college women. These studies focused on the impact of perceptions of chilly climate, as measured by scores on the 8-item Perceived Chilly Climate for Women Scale, on women's cognitive growth.

Because of the limited research conducted on the chilly climate for community college women, the present study attempted to extend previous research findings to that population. In particular, the findings of Janz and Pyke (2000), developers of the PCCS, helped frame the study. Administering the PCCS to a sample of 327 Canadian college students (57 males, 269 females, 9 did not indicate gender), Janz and Pyke found that females perceived the climate to be chillier than males, minority students perceived the climate to be chillier than non-minority students, and students who had been in school longer were more likely to perceive the climate as chilly.

The finding in the present study that females were morc likely to perceive a chilly climate than males is consistent with the findings of Janz and Pyke (2000). In their study, a statistically significant difference was found between scores of males $(M=84$, $S D=21)$ and females $(M=101, S D=27)$ on the PCCS. Results of the present study indicated significant differences as well, with females $(M=78.91, S D=26.10)$ scoring higher than males $(M=69.70, S D=24.81)$ on the PCCS total scores. However, mean scores for both males and females were lower than in the Canadian study.

That non-white students in the present study were more likely to perceive a chilly climate than white students is a finding which is also consistent with the findings of Janz and Pyke (2000). In their study, a statistically significant differcnce was found between scores of minority and non-minority students. Minority students $(M=102, S D=27)$ 
perceived the climate to be significantly chillier than non-minority students $(M=95$, $S D=26)$. The present study yielded similar results, with nonwhite students $(M=79.80$, $S D=26.87)$ scoring higher than white students $(M=72.29, S D=25.13)$ on the PCCS total scores.

Janz and Pyke (2000) found that students who had been in school longer were more likely to perceive a chilly climate. Using the class standing variable, they compared the responses of undergraduate students to the responses of graduate students. The researchers found that graduate students $(M=122, S D=34)$ perceived the climate to be significantly chillier than undergraduate students $(M=96, S D=25)$. As class standing designations in community colleges are limited to either freshman or sophomore, for the purpose of the present study, the variahle age was utilized instead of class standing. However, the analysis of the age variable yielded an unexpected result, a weak but statistically significant correlation of $r=-.171, p<.001$ between age and PCCS total scores. In the present study, younger students were more likely to perceive a chilly climate than older students, whereas older students were expected to perceive a chillier climate than younger students.

Hence, the results of the present study are inconsistent with the results of Janz and Pyke (2000); students who had been in school longer did not perceive the climate to be chillier than other students. As graduate students are better educated, they may be more aware of subtle discrimination becausc of their education, not because of their age. Consequently, age and class standing are not equivalent variables. The finding in the present study that younger studeuts were more likely to perceive a chilly climate than 
older students may actually be due to progress, over lime, in raising the awareness of what constitutes discrimination against women. It may be that the younger generation has been socialized to be more aware of the chilly climate. Given that the age of students in the present study ranged from 18 to 60 , generational differences in perceptions of discrimination against women would be expected.

In comparing the results of the present study to the findings of Janz and Pyke (2000), two of the findings are consistent, namely, that women perceived the climate to be chillier than did men and that minorities perceived the climate to be chillier than did white students. The finding in the previous study that students who had been in school longer perceived the climate to be chillier is inconsistent with the results of the present study. The variables of college major and intent to leave the field were not variables of interest in previous studies.

Interpretation of Results within the Theoretical Framework

According to the deficit model (Barbercheck, 2001), fewer women complete degrees in science because they are treated differently from men duc to formal and informal structural barriers. Proponents of this model would suggest that women in science are exposed to a chillier climate than women in traditionally female-dominated majors. However, in the present study, women in the traditionally male-dominated majors of IT and engineering actually had lower total scores $(M=72.9, S D=20.0, n=34)$ on the PCCS than women in the traditionally female-dominated majors of nursing and education $(M=80.0, S D=27.0, n=183)$. Considering that the PCCS total scores for all women had a mean of 78.9 , with a standard deviation of $26.1(n=217)$, the difference in scores 
between women in the two groups represents almost $1 / 3$ of a standard deviation. Although this unexpected result indicates that women in IT and engineering perceived less of a chilly climate than women in nursing and education, it does not mean that a chillier climate exists for women in traditionally female-dominated majors or that the climate is necessarily "warm" for women in traditionally male-dominated majors.

The possible range of scores on the PCCS is 28 to 196 , with a midpoint of 112. For each individual item on the PCCS, the range of possible scores is 1 to 7 . The higher the score, the chillier the student perceives the climate to be. PCCS total scores for students in all of the four majors combined were higher for women $(M=78.9, S D=$ 26.1, $n=217)$ than for men $(M=69.7, S D=24.8, n=186)$. Considering that the PCCS total scores for all students in the sample had a mean of 74.7, with a standard deviation of 25.9 , the difference in scores between men and women represents over $1 / 3$ of a standard deviation. These results indicate that women in the present study perceived that they were, in fact, being trcated differently from men, which lends support to the deficit model. While average scores of women in both traditionally female-dominated majors and traditionally male-dominated majors were under the midpoint for the PCCS, they were closer to the midpoint of 112 than to the minimum of 28 , which was also true for the average scores of men in the sample. Given that any score of above 1 on any of the 28 individual items indicates some perception of discrimination, scores of women and men in the present study are, in fact, indicative of a chilly climate for women.

Perceptions of chilly climate by women were especially evident in Subscale 5, Safety, $\left(\mathrm{r}_{8}=810\right)$, which continues to be an issue for women. For minorities, Subscale 1, 
Climate Students Hear About $\left(r_{\mathrm{s}}=.895\right)$, was most noteworthy, followed by Subscale 2, Sexist Attitudes and Treatment $\left(r_{s}=.645\right)$. That women in the traditionally maledominated majors of IT and engineering scored higher $(M=19.4, S D=5.4, n=34)$ on Subscale 4, Classroom Climate/Course Material, than women majoring in nursing and education $(M=16.0, S D=5.5, n=183)$ may be indicative of an awareness that women are infrequently represented in IT and engineering textbooks. Questions on Subscale 4 included items that pertained to the inclusion of women's contributions to the field and feminist research in textbooks, assigning readings written by women, and presenting course material from the perspective of women.

However, despite perceptions of chilly climate, these women intended to persist in their chosen field, either by pursuing further education in their current major, or entering the workforce in their career field after completion of their degree. In fact, only 19 students (10 males, 9 females) in the sample expressed an intention to leave the field. Of the 9 females, 7 were education majors and 2 were engineering majors. If there had been more variation in this variable, more noteworthy, findings may have resulted.

The degree to which women in traditionally male-dominated majors experienced chilly climate differently from women in traditionally female-dominated majors may be explained, in part, by their personalities. In a study of choices of traditional and nontraditional majors by male and female college students, Lackland and De Lisi (2001) found that students who had higher femininity scores and endorsed humanitarian eoncerns were more likely to major in nursing and education, and students who had higher masculinity scores and did not endorse humanitarian concerns were more likely to 
major in the sciences. Therefore, women who choose male-dominated majors may be less sensitive to chilly climate than women who choose female-dominated majors. This concept lends support to the difference model, that there are fewer women in nontraditional majors because of differences in women themselves (Barbercheck, 2001).

Women's perceptions of college environment can influence their self-efficacy and, consequently, their success, according to self-efficacy theory (Bandura, 1997). Findings of the present study indicate that students do not intend to let a chilly college climate negatively affect their success. Perhaps this is an indication of the resiliency of the women in this sample. Women who are not resilient, or are intimidated by nontraditional majors in which there are few other women, may have self-selected out of traditionally malc-dominated majors and therefore would not have been included in the study. Several authors have noted that, despite their science and mathematics abilities, many women lack confidence (Camp, 2001; Ethington, 1988; Vetter, 1996). Consequently, women who choose traditionally male-dominated majors may be more confident than women who do not, and therefore less likely to perceive a chilly climate. Further, these women may be less affected by the chilly climate when they do perceive it. Limitations of the Research Instrument

Although the study's intent was to examine perceptions of chilly climate in the community college environment as a whole, the research instrument employed does have some limitations. While the PCCS is the best measure of the chilly climate developed to date, it may not be an accurate measure of the college environment as a whole or an accurate measure of the perceptions of chilly climate by men. With the exception of a few 
items, the scale focuses primarily on the classroom climate, as most items make specific references to the "teaching staff" or the "classroom." Only the three items on Subscale 5 (Safety) do not make such references.

Further, most items on the PCCS refer specifically to the treatment of women. Besides the items on Subscalc 5, only the six items on Subscale 3 (Climate Students Experience Personally) refer equally to males and females. As only 9 of the 28 items on the PCCS refer equally to both genders, the PCCS is a more accurate measure of perceptions of chilly climate for women than for men.

While the range of scores of from 1 (strongly disagree) to 7 (strongly agree) on PCCS individual items allows for greater variation in responses and assessment of the degree to which the chilly climate is perceived, the manner in which the PCCS is scored may also be a limitation. The possible range of total scores for the PCCS is from 28 to 196 , with a midpoint of 112 . Hence, a score of less than 112 might erroneously lead one to believe that perceptions of chilly climatc are low. Janz and Pyke (2000) did not offer suggestions for interpreting scores on the scale, other than to say that the higher the score, the chillier the climate. If students were asked if they had ever heard of or experienced various types of discrimination and had to respond either "yes" or "no," the answer would be "yes" for many items, which presents a more powerful argument for the existence of the chilly climate.

Whitt et al. (1999) pointed out that the nature of the scale used to cstimate perceptions of the chilly climate might explain the difference in 2-year and 4-year students' experiences in their study, as the research instrument they employed, the 8- 
item Perceived Chilly Climate for Women Scale, emphasizes gender discrimination in classroom settings more than non-classroom settings. Because community college women tend to live off campus, they may view campus climate primarily as what occurs in class, so the scale described a comparatively large part of their college experience.

As the community college site where the present study was conducted has no dormitories, all students lived off campus. While the campus environment may be less relcvant to these students, they do interact with college personnel in admissions, financial aid, advisement, and career centers. Hence, college environment is a concern. The greater student focus of community colleges, compared to 4-year institutions, may also account for greater sensitivity to women.

Another consideration is whether or not the community college site has multiple campuses, as was the case in the present study. If students only attend classes at one site, the results may not be generalizable to the community college as a whole. On the other hand, students may interact with other sites via telcphone or e-mail, for example, contacting a central admissions office or requesting technical support for online classes from a central location. No items on the instrument pertained to a student's primary campus site.

One final concern about the research instrument employed pertained to the last item on the Climate Survey, which consisted of a two-part question that read, "Do you think that women are treated differently from men in classes in your major? If so, how?" It should be noted that even this item, which was created by the researcher, included a reference to "classes." The responses of students indicated there was confusion about 
this item, especially about the word "differently." Many students answered the first part "no," indicating there were no differences, but then elaborated on incidences of different treatment when they answered the second part of the question. To some students, it appeared that different treatment implied negative treatment. Many incidences of different treatment related by students were actually positive. Although differences in treatment were categorized as negative or positive, it is difficult to categorize such responses becausc positive trcatment for one gender (e.g., males being called on more frequently than females) often implies corresponding negative treatment for the other gender. The researcher would not recommend using this question in future studies.

\section{Conclusions and Recommendations}

The findings of the present study lead to conclusions, recommendations for educators, and recommendations for further research on the chilly climate in community colleges.

\section{Conclusions}

The results of the present study indicate that the chilly climate continues to exist in higher education more than 20 years after the phenotnenon was first identified by Hall and Sandler (1982). Further, the huge discrepancy between students' responses to the question whether there were differences in treatment of females and males in their major (95\% responded "no") and students' scores on the chilly climate scale may indicate that students are unawarc of differcnces in treatment to some degree, or at least are unable to articulate them. While the predictor variables of gender, ethnicity, age, college major, and intent to leave the field accounted for $16 \%$ of the variance in scores on the five subscalcs 
of the PCCS in the present study, $84 \%$ of the variance in scores was not accounted for. Hence, much of the variance in perceptions of chilly climate remains unexplained. Recommendations for Educators

As expressions of chilly climate are often unintentional on the part of the perpetrator, it is important for community college administrations to raise the awareness of faculty, staff, and students about the chilly climate through education. Such education must include specific examples of behaviors that cause students to feel unwelcome or treated differently, for example, calling on males more often than on females, giving students of one gender extra help which implies that they are unable to perform, referring to nurses as "she" and to engineers as "he," making comments that imply that students do not belong in traditionally male-dominated majors, or selecting textbooks that omit references to the minority gender.

After a basic awareness is developed and faculty and staff become aware of their own behaviors that contribute to perceptions of chilly climate and resolve to change them, the chilly climate can be "warmed." Awareness can be further enhanced through feedback, for example, through classroom or office observations by trained observers. Although students may be reluctant to give feedback to faculty and staff on discriminative behaviors for fear of retribution, they can do so through faculty evaluations or even complaints to the administration.

The classroom climate can be further warmed by incorporating feminist pedagogies, i.e., instructional practices that appeal to the learning styles of women and create a better learning environment for all students. Examples of feminist pedagogies 
include replacing competition with collaboration, replacing didactic teaching methods with more inclusive strategies, and incorporating constructivist methods into the classroom. Selecting textbooks, especially in traditionally male-dominated courses, that incorporate the writings of women and photographs of women in non-submissive roles may also serve to warm the climate. Because safety continues to be an issue for women, providing adequate campus security is essential to a non-chilly climate for women.

\section{Recommendations for Further Research}

While the sanple size $(n=403)$ of the present study was relatively large, the number of women in non-traditional majors (17 in IT, 17 in engineering) in the sample was small and results are generalizable primarily to students in the four majors at this specific community college site. In order to better understand perceptions of chilly climate of women in traditionally male-dominated majors, it is recommended that a larger sample such as a statewide community college system be studied, and a statewide profile of perceptions of chilly climate for women in community colleges be developed. Future studies could be expanded to include additional majors that are non-traditional for women. Qualitative studies of the chilly climate, which could help clarify how perceptions of chilly climate affect women in traditionally male-dominated majors and deepen the understanding of this phenomenon, would be of special benefit. Observational studies, utilizing trained observers, of classrooms and college departments that provide student services would provide objective evidence of the chilly climate. Longitudinal studies which illuminate how perceptions of chilly climate affect student learning, retention, and completion rates are needed as well. Finally, with the increase in student 
enrollment in distance learning courses in recent years, studies of perceptions of chilly climate in the online environment will become increasingly important.

\section{Contributions of the Study}

The present study is the first known research conducted on perceptions of the chilly climate that focused exclusively on community college students, which is, perhaps, the study's most significant contribution to the field of education. Further, the sample size of community college women in this study $(n=217)$ exceeds the sample size of community college women in any previous study. It is the only study on the chilly climate that compares perceptions of men and women in traditionally male-dominated and traditionally female-dominated majors, and examines how the chilly climate affects students' intentions to remain in or leave their field of study. The design of this study offers future researchers a basis upon which to conduct further empirical research on perceptions of chilly climate at any institution of higher education.

The study complements previous studies of the chilly climate, especially those in which instruments were used to measure the chilly climate (Janz \& Pyke, 2000; Pascarella et al., 1997; Whitt et al., 1999). Findings of the present study were consistent with the findings of Janz and Pyke (2000) that women and minoritics perceive the climate to be chillier than men and non-minorities.

The results of the study raise the awareness that the chilly climate persists in academia more than 20 years after the phenomenon was first identified. Perceptions of chilly climate continue to be stronger for women and minorities. These findings 
emphasize the need for community college administrations and faculties to improve the climate for women and minorities at their institutions. 
Appendix A 


\section{Climate Survey}

Major: Estimated GPA:

Class standing: Freshman __ Sophomore

Estimated \# of credits completed:

Estimated date of graduation:

Gender: Male Female Age:

Race: White African American

Native American Asian Other

I plan to (check one):

Pursue further education in my major

Get a job related to my major

Pursue further education in a different major

Get a job in a field NOT related to my major

Please rate each of the following items on a scale from 1 (strongly disagree) to 7 (strongly agree) about your experience. Please respond based on your experience as a whole at this community college.

\section{Strongly Strongly}

Disagree Agree

$\begin{array}{lllllllll}1 & 2 & 3 & 4 & 5 & 6 & 7 & \text { 1. I have NEVER HEARD that a female student }\end{array}$ has been sexually harassed by a member of the teaching staff.

$\begin{array}{lllllllll}1 & 2 & 3 & 4 & 5 & 6 & 7 & \text { 2. I have HEARD of one or more instances where a }\end{array}$ member of the teaching staff put a female student down or was rude to her because she was female.

$\begin{array}{lllllllll}1 & 2 & 3 & 4 & 5 & 6 & 7 & 3 & 3\end{array}$ member of the teaching staff has used humor (e.g., sexual/sexist humor, or told sexually suggestive stories, jokes, etc . $_{+}$to "liven up" the class.

$\begin{array}{lllllll}1 & 2 & 3 & 4 & 5 & 6 & 7\end{array}$

4. I have NEVER HEARD that a member of the teaching staff has attempted to establish a sexual relationship with a female student.

$\begin{array}{llllllll}1 & 2 & 3 & 4 & 5 & 6 & 7 & 5 . \text { I have HEARD of one or more instances when a }\end{array}$ member of the teaching staff has engaged in inappropriate physical contact toward a female student. 


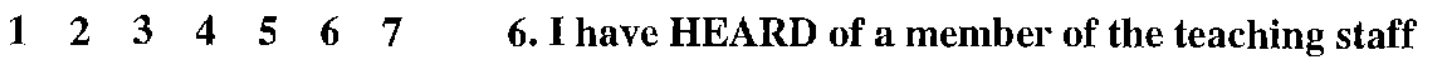
treating female students as though they have limited intellectual ability.

$\begin{array}{llllllll}1 & 2 & 3 & 4 & 5 & 6 & 7 & \text { 7. I have HEARD that some members of the teaching }\end{array}$ staff have said things that made female students feel uncomfortable.

$\begin{array}{lllllllll}1 & 2 & 3 & 4 & 5 & 6 & 7 & \text { 8. I have NEVER HEARD that a member of the }\end{array}$ teaching staff has made crude and offensive sexual remarks to female students.

$\begin{array}{lllllllll}1 & 2 & 3 & 4 & 5 & 6 & 7 & 9 & 9 \text {. The teaching staff most often use examples from }\end{array}$ men's lives.

$\begin{array}{lllllllll}1 & 2 & 3 & 4 & 5 & 6 & 7 & \text { 10. In general, I believe that the academic climate at this }\end{array}$ community college is very supportive of female students.

$\begin{array}{lllllllll}1 & 2 & 3 & 4 & 5 & 6 & 7 & \text { 11. A woman student must outperform male students in }\end{array}$ order to be taken seriously by the teaching staff.

$\begin{array}{lllllllll}1 & 2 & 3 & 4 & 5 & 6 & 7 & \text { 12. Some teaching staff have "put down" or belittled }\end{array}$ specific individuals who raise feminist issues or take a feminist position in the classroom.

$\begin{array}{lllllllll}1 & 2 & 3 & 4 & 5 & 6 & 7 & 13 \text {. The teaching staff generally seem to associate }\end{array}$ particular occupations or achievements with one sex (e.g., by saying, "suppose you went to the doctor and he..."; or "suppose you spoke with a psychologist and she...".

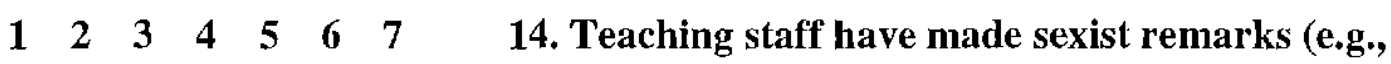
suggesting that women are too emotional to be scientists, or men are too aggressive to be caretakers of the young or elderly).

$\begin{array}{lllllllll}1 & 2 & 3 & 4 & 5 & 6 & 7 & 15 . \text { A member of the teaching staff has treated me as }\end{array}$ though I have limited intellectual ability.

$\begin{array}{lllllllll}1 & 2 & 3 & 4 & 5 & 6 & 7 & \text { 16. Most teaching staff have supported and encouraged }\end{array}$ me to obtain my academic goals (e.g., provided emotional support, important information, etc.). 
$\begin{array}{lllllllll}1 & 2 & 3 & 4 & 5 & 6 & 7 & \text { 17. I have received an unfair grade due to differences in }\end{array}$ opinion between myself and a member of the teaching staff.

$\begin{array}{lllllllll}1 & 2 & 3 & 4 & 5 & 6 & 7 & \text { 18. I have made a comment in class that has been }\end{array}$ ignored and later another student received credit for my idea.

$\begin{array}{lllllllll}1 & 2 & 3 & 4 & 5 & 6 & 7 & 19 . \text { A member of the teaching staff has incorrectly }\end{array}$ seemed to think that I was incompetent when I asked a question.

$\begin{array}{lllllll}1 & 2 & 3 & 4 & 5 & 6 & 7\end{array}$

20. Most teaching staff seem to have enough time to meet with me.

$\begin{array}{lllllll}1 & 2 & 3 & 4 & 5 & 6 & 7\end{array}$

21. Topics regarding women (e.g. women's contributions to the field) are integrated into the course material in most of the classes I have taken.

$\begin{array}{lllllll}1 & 2 & 3 & 4 & 5 & 6 & 7\end{array}$

22. Most teaching staff liave assigned readings that were written by women.

$\begin{array}{lllllll}1 & 2 & 3 & 4 & 5 & 6 & 7\end{array}$

23. Course material is presented from a broad range of perspectives (i.e., includes many ways of looking at the same material, includes the perspective of women, etc.).

$\begin{array}{lllllll}1 & 2 & 3 & 4 & 5 & 6 & 7\end{array}$

24. Most of my textbooks contain some examples of feminist research.

$\begin{array}{lllllllll}1 & 2 & 3 & 4 & 5 & 6 & 7 & 25 . \text { Most teaching staff seem to respond just as well to }\end{array}$ female students as they do to male students.

$\begin{array}{lllllllll}1 & 2 & 3 & 4 & 5 & 6 & 7 & \text { 26. I have HEARD that most female students are NOT }\end{array}$ afraid to go to the library alone at night.

$\begin{array}{lllllllll}1 & 2 & 3 & 4 & 5 & 6 & 7 & 27 .\end{array}$

$\begin{array}{lllllllll}1 & 2 & 3 & 4 & 5 & 6 & 7 & 28 \text {. The campus is a relatively safe place. }\end{array}$

Do you think that women are treated differently from men in classes in your major? If so, how? 
Appendix B 


\section{Perceived Chilly Climate Scale}

Items are scored on a 7-point Likert-type scale. The possible range of scores is 28 to 196, with a midpoint of 112. The higher the score, the chillier the student perceives the climate to be.

\section{Factor 1: Climate Students Hear About}

1. I have NEVER HEARD that a female student has been sexually harassed by a member of the teaching staff.*

2. I have HEARD of one or more instances where a member of the teaching staff put a female student down or was rude to her because she was female.

3. I have HEARD of one or more instances where a member of the teaching staff has used humor (e.g., sexual/sexist humor, or told sexually suggestive stories, jokes, etc.) to "liven up" the class.

4. I have NEVER HEARD that a member of the teaching staff has attempted to establish a sexual relationship with a female student.*

5. I have HEARD of one or more instances when a member of the teaching staff has engaged in inappropriate physical contact toward a female student.

6. I have HEARD of a member of the teaching staff treating female students as though they have limited intellectual ability.

7. I have HEARD that some members of the teaching staff have said things that made female students feel uncomfortable.

8. I have NEVER HEARD that a member of the teaching staff has made ciude and offensive sexual remarks to female students.*

\section{Factor 2: Sexist Attitudes and Treatment}

9. The teaching staff most often use exanples from men's lives.

10. In general, I believe that the academic climate at this university is very supportive of female students.*

11. A woman student must outperform male students in order to be taken seriously by the teaching staff.

12. Some teaching staff have "put down" or belittled specific individuals who raise feminist issues or take a feminist position in the classroom.

13. The teaching staff generally seem to associate particular occupations or achievements with one sex (e.g., by saying, "suppose you went to the doctor and he..."; or "suppose you spoke with a psychologist and she..".

14. Teaching staff have made sexist remarks (e.g., suggesting that women are too emotional to be scientists, or men are too aggressive to be caretakers of the young or elderly). 


\section{Factor 3: Climate Students Experience Personally}

15. A member of the teaching staff has treated me as though I have limited intellectual ability.

16. Most teaching staff have supported and encouraged me to obtain my academic goals (e.g., provided emotional support, important information, etc.).*

17. I have received an unfair grade due to differences in opinion between myself and a member of the teaching staff.

18. I have made a comment in class that has been ignored and later another student received credit for my idea.

19. A member of the teaching staff has incorrectly seemed to think that I was incompetent when I asked a question.

20. Most teaching staff seem to have enough time to meet with me.*

\section{Factor 4: Classroom Climate/Course Material}

21. Topics regarding women (e.g. women's contributions to the field) are integrated into the course material in most of the classes I have taken.*

22. Most teaching staff have assigned readings that were written by women.*

23. Course material is presented from a broad range of perspectives (i.e,, includes many ways of looking at the same material, includes the perspective of women, etc.).*

24. Most of my textbooks contain some examples of feminist research.*

25. Most teaching staff seem to respond just as well to female students as they do to male students.*

\section{Factor 5: Safety}

26. I have HEARD that most female students are NOT afraid to go to the library alone at night.*

27. I am not afraid to go to the library alone at night.*

28 . The campus is a relatively safe place.*

*These items are reverse scored (i.e., $1=7,2=6,3=5,4=4,5=3,6=2,7=1$ ). 
121

Appendix C 
MORRIS, LADONNA K

From: MORRIS, LADONNA K

Sent: Tuesday, July 22, 2003 9:00 AM

To: Sandra W. Pyke (spyke@yorku.ca)

Cc: Daniel Dr. Larry (Daniel, Dr. Larry)

Subject: Perceived Chilly Climate Scale

Dr. Sandra W. Pyke

Graduate Programme Director

Women's Studies Program

York University

4700 Keele St.

Toronto, Ontario

Canada

Dr. Pyke,

I read your article, "A Scale to Assess Student Perceptions of Academic Climates," in The Canadian Journal of Higher Education with great interest and was excited to learn that you had developed a valid and reliable instrument to measure the chilly climate. I also found your suggestions for future studies using the instrument very encouraging.

I would like to request permission to use your Perceived Chilly Climate Scale in the research for my doctoral dissertation at the University of North Florida. The purpose of my study will be to compare perceptions of the chilly climate between women and men in traditional majors versus non-traditional majors at a community college. My dissertation chair is Dr. Larry Daniel, Associate Dean of the College of Education and Human Services at the University of North Florida (1daniel@unf.edu).

I would have contacted Dr. Janz as well, but it appears that she is no longer with York University. If you have any questions, I can be reached at (904) 633-8363 at work, at (904) 992-8992 at home, or by e-mail at lmorris@fccj.edu. Thanks very much for your consideration. I look forward to your response.

Sincerely,

LaDonna K. Morris, Counselor Coordinator

Rosanne R. Hartwell Women's Center

Florida Community College at Jacksonville

101 W. State St.

Jacksonville, Florida 32202-3056

U.S.A. 
From:

Sent:

To:

Cc:

Subject:
Sandra Pyke [spyke@yorku,ce]

Tuesday, July 22, 2003 10:54 AM

MORRIS, LADONNA K

Daniel Dr. Larry (Daniel, Dr. Larry); Teresa Janz

Re: Perceived Chilly Climate Scale

Hello Ms. Morris,

You have my permission to use the Perceived Chilly Climate scale in your research. I am pleased to learn of your interest in the scale and wish you the best of luck with your project.

Sandra Pyke 
Appendix D 


\section{Request for Access}

Dear____ (faculty member):

I would very much appreciate your participation in the research for my doctoral dissertation at the University of North Florida. The purpose of my study is to examine differences in perceptions of campus climate between women and men in traditional majors (e.g., nursing for women, engineering for men) versus non-traditional majors (e.g., nursing for men, technology for women). I am requesting that you allow ine to use 20 minutes of your class time in (list course) to collect data for this study. A copy of the survey instrument and the consent form to be signed by students are attached.

Your confidentiality will be protected, as no names, social security numbers or any other information that could reveal the identity of students or instructors will be published and only aggregated data will be reported. All research materials will be kept in a secured file.

If you are willing to participate, please complete the bottom of this page and send it back to me by campus mail by . Then I will contact you to schedule an appropriate time to come to your class. Please feel free to call me with any questions at (904) 633-8363. Thank you very much for your consideration and for your participation in this study.

Sincerely,

LaDonna K. Morris, Counselor Coordinator

Rosanne R. Hartwell Women 's Center

Florida Community College at Jacksonville

Please sign below if you are willing to participate in the research study outlined above.

Signature Printed name

Date 
Appendix E 


\section{Informed Consent for Research Project Participation: Climate Survey}

\section{Dear Student:}

I would very much appreciate your participation in my research for my doctoral dissertation at the University of North Florida. The purpose of this study is to examine differences in perceptions of campus climate between women and men in traditional majors (e.g., nursing for women, engineering for men) versus non-traditional majors (e.g., nursing for men, technology for women). Your participation is voluntary and refusal to participate will involve no penalty or loss of benefits. It will include completing a survey in class.

Your confidentiality will be protected as no names, social security numbers or any other information that could reveal your identity will be published. Participants "gender (male/female), race/ethnicity (White, African-American), and age will be included as factors in the study. All research materials will be kept in a secured file.

Please feel free to call me with any questions at (904) 633-8363. For questions regarding the rights of research participants, you may also call Dr. James Collum, IRB Representative, at (904) 620-2445. Thank you very much for your participation!

Sincerely,

LaDonna K. Morris, Counselor Coordinator

Rosanne R. Hartwell Women's Center

Florida Community College at Jacksonville

Please sign below if you are willing to participate in the research study outlined above. By signing this form, I certify that I am 18 years of age or older.

Signature Printed name

Date

Principal Investigator LaDonna K. Morris Signature Date 
Appendix $\mathrm{F}$ 


\section{MEMORANDUM}

TO: $\quad$ LaDonna Morris

Education and Human Services

VA: $\quad$ Dr. Larry Daniel Education and Human Services

FROM: James L. Collom, Institutional Review Boar

DATE: $\quad$ November 18,2003

RE: $\quad$ Review by the Institutional Review Board \#03-205

"Perceptions of a Chilly Climate: Differences in Traditional and Non-Traditional Majors for Women"

This is to advise you that your project "Perceptions of a Chilly Climate: Differences in Traditional and Non-Traditional Majors for Women" has been reviewed on behalf of the Institutional Review Board and has been declared exempt from further IRB review.

This approval applies to your project in the form and content as submitted to the IRB for review. Any variations or modifications to the approved protocol and/or informed consent forms as they relate to dealing with human subjects must be cleared with the IRB prior to implementing such changes.

If you have any questions or problems regarding your project or any other IRB issues, please contact this office at $620-2498$.

sah

Attachments 
Appendix G 
Descriptive Statistics for the PCCS Subscales and Total

Table 18

Descriptive Statistics for PCCS Subscale 1: Climate Students Hear About

\begin{tabular}{|c|c|c|c|c|c|c|}
\hline & Gender & $\begin{array}{l}\text { Recoded } \\
\text { Major }\end{array}$ & Major & Mean & Std. Deviation & $\mathrm{N}$ \\
\hline \multirow[t]{33}{*}{ PCCS 1} & \multirow[t]{11}{*}{ Male } & \multirow{3}{*}{$\begin{array}{l}\text { Trad. } \\
\text { Male }\end{array}$} & IT & 19.0 & 11.4 & 74 \\
\hline & & & Engineering & 18.3 & 9.8 & 65 \\
\hline & & & Total & 18.6 & 10.7 & 139 \\
\hline & & Trad. & Education & 20.4 & 13.6 & 34 \\
\hline & & \multirow[t]{2}{*}{ Female } & Nursing & 19.7 & 11.6 & 13 \\
\hline & & & Total & 20.2 & 13.0 & 47 \\
\hline & & \multirow[t]{5}{*}{ Total } & $\mathrm{IT}$ & 19.0 & 11.4 & 74 \\
\hline & & & Engineering & 18.3 & 9.8 & 65 \\
\hline & & & Education & 20.4 & 13.6 & 34 \\
\hline & & & Nursing & 19.7 & 11.6 & 13 \\
\hline & & & Total & 19.0 & 11.3 & 186 \\
\hline & \multirow[t]{11}{*}{ Female } & \multirow{3}{*}{$\begin{array}{l}\text { Trad. } \\
\text { Male }\end{array}$} & $\mathrm{IT}$ & 14.8 & 7.1 & 17 \\
\hline & & & Engineering & 17.0 & 7.3 & 17 \\
\hline & & & Total & 15.9 & 7.2 & 34 \\
\hline & & \multirow{3}{*}{$\begin{array}{l}\text { Trad. } \\
\text { Female }\end{array}$} & Education & 26.1 & 12.9 & 84 \\
\hline & & & Nursing & 22.2 & 13.5 & 99 \\
\hline & & & Total & 24.0 & 13.3 & 183 \\
\hline & & \multirow[t]{5}{*}{ Total } & IT & 14.8 & 7.1 & 17 \\
\hline & & & Engineering & 17.0 & 7.3 & 17 \\
\hline & & & Education & 26.1 & 12.9 & 84 \\
\hline & & & Nursing & 22.2 & 13.5 & 99 \\
\hline & & & Total & 22.7 & 12.9 & 217 \\
\hline & \multirow[t]{11}{*}{ Total } & \multirow{3}{*}{$\begin{array}{l}\text { Trad. } \\
\text { Male }\end{array}$} & IT & 18.2 & 10.9 & 91 \\
\hline & & & Engineering & 18.0 & 9.3 & 82 \\
\hline & & & Total & 18.1 & 10.1 & 173 \\
\hline & & \multirow{3}{*}{$\begin{array}{l}\text { Trad. } \\
\text { Female }\end{array}$} & Education & 24.4 & 13.3 & 118 \\
\hline & & & Nursing & 21.9 & 13.2 & 112 \\
\hline & & & Total & 23.2 & 13.3 & 230 \\
\hline & & \multirow[t]{5}{*}{ Total } & IT & 18.2 & 10.9 & 91 \\
\hline & & & Engineering & 18.0 & 9.3 & 82 \\
\hline & & & Education & 24,4 & 13.3 & 118 \\
\hline & & & Nursing & 21.9 & 13.2 & 112 \\
\hline & & & Total & 21.0 & 12.3 & 403 \\
\hline
\end{tabular}


Table 19

Descriptive Statistics for PCCS Subscale 2: Sexist Attitudes and Treatment

\begin{tabular}{|c|c|c|c|c|c|c|}
\hline & Gender & $\begin{array}{l}\text { Recoded } \\
\text { Major }\end{array}$ & Major & Mean & Std. Deviation & $\mathrm{N}$ \\
\hline \multirow[t]{33}{*}{ PCCS 2} & Male & Trad. & IT & 14.1 & 7.1 & 74 \\
\hline & & Male & Engineering & 13.3 & 5.7 & 65 \\
\hline & & & Total & 13.7 & 6.5 & 139 \\
\hline & & Trad. & Education & 15.1 & 6.6 & 34 \\
\hline & & Female & Nursing & 12.7 & 5.3 & 13 \\
\hline & & & Total & 14.4 & 6.3 & 47 \\
\hline & & Total & IT & 14.1 & 7.1 & 74 \\
\hline & & & Engineering & 13.3 & 5.7 & 65 \\
\hline & & & Education & 15.1 & 6.6 & 34 \\
\hline & & & Nursing & 12.7 & 5.3 & 13 \\
\hline & & & Total & 13.9 & 6.4 & 186 \\
\hline & Female & Trad. & IT & 14.0 & 7.3 & 17 \\
\hline & & Male & Engineering & 16.0 & 4.8 & 17 \\
\hline & & & Total & 15.0 & 6.1 & 34 \\
\hline & & Trad. & Education & 16.6 & 7.0 & 84 \\
\hline & & Female & Nursing & 14.8 & 7.3 & 99 \\
\hline & & & Total & 15.7 & 7.2 & 183 \\
\hline & & Total & IT & 14.0 & 7.3 & 17 \\
\hline & & & Engineering & 16.0 & 4.8 & 17 \\
\hline & & & Education & 16.6 & 7.0 & 84 \\
\hline & & & Nursing & 14.8 & 7.3 & 99 \\
\hline & & & Total & 15.6 & 7.0 & 217 \\
\hline & Total & Trad. & IT & 14.1 & 7.1 & 91 \\
\hline & & Male & Engineering & 13.9 & 5.6 & 82 \\
\hline & & & Total & 14.0 & 6.4 & 173 \\
\hline & & Trad. & Education & 16.2 & 6.9 & 118 \\
\hline & & Female & Nursing & 14.6 & 7.1 & 112 \\
\hline & & & Total & 15.4 & 7.0 & 230 \\
\hline & & Total & IT & 14.1 & 7.1 & 91 \\
\hline & & & Engineering & 13.9 & 5.6 & 82 \\
\hline & & & Education & 16.2 & 6.9 & 118 \\
\hline & & & Nursing & 14.6 & 7.1 & 112 \\
\hline & & & Total & 14.8 & 6.8 & 403 \\
\hline
\end{tabular}


Table 20

Descriptive Statistics for PCCS Subscale 3: Climate Students Experience Personally

\begin{tabular}{|c|c|c|c|c|c|c|}
\hline & Gender & $\begin{array}{l}\text { Recoded } \\
\text { Major }\end{array}$ & Major & Mean & Std. Deviation & $\mathrm{N}$ \\
\hline \multirow[t]{33}{*}{ PCCS 3} & \multirow[t]{11}{*}{ Male } & \multirow{3}{*}{$\begin{array}{l}\text { Trad. } \\
\text { Male }\end{array}$} & IT & 12.4 & 7.3 & 74 \\
\hline & & & Engineering & 12.6 & 5.8 & 65 \\
\hline & & & Total & 12.5 & 6.6 & 139 \\
\hline & & \multirow{3}{*}{$\begin{array}{l}\text { Trad. } \\
\text { Female }\end{array}$} & Education & 13.7 & 8.5 & 34 \\
\hline & & & Nursing & 12.7 & 4.9 & 13 \\
\hline & & & Total & 13.4 & 7.6 & 47 \\
\hline & & \multirow[t]{5}{*}{ Total } & IT & 12.4 & 7.3 & 74 \\
\hline & & & Engineering & 12.6 & 5.8 & 65 \\
\hline & & & Education & 13.7 & 8.5 & 34 \\
\hline & & & Nursing & 12.7 & 4.9 & 13 \\
\hline & & & Total & 12.7 & 6.9 & 186 \\
\hline & \multirow[t]{11}{*}{ Female } & Trad. & $\begin{array}{l}\text { IT } \\
\end{array}$ & 11.2 & 4.8 & 17 \\
\hline & & \multirow[t]{2}{*}{ Male } & Engineering & 12.2 & 4.8 & 17 \\
\hline & & & Total & 11.7 & 4.7 & 34 \\
\hline & & \multirow{3}{*}{$\begin{array}{l}\text { Trad. } \\
\text { Female }\end{array}$} & Education & 14.3 & 6.5 & 84 \\
\hline & & & Nursing & 13.4 & 6.6 & 99 \\
\hline & & & Total & 13.8 & 6.5 & 183 \\
\hline & & \multirow[t]{5}{*}{ Total } & IT & 11.2 & 4.8 & 17 \\
\hline & & & Engineering & 12.2 & 4.8 & 17 \\
\hline & & & Education & 14.3 & 6.5 & 84 \\
\hline & & & Nursing & 13.4 & 6.6 & 99 \\
\hline & & & Total & 13.5 & 6.3 & 217 \\
\hline & \multirow[t]{11}{*}{ Total } & \multirow{3}{*}{$\begin{array}{l}\text { Trad. } \\
\text { Male }\end{array}$} & IT & 12.2 & 6.9 & 91 \\
\hline & & & Engineering & 12.5 & 5.6 & 82 \\
\hline & & & Total & 12.3 & 6.3 & 173 \\
\hline & & \multirow{3}{*}{$\begin{array}{l}\text { Trad. } \\
\text { Female }\end{array}$} & Education & 14.1 & 7.1 & 118 \\
\hline & & & Nursing & 13.3 & 6.4 & 112 \\
\hline & & & Total & 13.7 & 6.7 & 230 \\
\hline & & \multirow[t]{5}{*}{ Total } & IT & 12.2 & 6.9 & 91 \\
\hline & & & Engineering & 12.5 & 5.6 & 82 \\
\hline & & & Education & 14.1 & 7.1 & 118 \\
\hline & & & Nursing & 13.3 & 6.4 & 112 \\
\hline & & & Total & 13.1 & 6.6 & 403 \\
\hline
\end{tabular}


Table 21

Descriptive Statistics for PCCS Subscale 4: Classroom Climate/Course Material

\begin{tabular}{|c|c|c|c|c|c|c|}
\hline & Gender & $\begin{array}{l}\text { Recoded } \\
\text { Major }\end{array}$ & Major & Mean & Std. Deviation & $\mathrm{N}$ \\
\hline \multirow[t]{33}{*}{ PCCS 4} & \multirow[t]{11}{*}{ Male } & \multirow{3}{*}{$\begin{array}{l}\text { Trad. } \\
\text { Male }\end{array}$} & $\mathrm{IT}$ & 16.8 & 6.0 & 74 \\
\hline & & & Engineering & 17.3 & 4.7 & 65 \\
\hline & & & Total & 17.0 & 5.4 & 139 \\
\hline & & \multirow{3}{*}{$\begin{array}{l}\text { Trad. } \\
\text { Female }\end{array}$} & Education & 16.6 & 6.8 & 34 \\
\hline & & & Nursing & 13.8 & 3.4 & 13 \\
\hline & & & Total & 15.8 & 6.1 & 47 \\
\hline & & \multirow[t]{5}{*}{ Total } & IT & 16.8 & 6.0 & 74 \\
\hline & & & Engineering & 17.3 & 4.7 & 65 \\
\hline & & & Education & 16.6 & 6.8 & 34 \\
\hline & & & Nursing & 13.8 & 3.4 & 13 \\
\hline & & & Total & 16.7 & 5.6 & 186 \\
\hline & \multirow[t]{11}{*}{ Female } & Trad. & IT & 18.5 & 6.0 & 17 \\
\hline & & \multirow[t]{2}{*}{ Male } & Engineering & 20.4 & 4.8 & 17 \\
\hline & & & Total & 19.4 & 5.4 & 34 \\
\hline & & \multirow{3}{*}{$\begin{array}{l}\text { Trad. } \\
\text { Female }\end{array}$} & Education & 16.0 & 5.9 & 84 \\
\hline & & & Nursing & 15.9 & 5.2 & 99 \\
\hline & & & Total & 16.0 & 5.5 & 183 \\
\hline & & \multirow[t]{5}{*}{ Total } & I'T & 18.5 & 6.0 & 17 \\
\hline & & & Engineering & 20.4 & 4.8 & 17 \\
\hline & & & Education & 16.0 & 5.9 & 84 \\
\hline & & & Nursing & 15.9 & 5.2 & 99 \\
\hline & & & Total & 16.5 & 5.6 & 217 \\
\hline & \multirow[t]{11}{*}{ Total } & \multirow{3}{*}{$\begin{array}{l}\text { Trad. } \\
\text { Male }\end{array}$} & IT & 17.1 & 6.0 & 91 \\
\hline & & & Engineering & 17.9 & 4.8 & 82 \\
\hline & & & Total & 17.5 & 5.5 & 173 \\
\hline & & \multirow{3}{*}{$\begin{array}{l}\text { Trad. } \\
\text { Female }\end{array}$} & Education & 16.2 & 6.1 & 118 \\
\hline & & & Nursing & 15.7 & 5.0 & 112 \\
\hline & & & Total & 16.0 & 5.6 & 230 \\
\hline & & \multirow[t]{5}{*}{ Total } & IT & 17.1 & 6.0 & 91 \\
\hline & & & Engineering & 17.9 & 4.8 & 82 \\
\hline & & & Education & 16.2 & 6.1 & 118 \\
\hline & & & Nursing & 15.7 & 5.0 & 112 \\
\hline & & & Total & 16.6 & 5.6 & 403 \\
\hline
\end{tabular}


Table 22

Descriptive Statistics for PCCS Subscale 5: Safety

\begin{tabular}{|c|c|c|c|c|c|c|}
\hline & Gender & $\begin{array}{l}\text { Recoded } \\
\text { Major }\end{array}$ & Major & Mean & Std. Deviation & $\mathrm{N}$ \\
\hline \multirow[t]{33}{*}{ PCCS 5} & \multirow[t]{11}{*}{ Male } & \multirow{3}{*}{$\begin{array}{l}\text { Trad. } \\
\text { Male }\end{array}$} & IT & 7.0 & 3.4 & 74 \\
\hline & & & Engineering & 7.9 & 4.0 & 65 \\
\hline & & & Total & 7.4 & 3.7 & 139 \\
\hline & & \multirow{3}{*}{$\begin{array}{l}\text { Trad. } \\
\text { Female }\end{array}$} & Education & 6.3 & 3.0 & 34 \\
\hline & & & Nursing & 9.2 & 5.1 & 13 \\
\hline & & & Total & 7.1 & 3.9 & 47 \\
\hline & & \multirow[t]{5}{*}{ Total } & $\mathrm{IT}$ & 7.0 & 3.4 & 74 \\
\hline & & & Fngineering & 7.9 & 4.0 & 65 \\
\hline & & & Education & 6.3 & 3.0 & 34 \\
\hline & & & Nursing & 9.2 & 5.1 & 13 \\
\hline & & & Total & 7.3 & 3.8 & 186 \\
\hline & \multirow[t]{11}{*}{ Female } & \multirow{3}{*}{$\begin{array}{l}\text { Trad. } \\
\text { Male }\end{array}$} & IT & 10.4 & 5.7 & 17 \\
\hline & & & Engineering & 11.4 & 4.7 & 17 \\
\hline & & & Total & 10.9 & 5.2 & 34 \\
\hline & & \multirow{3}{*}{$\begin{array}{l}\text { Trad. } \\
\text { Fernale }\end{array}$} & Education & 10.3 & 4.8 & 84 \\
\hline & & & Nursing & 10.9 & 5.1 & 99 \\
\hline & & & Total & 10.6 & 5.0 & 183 \\
\hline & & \multirow[t]{5}{*}{ Total } & IT & 10.4 & 5.7 & 17 \\
\hline & & & Engineering & 11.4 & 4.7 & 17 \\
\hline & & & Education & 10.3 & 4.8 & 84 \\
\hline & & & Nursing & 10.9 & 5.1 & 99 \\
\hline & & & Total & 10.6 & 5.0 & 217 \\
\hline & \multirow[t]{11}{*}{ Total } & \multirow{3}{*}{$\begin{array}{l}\text { Trad. } \\
\text { Male }\end{array}$} & I'T & 7.6 & 4.1 & 91 \\
\hline & & & Engineering & 8.6 & 4.4 & 82 \\
\hline & & & Total & 8.1 & 4.3 & 173 \\
\hline & & Trad. & Education & 9.1 & 4.7 & 118 \\
\hline & & \multirow[t]{2}{*}{ Female } & Nursing & 10.7 & 5.1 & 112 \\
\hline & & & Total & 9.9 & 4.9 & 230 \\
\hline & & \multirow[t]{5}{*}{ Total } & IT & 7.6 & 4.1 & 91 \\
\hline & & & Engineering & 8.6 & 4.4 & 82 \\
\hline & & & Education & 9.1 & 4.7 & 118 \\
\hline & & & Nursing & 10.7 & 5.1 & 112 \\
\hline & & & Total & 9.1 & 4.7 & 403 \\
\hline
\end{tabular}


Table 23

Descriptive Statistics for PCCS Total Scores

\begin{tabular}{|c|c|c|c|c|c|c|}
\hline & Gender & $\begin{array}{l}\text { Recoded } \\
\text { Major }\end{array}$ & Major & Mean & Std. Deviation & $\mathrm{N}$ \\
\hline \multirow[t]{33}{*}{ PCCS Total } & \multirow[t]{11}{*}{ Male } & \multirow{3}{*}{$\begin{array}{l}\text { Trad. } \\
\text { Male }\end{array}$} & $\mathrm{IT}$ & 69.2 & 27.5 & 74 \\
\hline & & & Engineering & 69.3 & 20.2 & 65 \\
\hline & & & Total & 69.3 & 24.3 & 139 \\
\hline & & \multirow{3}{*}{$\begin{array}{l}\text { Trad. } \\
\text { Female }\end{array}$} & Education & 72.1 & 29.4 & 34 \\
\hline & & & Nursing & 68.2 & 17.6 & 13 \\
\hline & & & Total & 71.0 & 26.5 & 47 \\
\hline & & \multirow[t]{5}{*}{ Total } & IT & 69.2 & 27.5 & 74 \\
\hline & & & Engineering & 69.3 & 20.2 & 65 \\
\hline & & & Education & 72.1 & 29.4 & 34 \\
\hline & & & Nursing & 68.2 & 17.6 & 13 \\
\hline & & & Total & 69.7 & 24.8 & 186 \\
\hline & \multirow[t]{11}{*}{ Female } & \multirow{3}{*}{$\begin{array}{l}\text { Trad. } \\
\text { Male }\end{array}$} & IT & 68.9 & 20.7 & 17 \\
\hline & & & Engineering & 77.0 & 19.0 & 17 \\
\hline & & & Total & 72.9 & 20.0 & 34 \\
\hline & & \multirow{3}{*}{$\begin{array}{l}\text { Trad. } \\
\text { Female }\end{array}$} & Education & 83.3 & 26.1 & 84 \\
\hline & & & Nursing & 77.3 & 27.5 & 99 \\
\hline & & & Total & 80.0 & 27.0 & 183 \\
\hline & & \multirow[t]{5}{*}{ Total } & $\mathrm{IT}$ & 68.9 & 20.7 & 17 \\
\hline & & & Engineering & 77.0 & 19.0 & 17 \\
\hline & & & Education & 83.3 & 26.1 & 84 \\
\hline & & & Nursing & 77.3 & 27.5 & 99 \\
\hline & & & Total & 78.9 & 26.1 & 217 \\
\hline & \multirow[t]{11}{*}{ Total } & \multirow{3}{*}{$\begin{array}{l}\text { Trad. } \\
\text { Male }\end{array}$} & $\mathrm{IT}$ & 69.2 & 26.3 & 91 \\
\hline & & & Engineering & 70.9 & 20.1 & 82 \\
\hline & & & Total & 70.0 & 23.5 & 173 \\
\hline & & \multirow{3}{*}{$\begin{array}{l}\text { Trad. } \\
\text { Female }\end{array}$} & Education & 80.0 & 27.5 & 118 \\
\hline & & & Nursing & 76.2 & 26.7 & 112 \\
\hline & & & Total & 78.2 & 27.1 & 230 \\
\hline & & Total & IT & 69.2 & 26.3 & 91 \\
\hline & & & Engineering & 70.9 & 20.1 & 82 \\
\hline & & & Education & 80.0 & 27.5 & 118 \\
\hline & & & Nursing & 76.2 & 26.7 & 112 \\
\hline & & & Total & 74.7 & 25.9 & 403 \\
\hline
\end{tabular}


Appendix $\mathrm{H}$ 
Canonical Invariance Analysis

Sample 1

$(n=202)$

Table 24

Sample 1 Eigenvalues and Canonical Correlations

\begin{tabular}{crrrrr}
\hline $\begin{array}{c}\text { Root } \\
\text { No. }\end{array}$ & Eigenvalue & Percentage & $\begin{array}{c}\text { Cumulative } \\
\text { Percentage }\end{array}$ & $\begin{array}{c}\text { Canonical } \\
\text { Correlation }\end{array}$ & $\begin{array}{c}\text { Squared } \\
\text { Correlation }\end{array}$ \\
\hline 1 & .17 & 43.47 & 43.47 & .38 & .15 \\
2 & .11 & 28.27 & 71.73 & .32 & .10 \\
3 & .10 & 25.95 & 97.68 & .30 & .09 \\
4 & .01 & 2.19 & 99.88 & .09 & .01 \\
5 & $<.01$ & .12 & 100.00 & .02 & $<.01$ \\
\hline
\end{tabular}

Table 25

Sample 1 Function and Structure Coefficients for Independent/Predictor Variables

\begin{tabular}{lccccc}
\hline \multicolumn{1}{c}{ Variable } & Root 1 & Root 2 & Root 3 & Root 4 & Root 5 \\
\hline \multicolumn{1}{c}{ Independent/Predictor Variable } & Standardized & Canonical Function Coefficients \\
Gender & .70 & -.89 & -.01 & .46 & -.14 \\
Age & .38 & .08 & .62 & .02 & .70 \\
Ethnicity & $-.5 \mathrm{I}$ & -.53 & -.27 & .07 & .64 \\
Intent & .26 & -.26 & -.29 & -.90 & -.01 \\
Major & $-.0 \mathrm{I}$ & .84 & -.70 & -.08 & .56 \\
& Independent/Predictor Variable Canonical Structure Coefficients & \\
Gender & .70 & -.35 & -.44 & .44 & .04 \\
Age & .36 & .10 & .65 & -.14 & .65 \\
Ethnicity & -.60 & -.54 & -.20 & .04 & .56 \\
Intent & .28 & -.25 & -.16 & -.91 & .05 \\
Major & .42 & .40 & -.71 & .22 & .34 \\
\hline
\end{tabular}


Table 26

Sample I Function and Structure Coefficients for Dependent/Criterion Variables*

\begin{tabular}{cccccr}
\hline Variable & Root 1 & Root 2 & Root 3 & Root 4 & Root 5 \\
\hline Dependent/Criterion Variable Standardized Canonical Function Coefficients & \\
PCCS 1 & -.27 & -.01 & -.75 & .10 & 1.11 \\
PCCS 2 & -.01 & .16 & -.37 & .73 & -1.23 \\
PCCS 3 & -.05 & .13 & .01 & -1.25 & -.22 \\
PCCS 4 & -.47 & -.95 & .26 & .06 & .14 \\
PCCS 5 & .99 & -.37 & -.08 & -.03 & .04 \\
& Dependent/Criterion Canonical Structure Coefficients & \\
PCCS 1 & -.15 & -.15 & -.95 & -.06 & .23 \\
PCCS 2 & -.12 & -.23 & -.78 & .08 & -.56 \\
PCCS 3 & -.12 & -.18 & -.53 & -.76 & -.32 \\
PCCS 4 & -.34 & -.93 & -.07 & -.06 & -.13 \\
PCCS 5 & .80 & -.50 & -.32 & -.08 & -.02 \\
\hline
\end{tabular}

*Subscales are: PCCS 1 (Climates Students Hear About); PCCS 2 (Sexist Attitudes and Treatment); PCCS 3 (Climate Students Experience Personally); PCCS 4 (Classroom Climate/Course Material); PCCS 5 (Safety).

Sample 2

$(n=201)$

Table 27

Sample 2 Eigenvalues and Canonical Correlations

\begin{tabular}{lrrrrr}
\hline $\begin{array}{l}\text { Root } \\
\text { No. }\end{array}$ & Eigenvalue & Percentage & $\begin{array}{c}\text { Cumulative } \\
\text { Percentage }\end{array}$ & $\begin{array}{c}\text { Canonical } \\
\text { Correlation }\end{array}$ & $\begin{array}{c}\text { Squared } \\
\text { Correlation }\end{array}$ \\
\hline 1 & .27 & 53.60 & 53.60 & .46 & .21 \\
2 & .11 & 21.38 & 74.98 & .31 & .10 \\
3 & .08 & 16.54 & 91.52 & .28 & .08 \\
4 & .04 & 7.94 & 99.45 & .20 & .04 \\
5 & $<.01$ & .55 & 100.00 & .05 & $<.01$ \\
\hline
\end{tabular}


Table 28

Sample 2 Function and Structure Coefficients for Independent/Predictor Variables

\begin{tabular}{lccccc}
\hline \multicolumn{1}{c}{ Variable } & Root 1 & Root 2 & Root 3 & Root 4 & Root 5 \\
\hline \multicolumn{1}{c}{ Indepcndent $/$ Predictor } & Variable & Standardized Canonical Function Coefficients \\
Gender & -.71 & -.44 & .83 & .21 & -.47 \\
Age & .09 & -.25 & -.01 & -.97 & -.16 \\
Ethnicity & .14 & .90 & .42 & -.18 & .01 \\
Intent & -.14 & .20 & -.49 & .00 & -.84 \\
Major & -.37 & .57 & -.80 & -.44 & .62 \\
& Independent/Predictor Variable Canonical Structure Coefficients & \\
Gender & -.92 & -.05 & .37 & -.06 & -.08 \\
Age & .15 & -.26 & .13 & -.93 & -.16 \\
Ethnicity & .13 & .82 & .52 & -.18 & -.13 \\
Intent & -.11 & .25 & -.46 & .07 & -.84 \\
Major & -.82 & .23 & -.32 & -.19 & .38 \\
\hline
\end{tabular}

Table 29

Sample 2 Function and Structure Coefficients for Dependent/Criterion Variables*

\begin{tabular}{cccccc}
\hline Variable & Root 1 & Root 2 & Root 3 & Root 4 & Root 5 \\
\hline Dependent/Criterion Variable Standardized Canonical Function Coefficients & \\
PCCS 1 & -.44 & .74 & -.38 & .12 & .83 \\
PCCS 2 & .10 & -.56 & .33 & 1.13 & -.45 \\
PCCS 3 & -.11 & .38 & -.57 & -.50 & -.83 \\
PCCS 4 & .51 & .69 & .60 & -.07 & -.05 \\
PCCS 5 & -.80 & -.19 & .55 & -.41 & -.07 \\
& Dependent/Criterion Variable Canonical Structure Coefficients & \\
PCCS 1 & -.54 & .63 & -.19 & .49 & .20 \\
PCCS 2 & -.34 & .20 & .12 & .81 & -.42 \\
PCCS 3 & -.31 & .47 & -.34 & .06 & -.75 \\
PCCS 4 & .27 & .69 & .65 & .06 & -.19 \\
PCCS 5 & -.78 & .06 & .58 & -.14 & -.18 \\
\hline
\end{tabular}

* Subscales are: PCCS 1 (Climates Students Hear About); PCCS 2 (Sexist Attitudes and Treatment); PCCS 3 (Climate Students Experience Personally); PCCS 4 (Classroom Climatc/Course Material); PCCS 5 (Safety). 


\section{References}

Aber, C. S., \& Arathuzik, D. (1996). Factors associated with student success in a baccalaureate nursing program within an urban public university. Journal of Nursing Education, 35(6), 285-288.

Astin, H. S., \& Sax, L. J. (1996). Developing scientific talent in undergraduate women. In C. S. Davis, A .B. Ginorio, C. S. Hollenshead, B. B. Lazarus, \& P. M. Rayman (Eds.), The equity equation: Fostering the advancement of women in the sciences, mathematics, and engineering (pp. 96-121). San Francisco: Jossey-Bass Publishers.

Baker, D.R. (1987). The influence of role-specific self-concept and sex-role identity on career choices in science. Journal of Research in Science Teaching, 24(8), 739756.

Bandura, A. (1997). Self-efficacy: The exercise of control. New York: W. H. Freeman and Company.

Barbercheck, M. (2001). Mixed messages: Men and women in advertisements in science. In M. Wyer, M. Barbercheck, D. Giesman, H. Ö. Öztürk, \& M. Wayne (Eds.), Women, science, and technology: A reader in feminist science studies (pp. 117131). New York: Routledge.

Bauer, K. S. (2000) Promoting gender equity in schools. Contemporary Education, 71(2), $22-26$

Belenky, M. F., Clinchy, B. M., Goldberger, N. R., \& Tarule, J. M. (1986). Women's ways of knowing: The development of self, voice, and mind. New York: Basic 
Books, Inc.

Bem, S. L. (1974). The measurement of psychological androgyny. Journal of Consulting and Clinical Psychology, 42(2), 155-162.

Boughn, S. (1992). Nursing students rank high in autonomy at the exit level. Journal of Nursing Education, 31(2), 58-64.

Boughn, S. (2001). Why women and men choose nursing. Nursing and Health Care Perspective, 22(1), 14-19.

Boughn, S., \& Lentini, A. (1999). Why do women choose nursing? Journal of Nursing Education, 38(4), 156-161.

Brown, B. L. (2001). Women and minorities in high-tech careers (Report No. EDO-CE01-226). Columbus, OH: ERIC Clearinghouse on Adult, Career and Vocational 02- Education. (ERIC Document Reproduction Service No. ED452367)

Bunderson, E. D., \& Christensen, M. E. (1995). An analysis of retention problems of female students in university computer seience programs. Journal of Research on Computing in Education, 28(1), 1-18.

Camp, T. (2001). Women in computer sciences: Reversing the trend. Syllabus, 15(1), 24-28.

Campbell, P. F., \& McCabe, G. P. (1984). Predicting the success of freshmen in a computer science major. Communications of the ACM, 27(11), 1108-1113.

Chapman, O. (1993) Women's voice and the learning of mathematics. Journal of Gender Studies, 2(2), 206-221.

Characteristics of faculty members with teaching duties by type of institution, fall 1998 . 
(2001). The Chronicle of Higher Education, 48(1), 27.

Cohen, S. (2001). Welcome to the girls club. InfoWorld, 23(17), 55.

Commission on Professionals in Science and Technology. (2002). Professional women \& minorities: A total human resources data compendium. Washington, DC: Author,

Constantinople, A., Cornelius, R., \& Gray, J. (1988). The chilly climate: Fact or artifact? The Journal of Higher Education, 59(5), 527-550.

Cooper, S. E., \& Robinson, D. A. G. (1985). Students in highly technical careers; Sex differences in interpersonal characteristics and vocational identity. Journal of College Student Personnel, 26(3), 215-219.

Crawford, M., \& MacLeod, M. (1990). Gender in the collegc classroom: An assessment of the "chilly climate" for women. Sex Roles, 23(3/4), 101-122.

Daniel, L. G., Adams, B. N., \& Smith, N. M. (1994). Academic misconduct among nursing students: A multivariate investigation. Journal of Professional Nursing, $10(5), 278-288$.

Deloitte and Touche. (2001), Women in technology leadership survey (Roper \& Starch Worldwide No. CNO 503). New York: Author. Retrieved July 19, 2002, from http://www.deloitte.com/us

Drew, T., \& Work, G. (1998). Gender-based differences in perception of experiences in higher education: Gaining a broader perspective. The Journal of Higher Education, 69(5), 542-545.

Eisenhart, M. A., \& Holland, D. C. (2001). Gender constructs and career commitment: 
The influence of peer culture on women in college. In M. Wyer, M. Barbercheck,

D. Giesman, H. Ö. Öztürk, \& M. Wayne (Eds.), Women, science, and technology: A reader in feminist science studies (pp. 26-35). New York: Routledge.

Ethington, C. A. (1988). Differences among women intending to major in quantitative fields of study. Journal of Educational Research, 81(6), 354-359.

Etzkowitz, H., Kemelgor, C., \& Uzzi, B. (2000). Athena unbound: The advancement of women in science and technology. Cambridge, United Kingdom: Cambridge University Press.

Farmer, H., Wardrop, J., Anderson, M., \& Risinger, R. (1995). Women's career choices: Focus on science, math, and technology carecrs. Journal of Counseling Psychology, 42(2), 155-170.

Flowers, J. (1998). Improving female enrollment in tech ed. The Technology Teacher, $58(2), 21-25$.

Gilligan, C. (1993), In a different voice. Catnbridge, MA: Harvard University Press.

Gorsuch, R. L. (1983). Factor analysis ( $2^{\text {nd }}$ ed.). Hillsdale, NJ: Lawrence Erlbaum Associates.

Grandy, J. (1990). In search of the next generation of scientists: A new challenge for teachers. The College Board Review, 156, 2-9, 28.

Hall, R. M., \& Sandler, B. R. (1982). The classroom climate: A chilly one for women? Washington, DC: Association of American Colleges.

Hall, R. M., \& Sandler, B. R. (1984). Out of the classroom: A chilly campus climate for women? Washington, DC: Association of American Colleges. 
Harvey, V. C., \& McMurray, N. E. (1997). Students' perceptions of nursing: Their relationship to attrition. Journal of Nursing Education, 36(8), 383-389.

Heller, J. F., Puff, C. R., \& Mills, C. J. (1985). Assessment of the chilly college climate for women. The Journal of Higher Education, 56(4), 446-461.

Jackson, S. (1993). Enhancing the learning experiences of women: A case study of a women-only re-entry program. Unpublished master's thesis, Dalhousie University, Halifax, Nova Scotia, Canada.

Janz, T. A., \& Pyke, S. W. (2000). A scale to assess student perceptions of academic climates. Canadian Journal of Higher Education, 30(1), 89-122.

Jeffreys, M. R. (1998). Predicting nontraditional student retention and academic achievement, Nurse Educator, 23(1), 42-48.

Kersten, J., Bakewe11, K., \& Meyer, D. (1991). Motivating factors in a student's choice of nursing as a career. Journal of Nursing Education, 30(1), 30-33.

Kruschwitz, K., \& Peter, C. M. (I995). All-girl settings for teaching math and science. Education Digest, 60(6), 60-65.

Lackland, A. C., \& De Lisi, R. (2001). Students' choices of college majors that are gender traditional and nontraditional. Journal of College Student Development, $42(1), 39-47$.

Larsen, K. (2001). Lifelong learning for all. The OECD Observer, 225, 21-23.

Maher, F. A., \& Tetreault, M. K. T. (2001). The feminist classroom: Dynamics of gender, race, and privilege. Lanham, MD: Rownan \& Littlefield Publishers, Inc.

Mendez, D., \& Louis, M. (1991). College students' image of nursing as a career choice. 
Journal of Nursing Education, 30(7), 311-319.

Murray, D. (1998). Should colleges drop the SAT in admissions decisions? American Teacher, 82(7), 4.

National Research Council. (1991). Women in science and engineering: Increasing their numbers in the 1990s. Washington, DC: National Academy Press.

Neuman, D. (1991). Technology and equity (Report No. EDO-IR-91-8). Syracuse, NY: ERIC Clearinghouse on Information Resources. (ERIC Document Reproduction Service No. ED339400)

Nunnally, J. C. (1978), Psychometric theory (2 ${ }^{\text {nd }}$ ed.). New York: McGraw-Hill.

Odell, P., \& Schumacher, P. (1998). Attitudes toward mathematics and predictors of college mathematics grades: Gender differences in a 4-year business college. Journal of Education for Business, 74(1), 34-38.

Olsen, F. (2000). Institute for Women and Technology works to bridge the other digital divide. Chronicle of Higher Education, 46(31), A47.

Pascarella, E. T., Whitt, E. J., Edison, M. I., Nora, A., Hagedorn, L. S., Yeager, P. M., \& Terenzini, P.T. (1997). Women's perceptions of a "chilly climate" and their Cognitive outcomes during the first year of college. Journal of College Student Development, 38(2), 109-110.

Pedhazur, E. J. (1982). Multiple regression in behavioral research $\left(2^{\text {nd }}\right.$ ed.). New York: Holt, Rinehart \& Winston.

Pillitteri, A. (1994). A contrast in images: Nursing and nonnursing college students. Journal of Nursing Education, 33(3), 132-133. 
Rea, J. S., \& Strange, C. (1983). The experience of cross-gender majoring among male and female undergraduates. Journal of College Student Personnel, 24(4), 356363.

Roger, A., Cronin, C., \& Duffield J. (1999). Winning women in science, engineering, and technology in higher education in Scotland: Some epistemological and pedagogical questions. European Education, 30(4), 82-100.

Rosser, S. V. (1990). Female-friendly science: Applying women's studies methods and theories to attract students. New York: Pergamon Press.

Sadker, M., \& Sadker, D. (1994). Failing at fairness: How our schools cheat girls. New York: Touchstone,

Seymour, E. (1995). The loss of women from science, mathematics, and engineering undergraduate majors: An explanatory account. Science Education, 79(4), 437473 .

Seymour, E., \& Hewilt, N. M. (1997). Talking about leaving: Why undergraduates leave the sciences. Boulder, CO: Westview Press.

Shelton, E. N. (2003). Faculty support and student retention. Journal of Nursing Education, 42(2), 68-76.

Smith, L. (2000). The socialization of females with regard to a technology-related career: Recommendations for change. Meridian: A Middle School Computer Technologies Journal, 3(2), 2-30.

Solnick, S. J. (1995). Changes in women's majors from entrance to graduation at wornen's and cocducational colleges. Industrial and Labor Relations Review, 
$48(3), 505-514$.

SPSS, Inc. (2002). SPSS Base 11.5 user's guide. Chicago, IL: SPSS, Inc.

Staiger, D. O., Auerbach, D. I., \& Buerhaus, P. I. (2000). Expanding career opportunities for women and the declining interest in nursing as a career. Nursing Economics, $18(5), 230-236$.

Thom, M. (2001). Young women's progress in science and tcchnology studies:

Overcoming remaining barriers. NASSP Bulletin, 85(628), 6-19.

Thompson, B. (1984). Canonical correlation analysis: Uses and interpretations. (Series: Quantitative Applications in the Social Sciences, Number 07-047). Beverly Hills, CA: Sage.

Thorpe, K., \& Loo, R. (2003). The values profile of nursing undergraduate students: Implications for education and professional development. Journal of Nursing Education, 42(2), 83-90.

Turner, S., \& Bowen, W. (1999). Choice of major: The changing (unchanging) gender gap. Industrial and Labor Relations Review, 52(2), 289-313.

Vetter, B. M. (1996). Myths and realities of women's progress in the sciences, mathematics, and engineering. In C-S Davis, A. B. Ginorio, C. S. Hollenshead, B. B. Lazarus, \& P. M. Rayman (Eds.), The equity equation: Fostering the advancement of women in the sciences, mathematics, and engineering (pp. 2956). San Francisco: Jossey-Bass Publishers.

Weinman, J., \& Pamela, H. (1999). Gender equity in cyberspace. Educational Leadership, 56(5), 44-49. 
Whitt, E. J, Nora, A., Edison, M. I., Terenzini, P. T., \& Pascarella, E. T. (1999). Women's perceptions of a "chilly climate" and cognitive outcomes in college: Additional evidence. Journal of College Student Development, 40(2), 163-177.

Wright, R., Pamler, J., \& Miller, J. (1996). An examination of gender-based variations in the predictive ability of the SAT. College Student Journal, 30, 81-84. 


\section{Vita}

\section{LaDonna K. Morris}

\section{EDUCATION}

Ed.D., University of North Florida, Educational Leadership, August 2004.

M.S.Ed., Southern Illinois University, Educational Psychology, May 1989.

M.S.Ed., Southern Ilinois University, Health Education, August 1983.

B.A., Southern Illinois University, Biological Sciences major, German minor, May 1981.

\section{PROFESSIONAL EXPERIENCE}

1996 to present. Counselor Coordinator, Rosanne R. Hartwell Women 's Center at Florida Community College at Jacksonville, Florida.

1993 to 1996. Adjunct Professor, Psychology Department, Flagler College, St. Augustine, Florida.

1989 to 1996. Therapist and Supervisor, St. Johns County Mental Health, St. Augustine, Florida.

1985 to 1987. Academic Advisor, School of Art, Southern Illinois University, Carbondale, Illinois.

\section{CERTIFICATIONS}

Licensed Mcntal Health Counselor

\section{PUBLICATIONS/PRESENTATIONS}

Morris, L. (2002). The female friendly classroom. Women's Digest, 12(8), 7-8.

Morris, L. (2002). Building self-esteem in the female teen. Women's Digest, 12(5), 2021.

Morris, L. (2002). Take our daughters to work on April 25! Women's Digest, 12(4), 8-9.

Morris, L. (2002, November). Women in information technology literature review:

Recruitment, retention, and persistence factors. Paper presented at the annual meeting of 
the Mid-South Educational Research Association, Chattanooga, TN. (ERIC Document Reproduction Service No. ED477715)

Morris, L. (2002). Women's history month 2002: Women sustaining the American spirit. Women's Digest, 12(3), 24.

Morris, L. (2002). [Review of the book They taught you wrong! Raising cultural consciousness of stereotypes and misconceptions about American Indians]. Multicultural Perspectives, 4(1), 58.

Morris, L. (2002). [Review of the book Thanksgiving: A native perspective]. Multicultural Perspectives, 4(1), 59.

\section{AWARDS}

Exceptional Service and Initiative Award, FCCJ, 2001.

\section{PLACE OF BIRTH}

Carbondale, Illinois 